\title{
Materials of marine origin: a review on polymers and ceramics of biomedical interest
}

\author{
T. H. Silva ${ }^{1}$, A. Alves ${ }^{1}$, B. M. Ferreira ${ }^{1}$, J. M. Oliveira ${ }^{1}$, L. L. Reys ${ }^{1}$, \\ R. J. F. Ferreira ${ }^{1}$, R. A. Sousa ${ }^{1}$, S. S. Silva ${ }^{1}$, J. F. Mano ${ }^{1}$ and R. L. Reis ${ }^{* 2}$
}

Marine organisms are constituted by materials with a vast range of properties and characteristics that may justify their potential application within the biomedical field. Moreover, assuring the sustainable exploitation of natural marine resources, the valorisation of residues from marine origin, like those obtained from food processing, constitutes a highly interesting platform for development of novel biomaterials, with both economic and environmental benefits. In this perspective, an increasing number of different types of compounds are being isolated from aquatic organisms and transformed into profitable products for health applications, including controlled drug delivery and tissue engineering devices. This report reviews the work that is being developed on the isolation and characterisation of some polysaccharides, proteins, glycosaminoglycans and ceramics from marine raw materials. Emphasis is given to agar, alginates, carrageenans, chitin and chitosan, among other polysaccharides, collagen, glycosaminoglycans such as chondroitin sulphate, heparin and hyaluronic acid, calcium phosphorous compounds and biosilica. Finally, this report ends by reviewing the application of the previously mentioned materials on specific biomedical applications, in particular their participation on the development of controlled drug delivery systems and tissue engineering scaffolds.

Keywords: Marine origin materials, Marine biomaterials, Biopolymers, Chitosan, Alginate, Carrageenans, Calcium phosphates, Biosilica, Biomedical applications, Tissue engineering, Review

\section{Introduction}

Marine organisms still remain a largely unexploited resource on what concerns its biotechnology application. Many organisms are composed by molecules and materials exhibiting interesting characteristics and properties which constitute an inspiring reserve for the development of novel medical orientated products. Figure 1 illustrates some interesting architectures that can be found in marine environments, inspiring for the (bio)materials scientists, but many others can be found under the scope of marine biomimetics studies, in which nacre is a key material. ${ }^{1}$ In this regard, the biomedical market represents an enormous application opportunity for many of these molecules and materials, as the potential added value of such products can, in principle, justify the inherent risk related with the development and approval of such products. Furthermore, such products would also contribute to a more sustainable exploitation of natural resources in general and marine resources in particular. So, the valorisation of residues

13B's Research Group - Biomaterials, Biodegradables and Biomimetics, University of Minho, Headquarters of the European Institute of Excellence on Tissue Engineering and Regenerative Medicine, AvePark, 4806-909 Taipas, Guimarães, Portugal

${ }^{2}$ ICVS/3B's - PT Goverment Assciate Laboratory, Braga/Guimarães, Portugal

*Corresponding author, email rgreis@dep.uminho.pt from marine origin, like for example those normally obtained from food processing, could constitute an interesting platform for the development of novel value chains with economic and environmental advantages.

An increasing number of compounds are currently being isolated from aquatic organisms and proposed as novel products for health-related applications ranging from bioactive ingredients to medical devices. The ability to use nature as an inspiring framework for the development of novel products is not new. In fact, a large fraction of current pharmacopoeias derives directly or indirectly from natural products. ${ }^{2}$ In this regard, marine species have been a valuable resource during the last decades for the discovery of novel active pharmaceutical ingredients. In terms of drug development, the screening of marine products has involved a vast library of biomolecules. The investigation of many of these molecules has led to extensive preclinical studies, which have justified, in some cases, clinical trials in several therapeutic areas, including cancer. ${ }^{3-5}$

The exploration of marine potential on what concerns isolation of compounds and its further use and application in biomedical field is still in its infancy. The number of natural derived products continues to expand steadily in terms of number of compounds investigated, which has been closely followed by the increase of intellectual property, namely by the number of patents filled. ${ }^{6-16}$ Still, to a large extend, the marine 


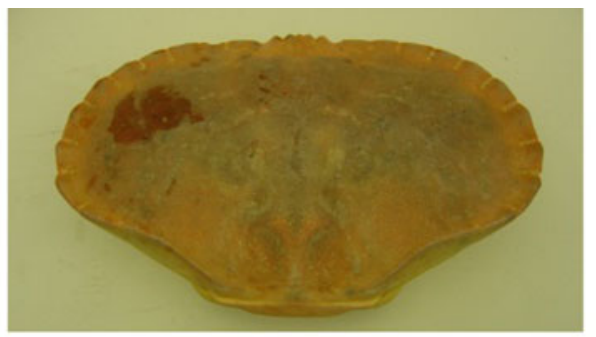

Cancer pagurus

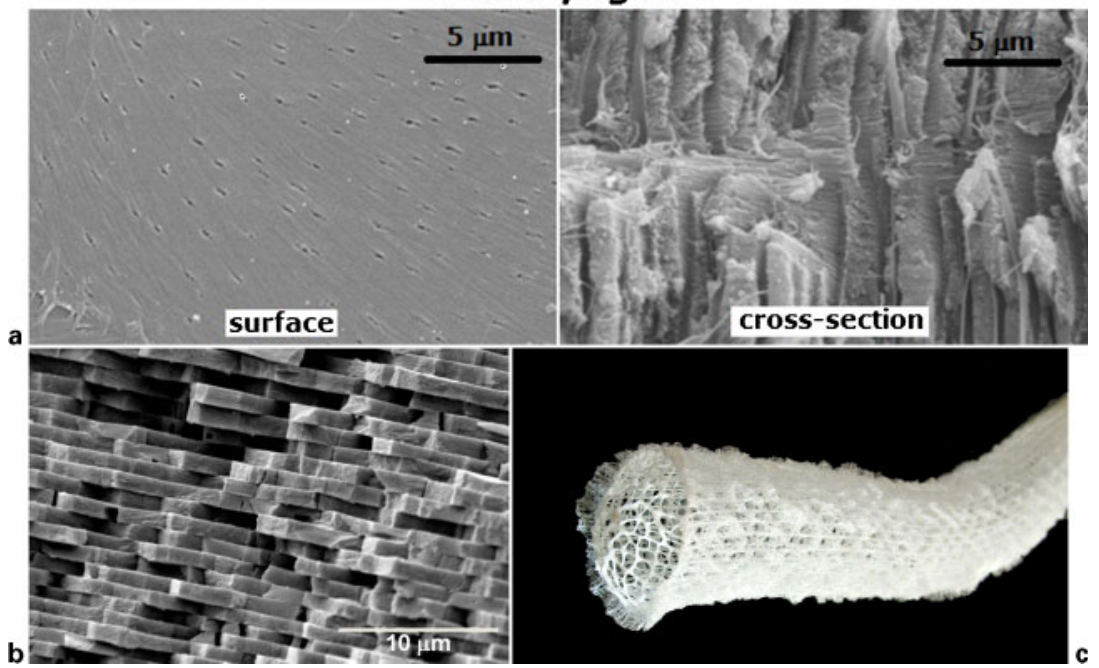

1 Images of marine organisms with interesting architectures. a Crab shells and respective SEM images; $b$ SEM image of nacre structure, evidencing the plate-like aragonite crystals; $c$ glass sponge (Randolph Femmer, Wikimedia Commons 2011)

environment is regarded as a large untapped source of chemical diversity. ${ }^{17}$ In fact, the harvesting of marine potential is not limited to drug discovery alone. Although the main emphasis has been given to pharmaceuticals, other potential applications for marine-derived materials have been additionally explored. Biopolymers produced by marine organisms are being increasingly investigated for several biomedical applications. ${ }^{18,19}$ Among the many biomedical applications explored during the last years, regenerative medicine and drug delivery have been areas of intensive research.

This review addresses research and application development mostly carried out during the last decade for several marine origin materials, including polysaccharides, proteins, glycosaminoglycans and ceramics. Several aspects are covered, namely, isolation methods, main properties and related biomedical applications, with special emphasis to tissue engineering and drug delivery applications.

\section{Polysaccharides}

Like their terrestrial fellows, marine organisms synthesise a considerable variety of biopolymers, which can be grouped in three main classes: polysaccharides, proteins and nucleic acids. ${ }^{20}$ This review will focus on biopolymers with structural function, namely polysaccharides and the support protein collagen. Within polysaccharides, a particular group - glycosaminoglycans (GAG) will be addressed in a different section, once these typically sulphated polymers, with a repeating unit constituted by a hexose and a hexosamine, are synthesised in the organism in association with proteins forming the proteoglycans. ${ }^{21}$ The only exception, also later addressed, is hyaluronic acid, which does not bear sulphate groups nor form proteoglycans. ${ }^{22}$

Polysaccharides are biopolymers constituted by carbohydrate monomers (normally hexoses) linked by glycosidic bonds. The most representative polysaccharides in marine environment are agar, alginate, carrageenans and chitin. Chitin is, in fact, the second most abundant biopolymer, just after cellulose. All these polysaccharides have similar chemical structures, but the apparently small differences are responsible for distinct properties of the polymers. In this perspective, depending on the application envisaged for the polymer, one or other may be selected. From all, chitin and its derivative chitosan can be distinguished by the presence of an amine $\left(\mathrm{NH}_{2}\right)$ group, which in chitosan can be protonated and thus, the polymer will bear positive charge, while the others are neutral or negatively charged. From the other polymers, the nature of the negative charge is also a difference: in carrageenans, it is due to sulphate $\left(\mathrm{SO}_{4}^{-}\right)$groups and in alginate. it is due to carboxylate $\left(\mathrm{COO}^{-}\right)$groups, while agar is neutral. Thus, if a negatively charged polymer is needed (for interaction with cations or positively charged polymers, for instance), a choice can be made between alginate and carrageenan, with the addition that negative charge density can be tuned by $\mathrm{pH}$ in alginate or by type of carrageenan (bearing different quantities of sulphate groups per repeating unit). Considering these characteristics, materials with different properties can be obtained, in which gels are the paramount example. In fact, the gelling capacity of alginate is well known, but gels can be also obtained with carrageenans, but only with two of the three commercial types, and the ones 


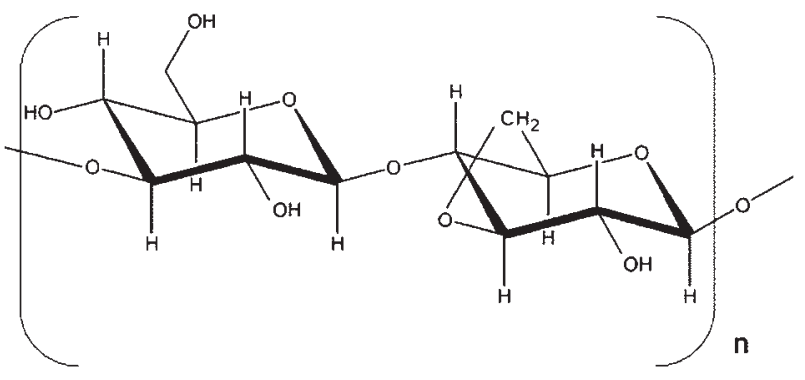

2 Structural scheme of agar exhibiting the galactopyranose units

produced with kappa-carrageenan are stronger that the ones prepared with iota-carrageenan.

In the following section, further details on each of these biopolymers can be found, as well as a brief reference to other less non-marine polysaccharides.

\section{Agar}

Agar is a complex polysaccharide present in the cellular wall of red algae, namely, agarophytes, including species belonging to the genera Gelidium and Gracilaria. ${ }^{23}$ Commercial agar is mainly extracted from species of Gelidium, Gracilaria, Acantkopeltis, Ceramium and Pterocladia. $^{24}$

It is a structural polymer which possesses in algae a function analogous to, but differing from, that of cellulose in land plants. A simplified way to describe its chemical structure is to represent agar as a polysaccharide composed of neutral agarose and charged agaropectin. However, a correct approach to understand its structure is to regard agar as a complex mixture of water-soluble galactan derivatives. It is a typical linear $(\mathrm{AB})_{\mathrm{n}}$ copolymer with alternating $\alpha-(1 \rightarrow 3)$ and $\beta-(1 \rightarrow 4)$ linked galactose residues. ${ }^{24,25}$ Its basic repeat unit is recognised to be composed of $4-O-3,6-$ anhydro- $\alpha$-L-galactopyranose and $3-O-\beta$-D-galactopyranose, illustrated by the scheme in Fig. $2 .{ }^{25}$ Frequently, the $(1 \rightarrow 4)$-linked residues are present as the 3,6anhydride. The main difference between agar and carrageenans is that $(1,4)$-linked residue in agar is a Lenantiomer, whereas in carrageenans, it is a D. Its complexity is increased by different substituents, like methoxyl, sulphate and pyruvate groups. ${ }^{25,26}$ The presence of ester sulphate and ketal pyruvate in the backbone provides ionic character to the polysaccharide. ${ }^{27}$ The chemical nature of agar, including the amount and type of substituents, will be affected by different factors like taxa and species, environmental and physiological conditions and extraction procedures. ${ }^{25}$

The existence of two types of agar, Gelidium and Gracilaria agars, is now recognised. These can be physically and chemically distinguished by their gelling temperature and methoxyl content. However, the largest source of agar is Gracilariales, due to its abundance and chemical nature of the agars extracted from this red algae order. ${ }^{28}$ Gracilaria agar gels around $40^{\circ} \mathrm{C}$ and has methyl ether groups, while Gelidium agar gels at around $30^{\circ} \mathrm{C}$ and methyl ether substituent groups are essentially absent. ${ }^{27}$ On the other hand, the presence of sulphate groups in Gracilaria agars lowers their gelling ability, when compared with Gelidium agar. This is the reason why Gracilaria agars may be regarded as low quality. In order to improve gelling capacity, and therefore quality,

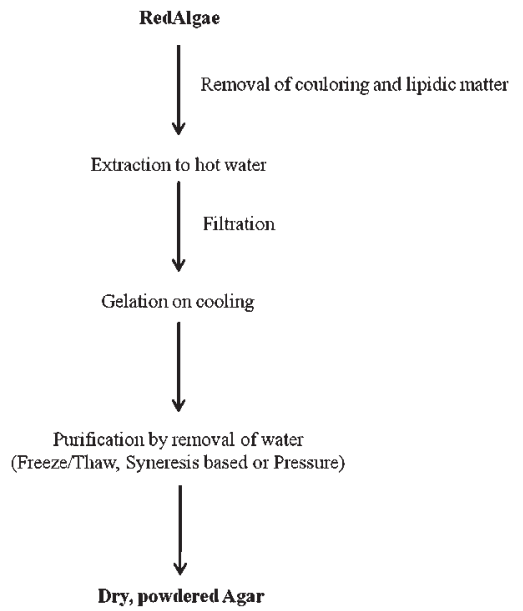

3 Schematic summary of the methodology of agar extraction from red algae

of Gracilaria agar, it is necessary to eliminate sulphate groups, by alkaline hydrolysis. This pre-treatment will convert L-galactose-6-sulphate to 3,6-anhydro-L-galactose, which is the main responsible for the increase in the gel ability. ${ }^{28,29}$ Furthermore Gracilaria gels exhibit low syneresis, when compared with Gelidium gels. ${ }^{28}$ These inherent characteristics will govern the technical applicability of these agars.

Surpassing these differences, agar typically forms soft, thermally reversible and cation independent gels. ${ }^{26,27}$ One important property of this polysaccharide is its ability to gel at low concentrations. ${ }^{24}$ Nowadays, the recognised gelation mechanism involves a shift from a random coil to double helix. ${ }^{27}$ Agar constituent polysaccharides, namely, agarose, play an important role in its gel-forming characteristics. Agaropectin provides the viscous component. ${ }^{30}$ In order to prepare an agar aqueous solution, agar requires heating above its gel melting point, around $85^{\circ} \mathrm{C}$. Upon cooling, agar solution will settle into a soft gel. As in many polysaccharides, gel-forming properties and viscosity of agar are generally affected by different factors like chemical substituents, sulphate content, molecular weight and molecular weight distribution, species of alga and extraction method. ${ }^{25,30}$

Applicative development of agar will depend on its chemical composition (sulphate, methoxyl substituints and sugar contents) which can be significantly affected by the variables used in the extraction process.

The technology of agar production starts with pretreatment of the algae, extraction of agar, purification, dehydration and desiccation (Fig. 3). The first step in agar extraction methodology consists in bleaching off colouring matter and elimination of lipidic matter, which will impair polysaccharide final quality. ${ }^{30}$ Agar is extracted by boiling the alga in water. Remarkable loss of yield and decrease in rheological properties of the resulting agar is usually related with elevated extraction temperatures and prolonged extraction time. ${ }^{28,29}$ Yield can be increased by addition of a small quantity of phosphate, usually pyrophosphate. ${ }^{30}$ As the extract solution cools, it will set to a gel. Purification of this gel is made by freeze and thaw in order to eliminate water, which contains salts, pigments and polysaccharides. ${ }^{24,29}$ One of the parameters that will define the quality of the final extract is its rheological properties. In this sense, a 


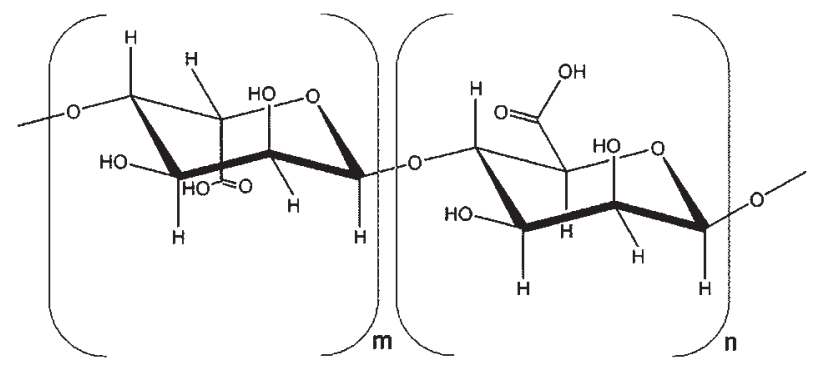

4 Structural scheme of alginate exhibiting the mannuronic and guluronic acid units

high quality agar will form a gel, from a $1 \cdot 5 \%$ solution, with strength greater than $700 \mathrm{~g} \mathrm{~cm}^{-2} .^{28}$

\section{Alginate}

Alginate is present in the cell wall of brown algae, as part of a wide family of glycans that compose this group of organisms. These glycans are laminaran, cellulose, sulphated hexouronoxylofucans, fucoidan and alginate. Among these, alginate is quantitatively the major polysaccharide in brown algae, building up to $45 \%$ of the dry weight of these seaweeds. It is responsible for its flexibility, having mechanical and structural functions as well as ionic exchange roles. ${ }^{31,32}$ Chemical structure and function of alginate in brown algae make it a functional analogue of pectin of higher plants. ${ }^{33}$

The biosynthesis of this polysaccharide within brown algae has been extensively studied and one attractive scheme is based on D-fructose-6-P as a starting material. Epimerisation of d-mannuronic residues, catalysed by mannuronan C-5-epimerases, will finally lead to the formation of alginate. ${ }^{33}$

Different structures have been proposed for this polysaccharide, since its discovery by Stanford. Chemically, it is now recognised as an unbranched anionic copolymer composed of two monomers, $(1 \rightarrow 4)$ linked $\beta$-D-mannuronic acid $(\mathrm{M})$ and $\alpha$-L-guluronic acid (G) (Table 1). ${ }^{31}$

Both $\beta$-D-mannuronic acid and $\alpha$-L-guluronic acid are stereoisomers, differing in the configuration of the carboxyl group, as can be seen in the chemical structure schemed in Fig. 4. The linkage of these uronic acid moieties is in such a way that the carboxyl group of each unit is free, while the aldehyde group is shielded by the glycosidic linkage. The position of each unit can vary so they can occur in blocks of separate (M or $\mathrm{G})$ or mixed (MG) sequences. ${ }^{34}$ The relative amount of each block type can vary between different alginates. ${ }^{35}$ This variability at the molecular level strongly affects the physicochemical and reological properties of alginate. ${ }^{36}$ While any brown algae can be used as a source of alginate, its actual chemical structure varies from one genus to another, and among different tissues in the algae. Alginate quantity, composition and sequential structure are affected by different factors, including taxa and species, season, tissue age and type and environmental conditions. ${ }^{37-41}$ High contents of $G$ generally are found

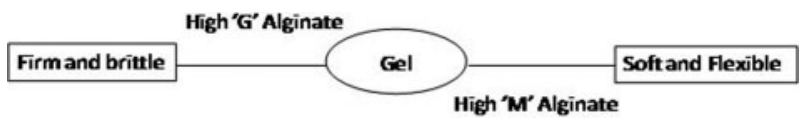

5 Dependence of alginate gel-type with chemical carbohydrate sequence ${ }^{391}$

in alginates prepared from stipes of old blade material from brown algae, whereas alginates from younger blades is characterised by low content of G-blocks and low gel strength. ${ }^{41}$ Compositional differences between different types of alginates reflect the relation between structure and function. These differences are correlated with the physico-chemical properties of alginate, which depend on the distribution of $\mathrm{M}$ and $\mathrm{G}$ units along the polysaccharidic chain and overall $\mathrm{M} / \mathrm{G}$ ratio. ${ }^{31,33}$ Alginates rich in $\alpha$-L-guluronic acid will give transparent, stiffer and more brittle gels, in the presence of divalent cations. These types of alginate possess a low $\mathrm{M} / \mathrm{G}$ ratio. ${ }^{31}$ Alginates with higher content of $\beta$-Dmannuronic acid or MG blocks will form flexible gels, with low elastic moduli (Fig. 5). ${ }^{33,42}$

Gelation is an important characteristic of alginates. ${ }^{31}$ Gelation and gel physical properties are determined by various factors, like solution viscosity, molecular weight and molecular structure of alginate, i.e. $\mathrm{M} / \mathrm{G}$ ratio and molecular sequence, and gelation agent concentration (e.g. calcium ions concentration). ${ }^{43}$ Alginate gels can be formed by diverse means, namely through hydrogen bonding at low $\mathrm{pH}$ or by ionic interactions with di- or trivalent ions. ${ }^{42,43} \mathrm{G}$ monomers play a crucial role in the mechanism of ionic gelation of alginate, since they form ionic bridges between different polymer chains. The presence of divalent ions, like calcium, induces chain to chain association in a particular manner known as the egg-box mechanism of gelation. ${ }^{34,43,44}$ Therefore, $G$ rich alginate is prone to ionic gelation. ${ }^{43}$

Commercial alginates are mainly extracted from species of Laminaria, Macrocystis, Ascophyllum, Eclonia, Lessonia, Durvillea and Sargassum. ${ }^{45}$ Although algal alginate is very well established for commercial purposes, some bacteria are able to produce alginate-like polysaccharides as an extracellular material. ${ }^{36}$ Bacterial alginate, produced mainly by Pseudomonas and Azotobacter, is abundant in vegetatively growing cells and is involved in cyst formation, protecting it from desiccation and unfavourable conditions. ${ }^{36,46}$

There are some differences between algal and bacterial alginate (Table 2); however, the main difference at the molecular level is the acetylation of mannurate units in bacterial alginate. $^{47}$

The quantity and quality of the alginates extracted from brown algae depend on different factors. A high quality alginate forms strong gels and gives thick aqueous solutions. A good raw material for alginate extraction should also give a high yield of alginate.

Alginate is present in the cell wall of brown algae as different salt forms of alginic acid, namely calcium,

Table 1 Chemical structure of alginate ${ }^{390}$

\begin{tabular}{lll}
\hline Polysaccharide & Sugar units & Sequence \\
\hline Alginate & 4-linked $\alpha$-L-GulAp $(\bigcirc)$ & $-\bigcirc-\bigcirc-0-\bigcirc-\bigcirc-\bigcirc-\bullet-\bullet-\bullet-\bullet-\bullet-\bullet-\bigcirc-\bullet-\bigcirc-\bullet-$ \\
& 4-linked $\beta$-D-ManAp $(\bullet)$ & \\
\hline
\end{tabular}




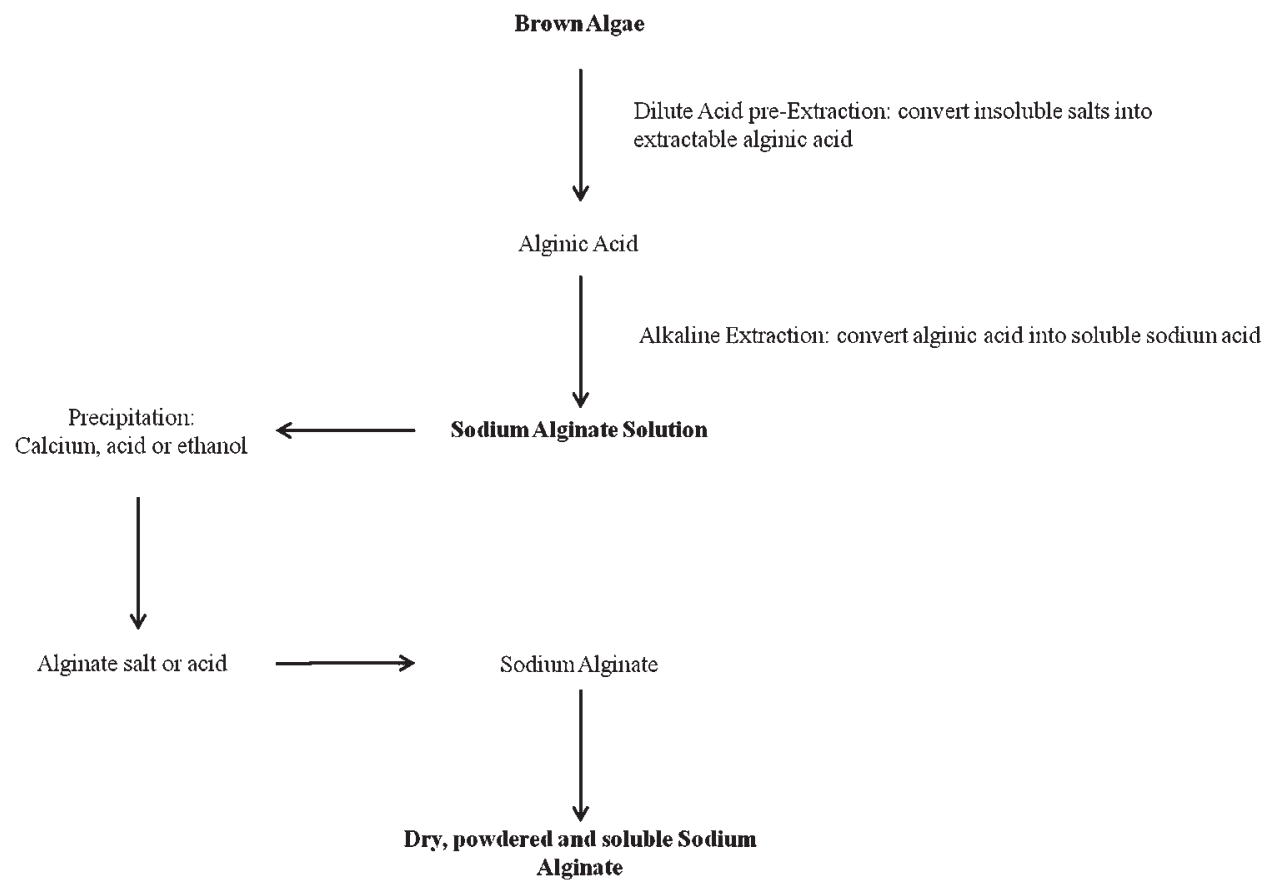

6 Schematic summary of alginate extraction

magnesium and sodium salts, possessing different properties. ${ }^{48}$ Thus, the extraction of alginate starts with an acidification step, to convert all the alginate salts in the water insoluble alginic acid form, which is more readily extracted. The acidification step will also allow the removal of contaminant glycans, like laminaran and fucan. ${ }^{48,49}$ This is followed by alkaline extraction, with sodium hydroxide solution, to convert insoluble alginic acid to soluble sodium alginate (calcium and magnesium salts would be insoluble), which is extracted by solid/ liquid separation, separating then the algal residue by filtration. Finally, sodium alginate is recovered from the aqueous solution by precipitation and is further dryed $^{50,51}$ (Fig. 6). The precipitation of sodium alginate can be done with calcium, by acidification of the sodium alginate solution, or with ethanol. ${ }^{45,52}$ Calcium precipitation will result in fibrous calcium alginate which is mixed with alkali slats in order to obtain sodium alginate. Acid precipitation will result in gelatinous alginic acid; neutralisation will render sodium alginate. The colour of extracted alginate will depend on the used algal raw material as well as the age of the algae. However, the pigmentation of alginate can be controlled by bleaching. ${ }^{52}$

A bio-refinery like concept can be applied to the extraction of alginate, where the valorisation of different byproducts of extraction is possible. One issue already addressed in this regard is the study of alginate extraction byproducts as sources of dietary fibres. ${ }^{49}$

The extraction of alginates from brown algae has been methodically studied so as to develop economically and industrially viable systems, with controlled properties as to satisfy different envisaged applications. ${ }^{45}$

\section{Carrageenan}

Carrageenan represents a family of linear sulphated polymers extracted from some species of red algae (Rodophyta - Class Gigartinales), mainly from Chondrus, Eucheuma, Gigartina and Iridaea genera. The red algae exhibit alternation of generations, and often the different phases are isomorphic, which makes it difficult to distinguishing them, and independent. Intra/interspecies differences at different stages of their life cycle often have different carrageenan types and amounts. Besides carrageenan, which can take up to $60-80 \%$ of its dry weight, red algae are also composed by proteins $(10-47 \%$, with higher levels in late winter and lower in summer), floridean starch and various compounds and metabolites such as phenols, essential oils and vitamins. ${ }^{53}$

Carrageenans are linear polymers consisting of a backbone derived from galactose (disaccharide repeating units of alternating link 3, $\beta$-D-galactopyranose and $4, \alpha$-D-galactopyranose) with regular but imprecise structures, depending on the source and the conditions of extraction/modification. There are three main types of carrageenan, classified according to the number of sulphate groups per disaccharide basic unit after alkaline modification (with the conversion of precursor molecules into their final commercial product): $\kappa$ (kappa), $l$ (iota) and $\lambda$ (lambda), ${ }^{54}$ bearing one, two and three sulphate groups per disaccharide respectively, according

Table 2 Main differences between algal and bacterial origin alginate

\begin{tabular}{ll}
\hline Algal alginate & Bacterial alginate \\
\hline $\begin{array}{l}\text { High variety of molar masses } \\
\text { Alternating sequences of } \mathrm{M} \text { and } \mathrm{G} \text { as well as }\end{array}$ & $\begin{array}{l}\text { Higher degree of polymerisation } \rightarrow \text { higher molar masses } \\
\text { homopolymeric monomers }\end{array}$ \\
\hline
\end{tabular}




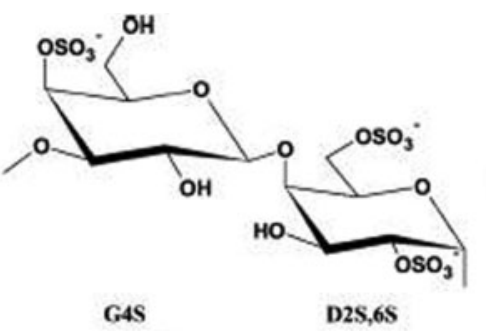

Nu-carrageenan $(v)$

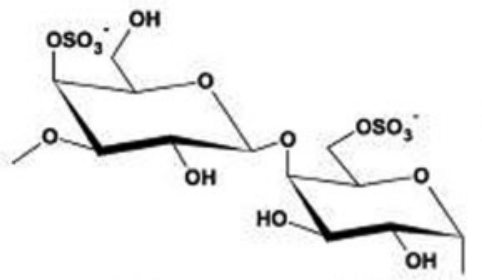

G4S

Mu-carrageenan $(\mu)$

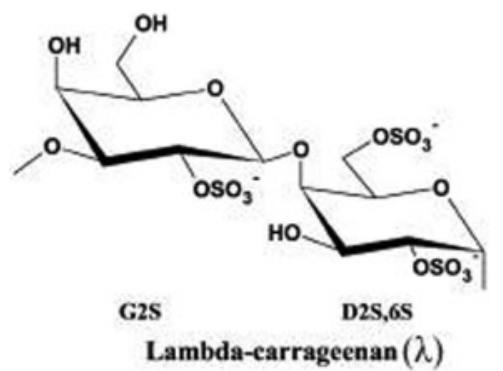

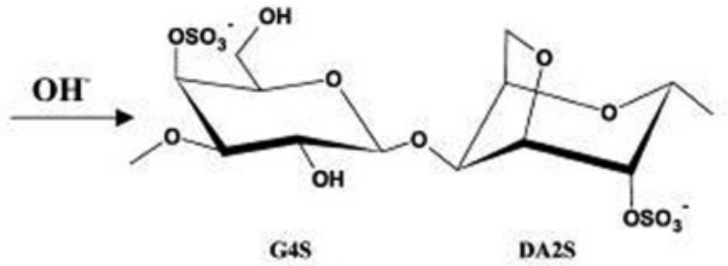

Iota-carrageenan ( 1 )

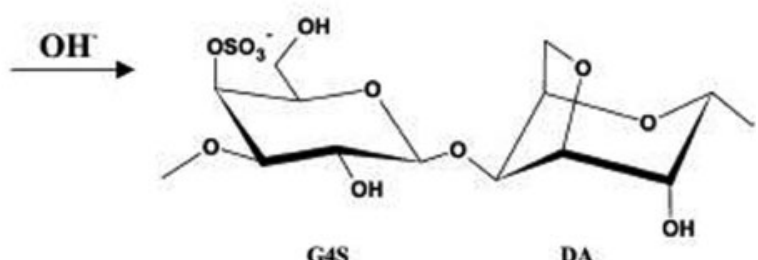

DA

Kappa-carrageenan $(\kappa)$

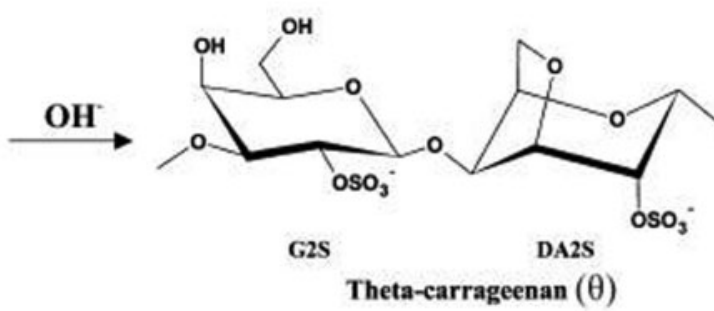

7 Structural schemes of $\kappa$ (kappa), $\imath$ (iota) and $\lambda$ (lambda) carrageenan

to the schemes in Fig. 7. The largest source of iota- and kappa-carrageenan is Kappaphycus and Eucheuma genera, while the lambda carrageenan is mostly extracted from sporophytes of several marine algae belonging to the family Gigantinaceae. Recently, a new type of carrageenan (kappa2-carrageenan) has been marketed by Shernberg Corporation (Cebu, Philippines), specially developed for use as a binder and gelling agent. Chemically, kappa2-carrageenan differs by being a hybrid polysaccharide with kappa and iota units in the same polymer chain (with a varying $\kappa / l$ ratio). ${ }^{55,56}$

Kappa- and iota-carrageenans can be gelified and the former results in relatively hard and brittle gels, while the iota ones are flexible and soft. Properties of the gel can be controlled by the concentration of polysaccharides, mixture with other polysaccharides and by complexation with different alkali metal ions. ${ }^{57}$ All types of carrageenan are soluble in water, but at low temperatures, only lambda form is soluble and hence hardly forms gels.

Carrageenan is extracted from red algae by solubilisation in hot mild alkaline solutions. ${ }^{58}$ This process is simultaneously an extraction and a modification step, because the precursor biosynthetic molecules are converted to its mature form enhancing the gelling properties of the final product, ${ }^{59}$ the abovementioned kappa, iota and lambda forms. Several purification strategies are already described in the literature and even commercially available, comprising dialysis, previous extraction of other components, reprecipitation, among others. The resulting polysaccharide is being currently used in new biotechnological approaches, taking advantage of its high potential for chemical modification ${ }^{60}$ and interesting viscoelastic ${ }^{61}$ and biological properties. ${ }^{62,63}$

\section{Chitin and chitosan}

Chitin, the second most abundant natural polymer, just after cellulose, ${ }^{64,65}$ is part of the organic matrix of exoskeletons of arthropods such as crustaceans (e.g. crabs, lobsters and shrimps) and of endoskeleton of mollusks. ${ }^{64-66}$ Chitin can be also found as a major polymeric constituent of the cell wall of fungi and algae, with fungal chitin presenting a greater uniformity in composition when compared with animal chitin. However, chitin in fungi is associated with other polysaccharides, as e.g. cellulose, glucan, mannan and polygalactosamine which make its isolation difficult. ${ }^{64}$

Structurally, chitin is composed by a linear chain of $(1 \rightarrow 4)$ linked 2-acetamide-2-deoxy- $\beta$-D-glucopyranose units, ${ }^{65}$ also designated as $N$-acetyl-D-glucosamine units. In its extracted crude form, chitin has a highly ordered crystalline structure with strong inter- and intramolecular hydrogen bonds, which chain arrangement leads to two allomorphs: $\alpha$ and $\beta .^{66} \alpha$-chitin is by far the most abundant, being present in arthropods, and is characterised by an antiparallel arrangement of the chains, which leads to stronger intra- and intermolecular hydrogen bonds.

The rare $\beta$-chitin, found in association with proteins in squid pens, is characterised by a parallel chain arrangement, and the weaker intermolecular hydrogen bonds render a materials with higher reactivity and higher affinity towards solvents. ${ }^{64}$ These forms can be differentiated by infrared and solid-state nuclear 


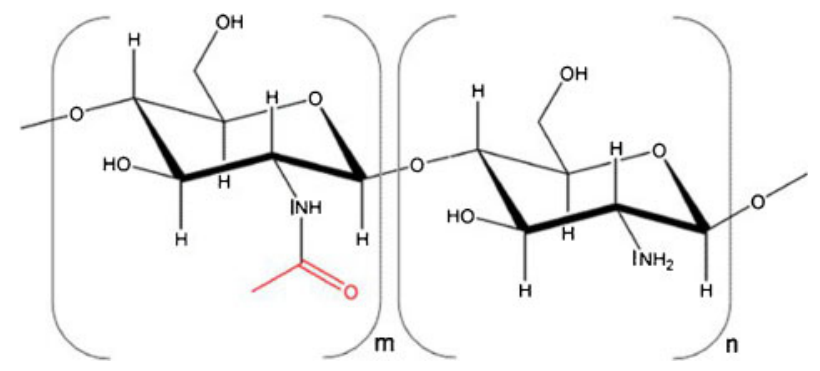

8 Structural scheme of chitin and chitosan exhibiting $\mathrm{N}$ acetylglucosamine (on the left) and glucosamine (on the right) units, with $m$ smaller than $n$ for chitosan

magnetic resonance spectroscopy together with X-ray diffraction. ${ }^{19,64}$

Despite its huge availability, the utilisation of chitin has been restricted by its poor solubility in usual organic solvents. ${ }^{64,65}$ In fact, only few examples of solubilisation of chitin are known, such as hexafluroacetone and N,Ndimethylacetamide containing 5-8\% lithium chloride, which have been used to prepare chitin-based structures from chitin solutions. ${ }^{67,68}$ Recently, room temperature ionic liquids, like 1-butyl-3-methylimidazolium acetate, have been proposed as new solvents for derivatisation of native chitin using green chemistry principles. ${ }^{69}$

In this sense, most attention has been devoted to the deacetylated derivative of chitin, chitosan. Chitosan is composed of D-glucosamine (70-90\%) and $N$-acetyl-Dglucosamine $(10-30 \%)$ units, connected through by $\beta$ $(1 \rightarrow 4)$ glycosidic linkage. ${ }^{65}$ In fact, the structural difference between chitin and chitosan is determined by the deacetylation degree, i.e. the ratio of deacetylated units in the polymer chain, since the structural scheme, in Fig. 8, is identical for both polymers.

Some authors point a value of degree of deacetylation varying from $50 \%$ to $90 \%$ for chitosan, ${ }^{70}$ but the most commonly accepted idea is that chitosan is the derivative which is soluble in dilute acetic acid solutions.

Both the content and the sequence of these units will determine the physico-chemical and biological properties of chitosan ${ }^{65,71}$ together with its molecular weight, ${ }^{65}$ which may range from 50 to $1000 \mathrm{kDa},{ }^{72}$ depending on the source and manufacturing procedure. Chitosan has many attractive properties, such as its polyelectrolyte and cationic nature, mucoadhesion, haemostatic action, biodegradability, bacteriostatic and fungistatic activity, and presence of reactive functional groups. ${ }^{64,65,71}$ Because of the stable crystalline structure, chitosan is normally insoluble in water, but soluble in dilute aqueous acidic solutions below its $\mathrm{p} K_{\mathrm{a}} \sim 6 \cdot 3$, in which amine $\left(-\mathrm{NH}_{2}\right)$ groups in glucosamine units are converted into the soluble protonated form $\left(-\mathrm{NH}_{3}^{+}\right) .^{71,73}$ This $\mathrm{pH}$-dependent solubility of chitosan provides a convenient mechanism for processing it under mild conditions, e.g. diluted solutions can be used in the production of membranes, ${ }^{74,75}$ while viscous solutions can be gelled in high $\mathrm{pH}$ solutions or baths of nonsolvents such as methanol or sodium hydroxide to form particles $^{76}$ or fibres. ${ }^{77}$ Alternatively, porous structures and tubes have been obtained by freezing and lyophilisation of chitosan solutions and gels where their mean pore size can be controlled by varying the freezing temperature/rate and pore orientation controlled by thermal gradients. ${ }^{73,78}$ Besides that, its high charge density (positive electrical charge) in solution allows chitosan to form insoluble ionic complexes or complex coacervates with a wide variety of water-soluble anionic polymers. ${ }^{78,79}$ Also, the cationic nature of chitosan is primarily responsible for electrostatic interactions with anionic GAG, proteoglycans and other negatively charged molecules. Additionally, chitin and chitosan have been investigated as an antimicrobial material against a wide range of target organisms like algae, bacteria, yeasts and fungi using chitosan in different forms (solutions, films and composites). ${ }^{80-82}$ Although the exact mechanism for its antibacterial action is not fully understood, the molecular weight and the degree of acetylation are important factors that may contribute for such activity. ${ }^{82}$ Other studies also indicated that in contact with blood, chitosan activates the formation of clots as a result of the interaction of the amino groups with the acid groups of blood cells. ${ }^{83}$ For that, it is claimed as good haemostatic agent, being used as biodegradable sponges and bandages. ${ }^{66}$ Nevertheless, other investigations indicated that chitosan has a natural selectivity for heavy metal ions, and is useful for treatment of wastewater. ${ }^{84}$ Furthermore, the presence of amino groups has been beneficial for chemical modifications on chitin/chitosan to construct a broad range of useful derivatives with satisfactory mechanical, solubility and biological properties for specific purposes. $^{18,66,85}$

Commercially, chitosan is almost all obtained from chitin previously isolated from crustacean exoskeletons. ${ }^{19}$ Basically, the chitin isolation from those sources consists of three important steps: demineralisation (acid removal of calcium carbonate), deproteinisation (removal of proteins) and depigmentation (removal of pigments), which involve the use of hydrochloric acid baths such as $2 \cdot 5 \% \mathrm{HCl}$ solution, ${ }^{86}$ alkaline treatment using typically $2 \% \mathrm{NaOH}$ solutions ${ }^{86}$ and a solid-liquid extraction with acetone or other solvents or a mild oxidising treatment respectively ${ }^{64,87,88}$ in a $1: 20$ solids to solution ratio. ${ }^{86}$ Depending on the severity of these treatments, such as temperature, reaction time, concentration of the chemicals, concentration and size of the crushed shells, the physico-chemical characteristics of the extracted chitin will vary. ${ }^{66}$ Then, chitosan is obtained from chitin by a deacetylation reaction. According to literature, ${ }^{87,89,90}$ two methods are used for deacetylation of chitin: the Broussignac process and Kurita process. According to Broussignac, ${ }^{91}$ a mixture of solid potassium hydroxide $(50 \% \mathrm{w} / \mathrm{w}), 96 \%$ ethanol $(25 \% \mathrm{w} / \mathrm{w})$ and monoethylene glycol $(25 \% \mathrm{w} / \mathrm{w})$, which is nearly an anhydrous reaction medium, is used as deacetylation reagent. In Kurita process, ${ }^{92}$ a suspension of chitin in aqueous sodium hydroxide solution $(50 \% \mathrm{w} / \mathrm{v})$ is heated up to a certain temperature, under a nitrogen stream with stirring. In both processes, after the desired reaction time, the solid is filtered off and washed with distilled water to neutral $\mathrm{pH}$. It can be further dried with ethanol, acetone or in an oven at $50^{\circ} \mathrm{C}$ or below. Figure 9 summarises the sequential steps for the just described isolation of chitin and further conversion into chitosan. Derivative processes using different reaction conditions (reaction time, temperature, concentration and nature of alkaline reagent) and multiple repeating steps can be also found in literature. The Broussignac 


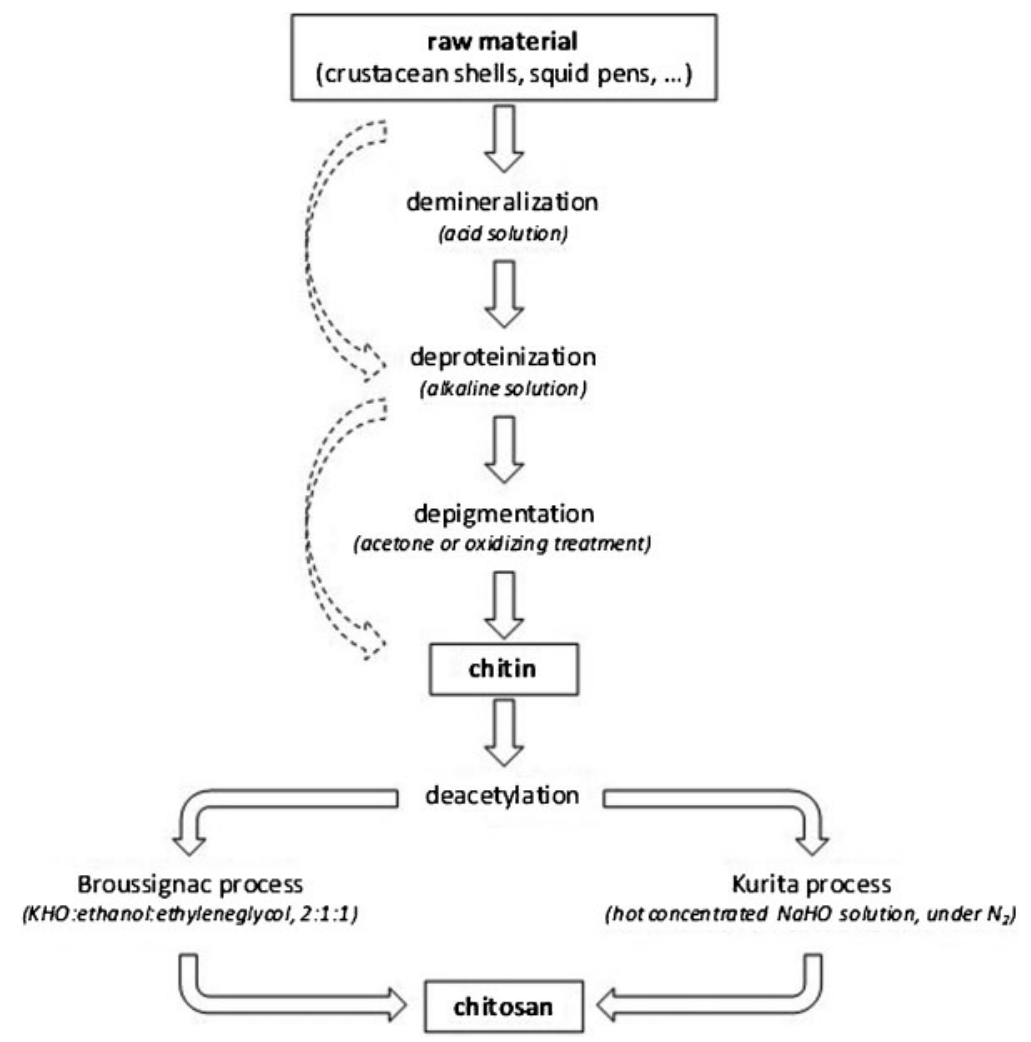

9 Scheme of common process for isolation of chitin from raw materials such as crustacean shells and squid pens (dashed arrows) and its further conversion into chitosan

process presents the advantage to provide chitosan with better quality (higher molecular weight and higher degree of deacetylation) and can be used with stainless steel reactors (industrially relevant), while the Kurita process does not allow reaching a very high deacetylation without larger reaction time and higher temperature and thus larger degradation of polysaccharide chain. ${ }^{87}$

\section{Others}

The oceans continue to provide new opportunities for the discovery of valuable materials from different organisms, with polysaccharides receiving the most interest (Table 3). These compounds encompass a wide variety of chemical structures and functionalities, broadening their applicative potential. In fact, applications of novel marine molecules are found in foods, cosmetics, pet food, animal feeds, dietary supplements, bioactive packaging and industrial products, as well as in biomedical high-tech fields.

Among the wide variability of marine origin molecules, algae sulphated polysaccharides are of proven economical importance, demonstrated by their wide application in food industry and medicine and because they found no equivalent in terrestrial organisms.
There are four major classes of algae, namely, Rhodophyta (red), Phaeophyta (brown), Cyanophyta (blue-green) and Chlorophyta (green). From these, red and brown algae are the most explored and the main sources of economically and industrially relevant polysaccharides, specifically the abovementioned agar, carrageenan and alginate. ${ }^{93}$ However, as the main constituents of seaweeds are polysaccharides, many others can be obtained from algae with interesting properties that justify any efforts in their study and applicative development. Besides, other polysaccharides can be also obtained from different marine sources, such as animal or bacterial. In this perspective, it is here highlighted the considerable attention that is being given to fucoidan or ulvan, two sulphated polysaccharides that can be found in brown and green algae respectively. ${ }^{94,95}$ In addition, other non-common polysaccharides are also being considered, such as tunicin, which is an highly crystalline marine-derived cellulose of animal origin extracted from tunicates, ${ }^{96}$ laminarin, which is a linear storage glucan that can be extracted from some species of brown algae ${ }^{97}$ and furcellaran, which is an anionic sulphated polysaccharide extracted from the red alga and that may also be considered a type of $\kappa$-carrageenan. ${ }^{98}$

Table 3 Principal marine organisms groups and their related polysaccharides

\begin{tabular}{ll}
\hline Marine source & Examples of polysaccharides \\
\hline Algal & Starch, laminarin, cellulose, mannans, glucomannans, xylans, pectic acid, complex \\
& hemicelluloses, carrageenans, furcellaran, agar, glycogen, glucans, lipopolysaccharides \\
Microbial & Different extracellular polymeric substances (EPS) \\
Fungi & Capsular polysaccharides and different EPS \\
Others & Tunicin, chitin, chondroitin sulphate \\
\hline
\end{tabular}




\section{Glycosaminoglycans}

Glycosaminoglycans (GAGs) are linear, complex and polydisperse natural polysaccharides, typically bearing a repeating disaccharide unit constituted by a hexose and a hexosamine. The presence of sulphated GAG in a diverse range of marine phyla-like sponges (Porifera) ${ }^{99}$ and several classes of fishes (Actinopterygii and others), particularly in commercially relevant species like sharks, skate, codfish, salmon and trout, ${ }^{100-102}$ is now well documented and increasing interest is being shown by different sectors (research, biochemical industries, biophamaceutical, nutraceutical and biomedical). Because of their unusual chemistry, marine-derived GAGs are being extensively studied because of their pharmaceutical activities (anti-pathogenic, antitumor and anticoagulant) and as new biomaterials with application in different areas (such as biomedical/bioengineered biomaterial applications, i.e. bioadhesive molecules, tissue engineering and regenerative medicine research). However, heterogeneity on GAG can be observed when comparing different species, intra-species and even within the same organism comparing different maturing states and tissues, ${ }^{103}$ because of their high susceptibility for post-translational modification by several enzymes like glycotransferases, thus representing a main obstacle when considering these biopolymers for the development of different applications. ${ }^{104}$

Different types of glucosaminoglycans attached to different protein cores compose the proteoglycans, which hold important properties in cells, connective tissues and basal membranes, due to the structure and charge of their polyanionic GAG side chains. They are a highly heterogeneous group that can be responsible for properties like increased hydration or capacity to bind and store specific growth factors, ${ }^{105-108}$ and have the potential to act as co-receptors in cellular adhesion as well as to interact with extracellular matrix molecules, such as laminin and fibronectin. ${ }^{109}$ The heterogeneity that can be found in sulphate composition can result in large differences in negative charge density, which is directly associated with protein binding ${ }^{106,110}$ and play a role in cell adhesion and proliferation mechanisms. ${ }^{111}$

GAG can be isolated from selected proteoglycan bearing tissues following quite general methods. ${ }^{12-118}$ Intact proteoglycans generally require the use of dissociative solvent conditions for efficient extraction from the tissue, ${ }^{112}$ with high guanidine $\mathrm{HCl}$ concentrations (ordinarily at $4 \mathrm{M}$ ) being widely employed. The use of protease inhibitors is highly recommended to hinder early proteoglycan degradation. The concomitant use of detergents is also needed, in particular non-ionic detergents (such as Triton X-100 and NP-40 with low critical micellar concentration) or zwitterionic detergents (such as 3-[(3-cholamidopropyl)-dimethylammonio]-1propanesulfonate, with high critical micellar concentration). Following proteoglycan extraction, the use of specific enzymes (like keratanase, chondroitinase ABC and hyaluronidase) to break GAG linkage with protein core is required (so the isolation of specific GAG is achieved). ${ }^{119}$ After the separation from the protein core, different separation methodologies can be applied, including sodium dodecyl sulfate-polyacrylamide gel electrophoresis), membrane separation and chromatographic separation (e.g. size exclusion chromatography).

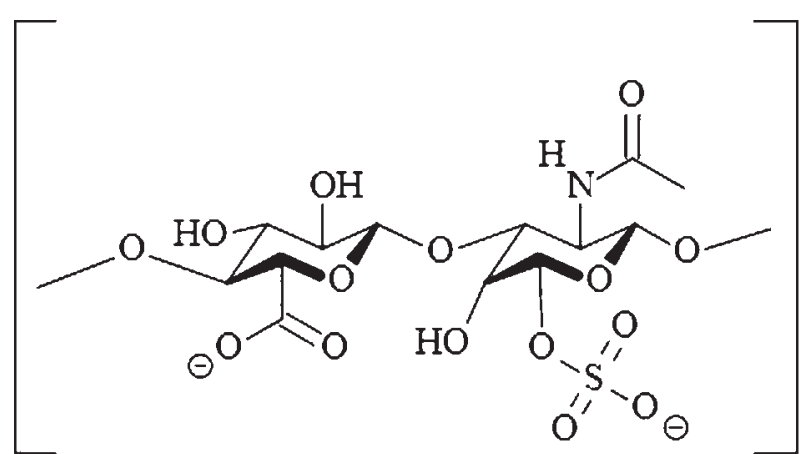

10 Structural scheme of glucuronic acid and sulphated hexosamine, the disaccharide repeating unit of chondroitin sulphate

Further purification can be achieved with gel filtration, dialysis and ultrafiltration.

Because of their exceptional diversity in molecular constructions and interactions, there is no single set of extraction or separation procedure usable for every proteoglycan and every source. Thus, these general principles have to be modified in different combinations for successful isolation of a particular GAG of interest. This review will give emphasis to chondroitin sulphate (CS), dermatan sulphate (DS), heparan sulphate (HS) and keratan sulphate (KS), as well as to the non-sulfated GAG hyaluronan.

\section{Chondroitin sulphate}

Chondroitin sulphate (CS), has been isolated from various natural sources including terrestrial species (bovine, porcine and chicken cartilage) and marine species. ${ }^{120-122}$ Regarding marine sources, it has been obtained from whale, ${ }^{123}$ shark, ${ }^{124,125}$ skate, ${ }^{119}$ squid, ${ }^{126,127}$ salmon, ${ }^{128}$ king $\mathrm{Crab}^{129}$ and sea cucumber. ${ }^{130}$ Presence in marine invertebrates, such as Cnidaria, Polychaeta and molluscs, has also been described. ${ }^{131}$ Among them, shark cartilage has been the most commonly used as a commercial source of non-mammalian CS. Still, obtaining CS from shark cartilage might become problematic in the future, as the price of this raw material has been rising and ecological aspects are the reasons why it is expected to have new developments in the upcoming years. ${ }^{102}$

$\mathrm{CS}$ consists in a disaccharide basic unit of hexosamine (D-galactosamine) and hexuronic acid (D-glucuronic acid) that are arranged in alternating unbranched sequence that can bear sulphate ester substituents in a variety of positions. Depending on the species, there are variations in molecular weight, chain length and the position of sulphate substitution, which renders sequence heterogeneity. Nevertheless, the most common (and commercial) form of CS presents sulphated groups at position C-4 or C-6 of the hexosamine in the disaccharide basic unit (corresponding to chondroitin4-sulphate and chondroitin-6-sulphate respectively). ${ }^{132}$ Figure 10 illustrated the chemical structure of this disaccharide basic unit. In particular, marine CS contains oversulphated disaccharides, including 2,6(CS D, shark cartilage), 4,6-(CS E, squid and salmon cartilage) and 3,4-(CS K, king crab) disulphated hexosamine. ${ }^{133-135}$

CS and DS (discussed in the next section) chains have intriguing functions in central nervous system development, wound repair, infection, growth factor signalling, 


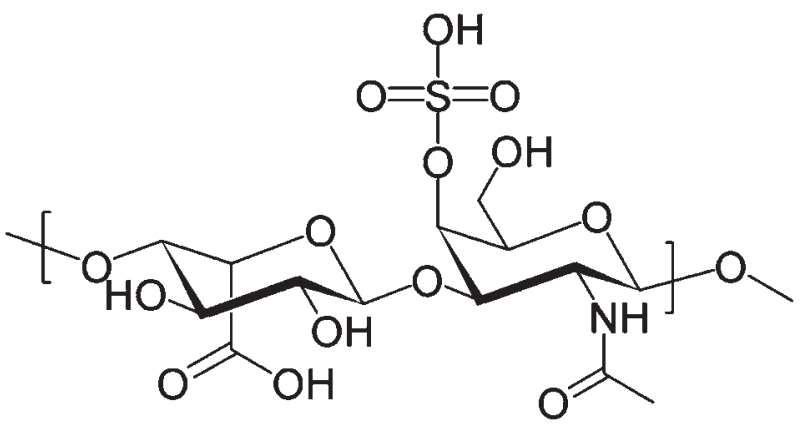

11 Structural scheme of dermatan sulphate repeating unit (Akane700 user, Wikimedia Commons 2011)

morphogenesis and cell division, in addition to their conventional structural roles. ${ }^{136}$

The CS enclosed in a variety of tissues can be extracted along with other GAG by proteolytic digestion. Once extracted, CS can be purified from other contaminant GAG by precipitation with organic solvents or enzymatic degradation of contaminant GAG species or also by column chromatography techniques. The most frequently assays for tracking CS isolation typically utilise uronic acid content as a marker. ${ }^{132}$ Recovery and purification with concomitant detection of CS can be performed by three main methodologies: (1) precipitation with ethanol; (2) precipitation with quaternary ammonium compounds; ${ }^{137}$ and (3) ion-exchange chromatography. ${ }^{132}$ The colorimetric carbazole-sulfuric acid assay, based on the reaction of unstable acid hydrolyzed dehydrated derivatives of hexuronic acid with carbazole, is frequently used to quantify the GAG content in solution. Alternatively, there are colorimetric assays, such as alcian blue, or 1,9-dimethylmethylene blue, ${ }^{138}$ although they are not so specific. Electrophoresis is then generally utilised for qualitative and quantitative analyses of GAGs in mixtures or single species, in particular using cellulose acetate, ${ }^{139}$ polyacrylamide gel ${ }^{140}$ and agarose gel. ${ }^{103,141,142}$ If necessary, enzyme digestion may be explored to remove contaminant nucleic acids. ${ }^{141}$

\section{Dermatan sulphate}

From marine environment, Ben Mansour et al. ${ }^{143,144}$ described the isolation and characterisation at a molecular level and also biological properties of dermatan sulphate (DS) from ray skin (Raja radula). Similar studies were performed by Volpi et al. ${ }^{145}$ using the marine clam Scapharca inaequivalvis and Pelli et al. ${ }^{146}$ with DS present in the integument of the anuran (amphibian) Bufo ictericus.

DS, also known as chondroitin sulphate $\mathrm{B}$, is composed of linear polysaccharides assembled as disaccharide basic units containing a hexosamine, $\mathrm{N}$ acetyl galactosamine (GalNAc) or glucuronic acid (GlcA) joined by $\beta-1,4$ or $-1,3$ linkages respectively. DS is defined as a chondroitin sulphate by the presence of GalNAc. The presence of iduronic acid (IdoA) in DS distinguishes it from chondroitin sulfphates-A (4- $O$ sulphated) and -C (6-O-sulphated) and relates it to heparin and heparin sulphate (discussed later on), which also contain this residue.

DS serve as key biological response modifier by acting as: (1) stabiliser, cofactor and/or co-receptor for growth factors, cytokines and chemokines; (2) regulator of

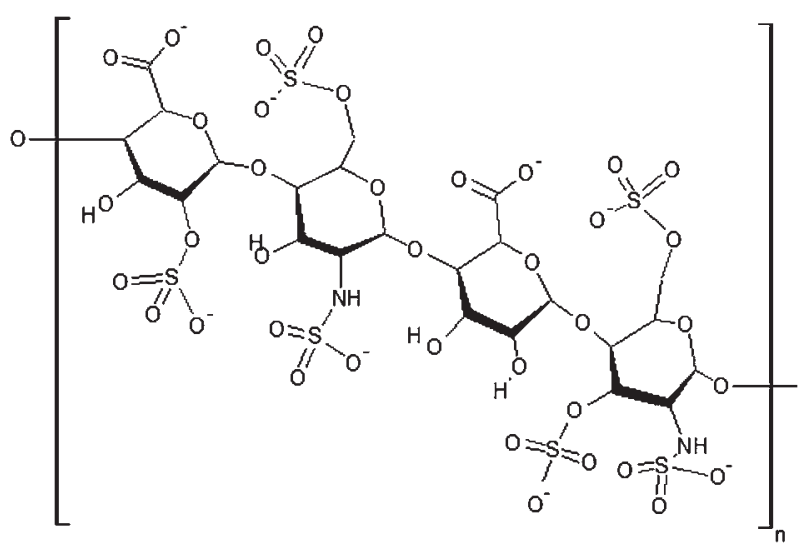

12 Structural scheme of heparan sulphate repeating unit (Hsa2011 user, Wikimedia Commons 2011)

enzyme activity; (3) signalling molecules in response to cellular damage, such as wounding, infection, and tumorigenesis; and (4) target for bacterial, viral and parasitic virulence factors for attachment, invasion and immune system evasion. ${ }^{136,147}$

Owing to the chemical similarities of DS and CS, as observed by comparing their chemical structures illustrated in Figs. 11 and 10 respectively, very similar methodologies can be used for their isolation and purification from tissues ${ }^{136,139,148}$ and thus a similar process to the one describe for CS can be used for DS, choosing the appropriate raw materials.

\section{Heparan sulphate}

Heparan sulphate (HS) is also a member of the GAG family of carbohydrates and is related in structure to heparin. ${ }^{149-151}$ Nevertheless, the criteria for distinguishing between heparan sulphate and heparin are still dubious. The term heparan sulphate has been traditionally used to describe heparin-like byproducts of the industrial preparation of heparin from animal tissues such as bovine lung or pig mucosa. The heparan sulphates in these byproducts had little or no anticoagulant activity and displayed considerable heterogeneity in molecular mass and sulphate content with degree of polymer sulphation. However, it is now clear that HS has a distinct structure from heparin and a broader range of biological activities. In contrast to heparin, which is only synthesised by connective tissue mast cells, HS in the form of proteoglycans are found on cell surfaces or in the extracellular matrix of all mammalian organs and tissues. Both consist of a variably sulfated repeating disaccharide unit and the only GAG in which $N$-sulpho-glucosamine monosaccharide $\left(\mathrm{GlcNSO}_{3}^{-}\right)$is present. The initial product in their biosynthesis is a non-sulphated polymer composed of alternating sequences of glucuronic acid (GlcUA) and $N$-acetylglucosamine (GlcNAc). This precursor substance is then enzymatically transformed into complex sulphated derivatives.

HS polysaccharide is composed of alternating hexuronic acid [D-glucuronic acid (GlcA) or L-iduronic acid $(\mathrm{IdoA})]$ and D-glucosamine $(\mathrm{GlcN})$ residues, which may be $N$-sulphated (NSO) or $N$-acetylated (NAc). An example of the chemical structure of a possible repeating unit of a heparin sulphate is given in Fig. 12. On the other hand, heparin is composed by $\operatorname{IdoA}(2 S)-G l c N S(6 S)$. Problems arise when defining hybrid GAGs that contain 


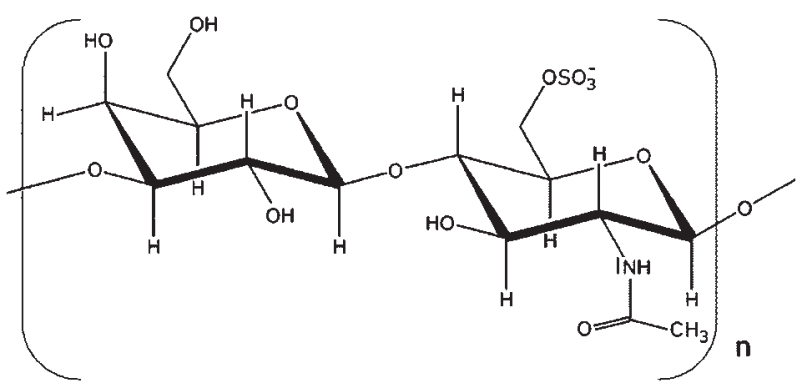

13 Structural scheme of a keratan sulphate repeating unit, with only one sulphate group in $\mathrm{C6}$ of $\mathrm{N}$-acetylglucosamine residue (galactose unit can be also sulphated in C6)

both 'heparin-like' and 'HS-like' structures. It has been suggested that a GAG should qualify as heparin only if its content of $N$-sulphate groups largely exceeds that of $\mathrm{N}$ acetyl groups and the concentration of $\mathrm{O}$-sulphate groups exceeds those of N-sulphate.

A comprehensive survey of different classes of invertebrates has shown that HS-like and/or heparin-like compounds, besides CS, are present in many species. There is a significant number of works describing HS-/ heparin-like compounds from a wide number of marine sources, from molluscs - Tapes phylippinarum, ${ }^{152}$ crustacean Penaeus brasiliensis, ${ }^{103,153}$ and from invertebrates ${ }^{154}$ and Algal heparinoids. ${ }^{155}$

In fact, HS is found in all animal tissues and it occurs as a proteoglycan in which two or three HS chains are attached in close proximity to cell surface or extracellular matrix proteins. ${ }^{156}$ Under physiological conditions, the ester and amide sulphate groups are deprotonated and attract positively charged counterions to form a salt and is in this form that is thought to exist at the cell surface. ${ }^{157}$ In this way, HS binds to a variety of protein ligands and regulates a wide variety of biological activities, including developmental processes, angiogenesis, blood coagulation and tumour metastasis. ${ }^{158}$

\section{Keratan sulphate}

The extracellular matrix of lophophores from some brachiopods (Brachiopoda phylum, order Terebratulida) stains for both collagen and acidic GAG, being intensely stained in a certain region with antibodies against keratan sulphate (KS). ${ }^{131}$ The presence of KS was also described in teleost fish (catfish - Corydoras aeneus - and loaches - Acanthophthalmus semicinctus, Botia horae ${ }^{159}$ ), in particular in skin, bounded to the protein core via an $N$-glycosyl linkage between $N$-acetylD-glucosamine and asparagines. ${ }^{160}$

$\mathrm{KS}$ is an atypical GAG specimen and represents the only of this family in which there is no acidic residue alternating in the basic unit structure with an $N$ acetylated amino-sugar. The basic unit of the $\mathrm{KS}$ is a repeating disaccharide of $N$-acetylated lactosamine [-3 galactose $\beta 1-4 \quad N$-acetylglucosamine $\beta 1-]$, which is partially substituted in C6 with O-ester sulphate groups of one or both monosaccharide residues. Figure 13 illustrates the chemical structure of the disaccharide repeating unit with the $N$-acetylglucosamine unit bearing the sulphate group in C6. The extent of $\mathrm{N}$ acetylglucosamine sulphation is normally complete contrasting with galactose (that can be quite varied), relating to the origin of the KS.

Three distinct KS families are now documented, classified according to the nature of the link section to the protein core. ${ }^{161} \mathrm{KS}-\mathrm{I}$ systems include those derived from cornea and from the small cartilage proteoglycan, fibromodulin. ${ }^{162}$ This type is $N$-linked to an asparagine residue within the protein core; through an $\mathrm{N}$-acetylglucosamine extending from the central residue of a triple mannose unit. KS-II linkage is typical of the skeletal KS found in articular and non-articular cartilage, nasal septa and tracheal rings. The $N$-acetylgalactosamine anomerically attached through an $O$-link to either a serine or a threonine contained in the core protein. It was first recognised in material isolated from the nucleus pulposus of intervertebral discs and costal cartilage. A third class (KS-III) has been proposed and it was first

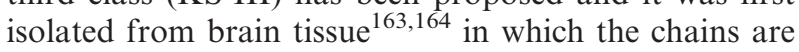
again attached to a protein core through an $O$-glycosidic linkage, which in this case connects a mannose residue contained in a $\operatorname{GlcNAc}(\beta 1-3)$ Man-sequence to either serine or threonine. ${ }^{165}$

Pfeiler ${ }^{166}$ described and compared several methods to isolate the proteoglycans fractions bearing KS. Extraction of proteoglycans was executed under both dissociative (generally described above) and associative (performed as described above except that 4M guanidine HCI was deleted from the homogenising solution and extracted proteoglycans were dissolved in water only conditions). Free KS chains are obtained by both an enzymatic method utilising chondroitinase $\mathrm{ABC}$ and by ethanol fractionation. The purity of the preparation is checked by cellulose acetate electrophoresis. ${ }^{166}$ Preparative and purification methods to obtain medical grade materials can be also further explored. ${ }^{166}$

\section{Hyaluronic acid}

Hyaluronic acid (HA), or hyaluronan, a naturally occurring non-sulfated glycosaminoglycan, is a major macromolecular component of the intercellular matrix of most connective tissues such as cartilage, vitreous of the human eye, umbilical cord and synovial fluid, ${ }^{167}$ being also found in umbilical cord and rooster comb. HA can be also found in marine environment, mostly in cartilaginous fishes and in vitreous humour of different fish species. In addition, HA can be easily and controllably produced in large scales through microbial fermentation, from strains of bacteria such as Streptococci, ${ }^{167}$ enabling the scale-up of derived products and avoiding the risk of animal-derived pathogens.

HA consists of alternating disaccharide units of $\alpha-1,4-$ D-glucuronic acid and $\beta-1,3-N$-acetyl-D-glucosamine, linked by $\beta(1 \rightarrow 3)$ bonds. ${ }^{168}$ Figure 14 illustrates the chemical structure of this disaccharide repeating unit.

Initially, it was thought that the major role of HA was to serve as an inert molecular filling of the connective tissue. ${ }^{169}$ However, despite their uniform and simple primary structure, HA polymers have extraordinarily wide-ranging and often opposing biological functions depending on the size of the molecule. ${ }^{167,169}$ Large matrix polymers of HA, which can reach molecular mass values as high as $10^{7} \mathrm{Da}$ and are thus associated to unique viscoelastic and rheological properties, are spacefilling, antiangiogenic and immunosuppressive materials. Intermediate-sized polymers comprising 25-50 


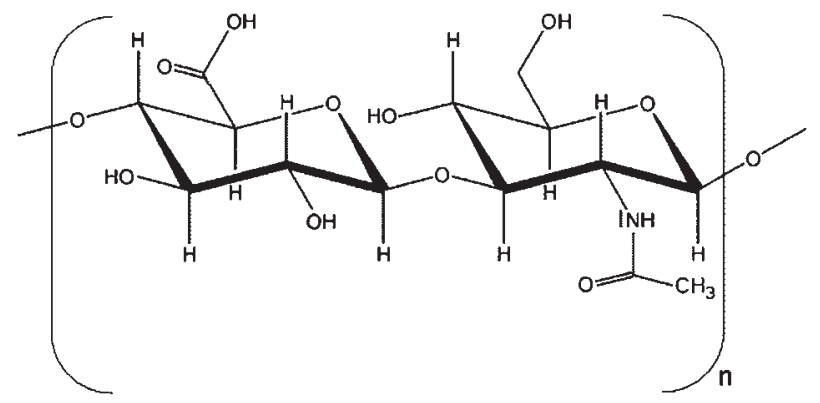

14 Structural scheme of hyaluronic acid disaccharide repeating unit

disaccharides are inflammatory, immunostimulatory and highly angiogenic, whereas smaller oligosaccharides are antiapoptotic and induce heat shock proteins. ${ }^{170}$

In cartilage, despite its relatively low content, HA functions as an important structural element of the matrix, forming an aggregation centre for aggrecan, a large chondroitin sulfate proteoglycan that retains its macromolecular assembly in the matrix due to specific HA-protein interactions. ${ }^{171}$ These aggregates have enormous molecular mass of up to $100 \mathrm{MDa}$ and are embedded within a collagenous framework. ${ }^{172}$ In synovial fluid, the high concentration of high molar mass HA provides necessary lubrication for the joint and serves as shock absorber, due to its enhanced viscoelastic properties, ${ }^{173}$ reducing friction of the moving bones and diminishing wear of the joint. Under inflammatory conditions of arthritic diseases, such as osteoarthritis or rheumatoid arthritis, high molar mass HA is degraded by reactive oxygen species, which reduces its viscosity and impairs its lubricant and shock absorbing properties leading to deteriorated joint movement and pain. ${ }^{174}$ In the skin, the largest organ of the human body, constituting the primary protecting barrier between the underlying tissues and the hostile action of the environment, HA plays a role of a scavenger of free radicals generated by the ultraviolet rays from sunlight, which otherwise would inflict oxidative stress on cells,

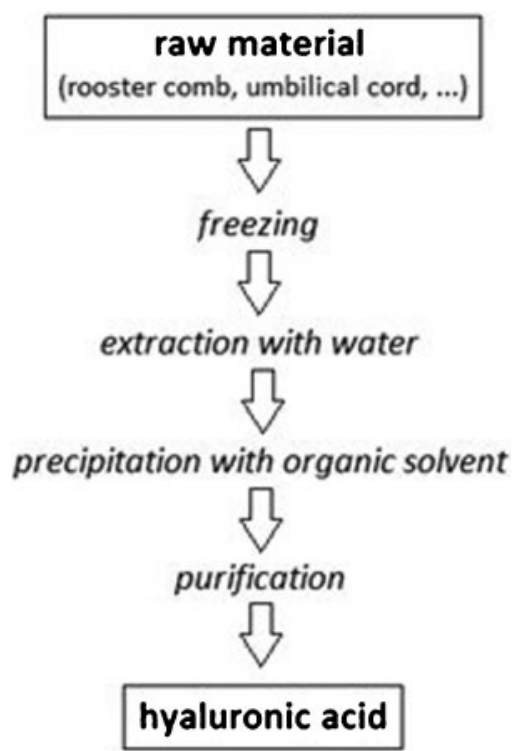

15 Scheme of extraction of hyaluronic acid from raw materials such as rooster combs and umbilical cords, according to the procedure described by Balazs ${ }^{176}$<smiles>O=C(O)C1CC(O)CN1</smiles>

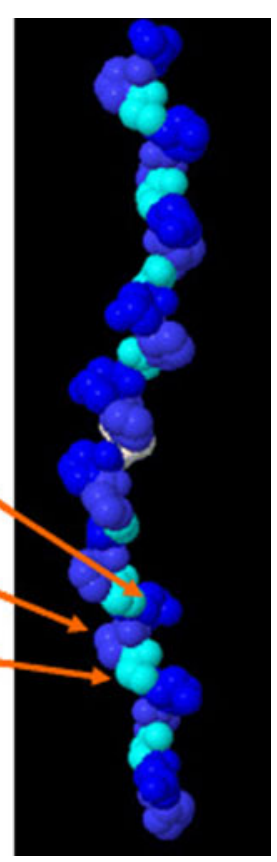

16 Cartoon of one protein chain from collagen triple helix, with the typical amino acid residues of Glycine, Proline and Hydroxyproline (Joint-Muscle-Relief.com, November 2011)

which might damage their genetic material, thus causing degeneration and death. ${ }^{175}$

Besides recombinant technology, commercially available hyaluronan can be produced by extraction from umbilical cord, rooster comb, synovial fluid or vitreous humour. The first industrial process, schematised in Fig. 15, was described by Balazs ${ }^{176}$ and consists in freezing of umbilical cords and rooster combs, in order to destroy the cell membranes, followed by extraction of HA with water, which was then precipitated with ethanol, chloroform or other organic solvents. The resulting product needs to be further purified and a yield of $0.09 \%(0.9 \mathrm{~g}$ of HA per kilogram of raw material) was observed.

\section{Collagen}

Collagen is structurally formed as a triple helix by three extended protein chains that wrap around one another. Collagen and gelatin are different forms of the same macromolecule and gelatin is the partially hydrolysed form of collagen. Heat denaturation easily converts collagen into gelatin. Collagen and gelatin are unique proteins compared to muscle proteins and this uniqueness relies on its amino acid content, in particular nonpolar amino acids such as Glycine - Gly (30\%), Alanine - Ala $(10 \%)$ and Proline - Pro (10\%), and to the significant presence of Hydroxyproline - Hyp. ${ }^{177-179}$ Figure 16 shows a cartoon of one of the protein chains in the collagen triple helix bearing the typical Gly, Pro and Hyp residues. Although main industrial sources of collagen and gelatin are bovine and porcine skin, many studies have been conducted to extract collagen and gelatin from marine sources and have used to screen their potential industrial applications. ${ }^{177,178,180-182}$ These efforts and the expected interest of the industry are explained by the comparative unpopularity of porcine skin collagen and gelatin in relation due to religious 
constrains and to active discussion on the use of bovinederived collagen and gelatin due to the mad cow disease, bovine spongiform encephalopathy and the risk they pose to humans. In contrast, fish collagen and gelatin have a relatively low risk of possessing unknown pathogens such as bovine spongiform encephalopathy. ${ }^{183,184}$ In marine environment, collagen can also be found in several marine sponges (e.g. Chondrosia reniformis), ${ }^{180}$ showing unique advantages compared to mammalian connective tissue-extracted collagens, ${ }^{185}$ as well as from gellyfish. ${ }^{186-188}$

Techniques have been developed to obtain collagenbased macromolecules with different physico-chemical properties, such as very long and compact fibres, films, nano- and microparticles or porous scaffolds for biomimetically inspired hybrid materials or for biocomposite such as the newly-discovered silica-aragonitechitin biocomposites ${ }^{189}$ in demosponges. These may serve for example as models for biomimetic synthesis of composites analogous to well established chitosan-silica hybrid materials, with very attractive bioactive properties for applications in biomedicine or as biocompatible structures that would support and organise functional tissues if applied in tissue engineering. Nevertheless, collagen can be obtained from several marine resources, such as fish skins, following simple procedures, ${ }^{177,190,191}$ according to which fish skins are cleaned and further treated with acetic acid solution (normally $0 \cdot 5 \mathrm{M}$ ) for collagen extraction, sometimes with concomitant use of $10 \%$ pepsin. When considering marine sponges, the available methodologies are different, since sponge collagen is not soluble in acetic acid solution. Thus, Swatschek and co-workers proposed an extraction methodology aiming scale-up, based on treatment with $100 \mathrm{mM}$ Tris-HCl buffer ( $\mathrm{pH}$ 9, $10 \mathrm{mM}$ EDTA, 8M Urea, $100 \mathrm{mM}$ 2-mercaptoethanol), during $24 \mathrm{~h}$, with stirring, at room temperature, after which the extract is centrifuged and collagen is precipitated from the supernatant by adjusting the $\mathrm{pH}$ to 4 with acetic acid. ${ }^{180}$

Recombinant collagen will be an alternative solution for large scale collagen production. Up to date, there is a great diversity in systems allowing the production of recombinant proteins ranging from the simplest (bacteria) to more sophisticate ones (as transgenic organisms), all being used for the production of collagen molecules or derived domains. However, the same principle governs them all: the cDNA of interest is sub-cloned into an appropriate expression vector for the expression of the protein in a cultured cell. ${ }^{192}$ Although the Escherichia coli expression system combines several advantages, its weaknesses for expressing eucaryotic proteins lies in its being restricted to the production of small fragments and the proteins produced lack posttranslational modifications. Thus, different eukaryotic systems have been developed to try to achieve a higher degree of similarity with the tissue proteins. Among them, yeast (Pichia pastoris), insect cells (High Five, Sf9, S2) mammalian cells (HT1080, 293-HEK, CHO, HeLa, COS-1) and tobacco cells have been used for collagen production. ${ }^{192}$ The methylotrophic yeast Pichia pastoris, in particular, is a favoured yeast species as a host for heterologous protein production. ${ }^{193-197} P$. pastoris has the potential for high expression levels, efficient secretion of target proteins, post-translational modifications, and is easily grown to high cell densities on mineral salt medium in bioreactors. It has been demonstrated that $P$. pastoris is an efficient production system also for very large and complex proteins, such as collagens, which besides the recombinant gene(s) needed for the collagen polypeptide chain(s), needs the parallel expression of two different genes coding for collagen prolyl 4-hydroxylase (C-P4H), an enzyme required for the thermal stability of collagens. ${ }^{198-200}$

\section{Ceramics}

Besides biopolymers, natural materials of marine origin such as corals, nacres and sponges provide also an abundant source of inorganic materials with significant relevance for tissue replacement and regeneration. Much work has been treated extensively in the literature, though data on their properties, sources, as well as isolation, chemical modification and purification methods are still scarce. This section will review the advances on marine-derived calcium compounds (carbonates and phosphates) and silicates with relevance for biomedical applications.

\section{Calcium carbonates and phosphates}

Calcium phosphorous compounds such as hydroxyapatite (HAp), $\mathrm{Ca}_{10}\left(\mathrm{PO}_{4}\right)_{6}(\mathrm{OH})_{2}$, have a special importance in the biomedical field due to its similarities with the mineral constituents of bones. By its turn, the abundant calcium carbonate $\left(\mathrm{CaCO}_{3}\right)$, which is not as interesting as calcium phosphates from the biomedical application point of view, can be the precursor material for obtaining different calcium phosphates and consequently, there is a growing interest in finding new sources of this inorganic material.

Calcium carbonate (aragonite or calcite forms) can be found in many marine organisms. Several good reviews $^{201-203}$ give special attention to these materials, not only summarising the aspects dealing with the evolution and physiology of those organisms but also looking into other properties such as inorganic/organic composition and mechanical properties. Some examples of marine species possessing calcium carbonates that might be used as calcium precursors, and thus further exploited in the biomedical field, ${ }^{204-210}$ can be found in Table 4.

Although there are many sources of calcium carbonate, coral skeletal carbonate has been attracting great deal of attention namely as substitute materials for orthopaedics and dentistry. Corals possess a unique architecture, namely, porosity, pore size and pore interconnectivity. ${ }^{211}$ Actually, these characteristics have been shown ${ }^{212}$ to be important in bone tissue regeneration. Besides microstructure, other characteristics play a key role in the in vivo performance of these biomaterials, such as microstructural composition and mechanical properties. In this respect, it has been reported ${ }^{213}$ that marine-derived calcium carbonate skeletons are unsuitable for most applications aiming bone tissue repair due to its fast dissolution rate and poor structural stability. Actually, Braye et al. ${ }^{214}$ investigated the resorption rate of different bone substitutes when implanted in femora. This study has confirmed that the kinetics of coral resorption was faster than that of HAp. To circumvent these limitations, several authors ${ }^{215,216}$ have shown the possibility of converting the hard calcium carbonate skeleton of mineralised algae into more stable structures 


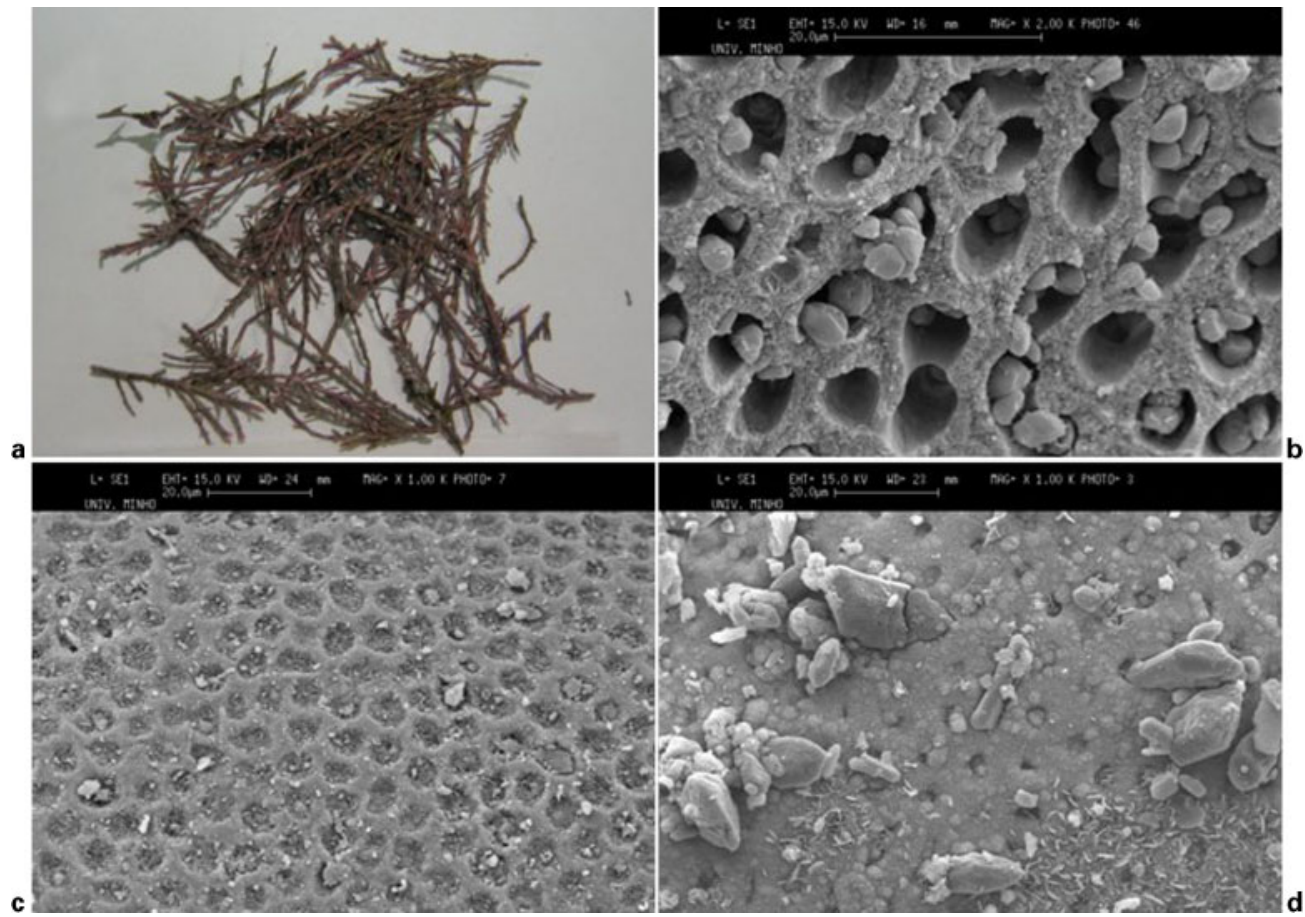

17 Photos of Coralline officinallis red algae used as source of calcium carbonate: Coralline officinallis (a), SEM image of Coralline officinallis (b), SEM image of Corallina after heat treatment at $400^{\circ} \mathrm{C}$ for $3 \mathrm{~h}(c)$ and SEM image after heat treatment at $400^{\circ} \mathrm{C}$ for $3 \mathrm{~h}$, followed by chemical treatment with ammonium phosphate dibasic (d)

such as calcium phosphates. These coral-derived materials have been mainly used in the forms of granules and blocks for bone grafting and in bone tissue engineering scaffolding. ${ }^{204,217-219}$ However, while they succeeded in generating the marine-derived calcium phosphates, often the original coral architecture was lost upon the conversion process.

In the work reported by Oliveira et al. ${ }^{220}$ different routes to convert the calcium carbonate skeleton of Coralline officinallis red algae (Fig. $17 a$ and $b$ ) into calcium phosphates are described. This interesting work showed that by performing a combined treatment (thermal and chemical), it became possible to obtain a calcium phosphate material with HAp nanocrystallites, while the native microstructure of the red algae could be maintained. First, red algae particulates (Figure 17c) free of the organic phase were obtained by heat treatment at $400^{\circ} \mathrm{C}$ for $3 \mathrm{~h}$ in a furnace. This temperature was chosen since it has been reported ${ }^{221}$ that at higher temperatures, carbonate phases can decompose. Then, the conversion of the calcium carbonate skeleton into calcium phosphates ( $\mathrm{Ca}-\mathrm{Ps})$ was achieved following the hydrothermal exchange (equation (1)) strategy ${ }^{222}$

$$
\begin{aligned}
& 10 \mathrm{CaCO}_{3}+6\left(\mathrm{NH}_{4}\right)_{2} \mathrm{HPO}_{4}+2 \mathrm{H}_{2} \mathrm{O} \rightarrow \mathrm{Ca}_{10}\left(\mathrm{PO}_{4}\right)_{6} \\
& (\mathrm{OH})_{2}+6\left(\mathrm{NH}_{4}\right)_{2} \mathrm{CO}_{3}+4 \mathrm{H}_{3} \mathrm{CO}_{3}
\end{aligned}
$$

This step forward seems very promising towards developing adequate algae-derived calcium phosphate particulates (Figure 17d) to find applications as bone filler and scaffolds for tissue engineering strategies.

Interestingly, Walsh et $a .^{223}$ prepared equivalent coralline-derived HAp by developing a low-pressure hydrothermal process. The synthesis method consisted in using ambient pressure at a low temperature of $100^{\circ} \mathrm{C}$ in a highly alkaline environment to convert the original calcium carbonate structure of coralline into a calcium phosphate material. Results have shown that the resulting HAp maintained the unique microporous structure of the original algae, as evidenced in Fig. 18. Therefore, in order to convert carbonate phases into HAp using the hydrothermal method, we should bear in mind: (1) to remove the organic matter from algae by burning or using chemical methods; (2) to avoid decompose carbonate phases; and (3) to preserve the original algae morphology.

Besides using calcium carbonates as precursors, calcium phosphates, including hydroxyapatite, can be

Table 4 Marine organisms (invertebrates and vertebrates) possessing calcium carbonate with potential interest in the

\begin{tabular}{|c|c|c|c|}
\hline Sources & Species & Potential application(s) & References \\
\hline \multirow[t]{3}{*}{ Corals } & Coralline officinallis & Bone filler & 204 \\
\hline & Lithothamnion glaciale & Bone filler & 205 \\
\hline & Phymatholithon calcareum & Bone filler & 205 \\
\hline Sponges & $\begin{array}{l}\text { Calcareus sponge spicules from triactines } \\
\text { of Pericharax heteroraphis }\end{array}$ & $\begin{array}{l}\text { Precursor material for } \\
\text { bioceramic coatings }\end{array}$ & 202 \\
\hline Mollusc shells & $\begin{array}{l}\text { Nacre from Haliotis (abalone); Mytilus galloprovincialis and } \\
\text { Ostrea edulis (oysters); and Pinctada maxima (bivalve) }\end{array}$ & $\begin{array}{l}\text { Precursor material for } \\
\text { bioceramic coatings }\end{array}$ & $206-209$ \\
\hline Fish bones & Prionace glauca (blue shark) & $\begin{array}{l}\text { Bone filler and precursor material } \\
\text { for bioceramic coatings }\end{array}$ & 210 \\
\hline
\end{tabular}
biomedical field 

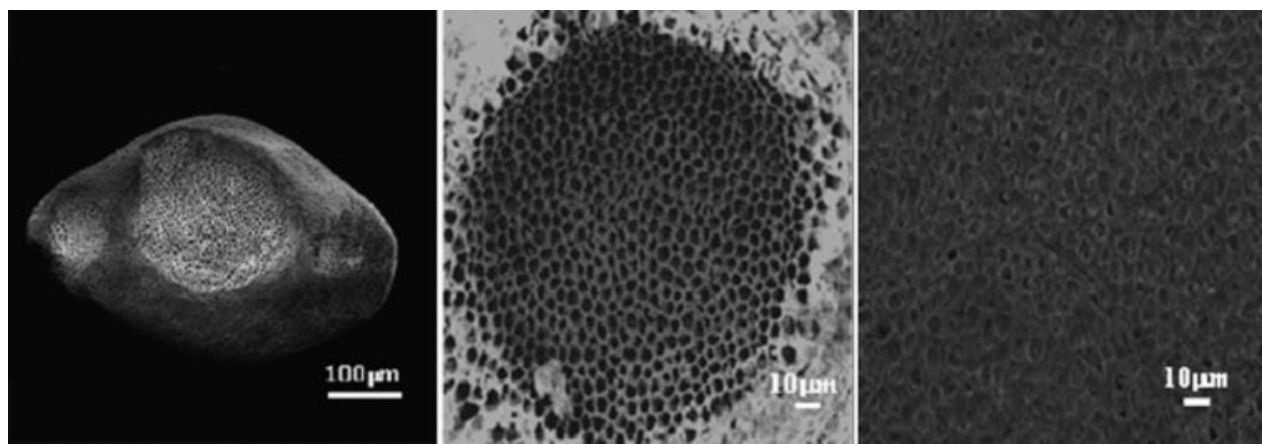

18 SEM images of Corallina-derived hydroxyapatite after conversion process developed by Walsh et al. (reprinted from Ref. 223 with permission from Elsevier)

found and obtained directly from marine resources, namely, in fish bones. In addition to the process of pyrolysis to eliminate all the organic matter and save the inorganic calcium phosphates, Pou and co-workers ${ }^{224-227}$ have described a laser-based process for the production of calcium phosphates from fish bones in microparticulate form, in which a laser beam irradiates the surface of fish bones with the necessary energy to result in the ablation of material in particulate form that is collected into a filter by a perpendicular gas flow or stay dispersed in deionised water, where the procedure can be performed. $^{224,226}$ Figure 19 depicts a cartoon of this laser ablation methodology (Fig. 19a), with an example of calcium phosphate particles prepared by this technique (Fig. 19b and c). Hydroxyapatite powder can be reduced to obtain nanoparticles by using continuous wave as well as pulsed laser in deionised water; ${ }^{224}$ following several mechanisms, such as melt ejection and fracture ${ }^{25,227}$ and different crystal structures, can be obtained with experimental parameters such as the energy of the laser and its pulse, where pulsed laser promotes the formation of crystalline nanoparticles, while the continuous wave laser favours the formation of amorphous particles). ${ }^{226}$

Similarly to sea shells, different human body parts (e.g. bone, tooth and mineralised tendon) are nanocomposites of protein and mineral which possess superior mechanical properties. ${ }^{228}$ Succinctly, we can state that from both mechanical and biological performance perspectives, it is interesting to design man-made novel materials for biomedical applications that mimic the natural nanostructures consisting of protein and mineral.

\section{Biosilica}

Biogenic silica, commonly known as biosilica, consists of glassy amorphous silica and is formed in many aquatic organisms (and in terrestrials as well, like higher plants), such as sponges, diatoms, radiolarians and choanoflagellates. $^{229}$ The most representative biosilicifying organisms are sponges and diatoms and those will be the focus of this review.
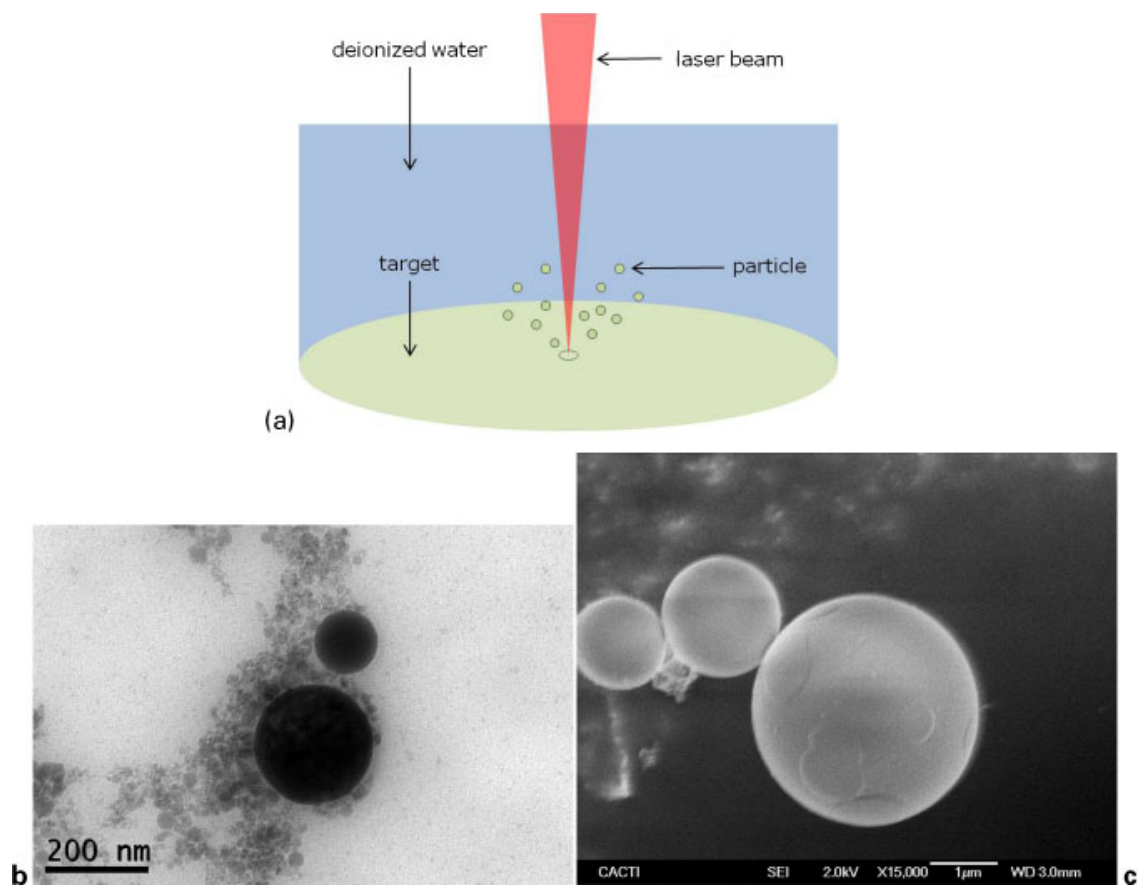

19 a cartoon of the laser ablation process in deionised water for production of calcium phosphate particles, $b$ HRTEM image and $c$ SEM image of calcium phosphate submicro- and microparticles respectively, obtained from fish bones by using laser ablation technique (micrographs reprinted from Ref. 226, Open Access article distributed under the terms of the Creative Commons Attribution License) 
Besides being inspiring and a valuable source of marine collagen, as aforementioned, some sponges species are also an important source of biosilica, as also already mentioned. In fact, there are two classes of sponges that have a silica skeleton: Demospongiae and Hexactinellida; the third class, Calcarea, has a calcium carbonate skeleton. ${ }^{229}$ Figure $1 \mathrm{C}$ shows one example of a silica skeleton of a sponge from Hexactinellida class: the impressive skeleton of Euplectella aspergillum species, ${ }^{230}$ also known as glass sponge or Venus' flower basket. The silica skeleton is constituted by siliceous spicules, ${ }^{231}$ which are rod-like glassy spikes consisting of an axial filament surrounded by several hundred concentric layers of hydrated silica. ${ }^{229}$ The process of biosilica formation in sponges is enzyme-mediated. The axial filament consists predominantly of an enzyme called silicatein, with mediates the silicification process around it through the formation of the mentioned concentric layers. ${ }^{229,230,232-235}$ At a lower scale, these layers are made of densely-packed silica nanoparticles in the 70-200 nm range. ${ }^{229,236}$ The silica content of these sponges can amount to $75 \%$ or more of the dry mass of the animals. Collagen is also present, being the predominant protein in the spicules, constituting thus a composite material. 229,234

If the objective is to isolate silica from these marine sources, it can be accomplished for instance by treating collected sponges with $5 \cdot 25 \%(\mathrm{v} / \mathrm{v})$ sodium hypochlorite solution until all cellular material had been removed and after washing with water, treating the residual material by soaking in concentrated $\mathrm{HNO}_{3} / \mathrm{H}_{2} \mathrm{SO}_{4}(1: 4)$ overnight. The resultant acid-insoluble material consists of cleaned silica spicules with an axial silicatein filament. ${ }^{236,237}$

Sponge spicules have been characterised in terms of mechanical, ${ }^{230,238-240}$ optical $^{241}$ and electric ${ }^{242}$ properties. These natural biocomposites have been characterised as highly flexible and tough, which is attributed to their layered structure and hydrated nature of sílica. ${ }^{238}$ Spicules present reduced stiffness ${ }^{240}$ and nanohardness ${ }^{238}$ as compared to commercial glass systems, but this biogenic silica has an architecture that provides a substantial toughness ${ }^{238,240}$ and mechanical stability. ${ }^{230}$ It has been also observed that sponge spicules can be excellent light transmitters, functioning as single-mode, few-mode or multimode fibres, with the lens-like structure at the end of the fibre contributing to increase its light-collecting efficiency. ${ }^{241}$ The refractive index of these biocomposites is dependent on the organic material content, as well as on hydration of silica. ${ }^{229}$ Regarding electric properties, it was observed that sponge spicules are electrical conductors, with the electric charge being probably transported along the paths formed by collagen, since deproteinised spicules presents a reduced electric conductivity. ${ }^{242}$

In this perspective, sponge spicules are remarkable structures that offer bioinspired lessons for potential biomimetic design of several devices, such as optical fibres, which could be fabricated at room temperature, thus highlighting the advantages of the synthesis used by biology. ${ }^{238,241}$ In the same way, the knowledge of sponge enzymes silicatein and silicase is of great importance also for nanobiotechnology, since they can be used on the formation of nanocomposite materials, using nature as a model for the production of new nanoscale systems. ${ }^{237,243}$ This is particularly interesting because enzyme-mediated silica formation allows the formation of silica glass under mild conditions (low temperature, low pressure and near-neutral $\mathrm{pH}$ ), while the current methods require high temperatures and pressures and the use of harsh chemicals. ${ }^{229,234,237}$ On the other hand, the work of Daniel Morse have been showing that this knowledge can be also used for the production of other materials using silicatein-mediated processes, such as titanium, gallium and other metal(loid) oxides, ${ }^{237}$ including also semiconductors, ${ }^{244}$ but also polymer such as polylactide. ${ }^{245}$ Moreover, it has been demonstrated that equivalent processes can be used with native silicatein, but also with recombinant forms ${ }^{237,245}$ or even with bioinspired synthetic analogues. ${ }^{237,244,246}$

Diatoms are a major group of microalgae, being normally unicellular organisms, although some form chains or simple colonies. These are classified as centric and pennate diatoms and can be distinguished from each other on the basis of cellular symmetry, i.e. centric diatoms are radially symmetrical, whereas pennate diatoms are elongated and bilaterally symmetrical. ${ }^{229}$ Further details on the physiology of these organisms may be found elsewhere. ${ }^{247}$

The living part of the diatom is within a box, which is made up of silicon dioxide. ${ }^{248}$ These exoskeletons, named frustules, are made of silica nanoparticles assembled in a highly organised structure exhibiting porous networks at different scales. ${ }^{249}$ Silica nanoparticles are associated with a matrix of carbohydrates and proteins, and thus frustules are in fact composite materials and their nanostructure is species-specific and genetically determined. ${ }^{229}$ Although the precise mechanism of formation has not been clearly described, it is known that the frustules are formed within a few hours, from naturally-occurring precursors at low concentrations. $^{249}$ The mechanism of formation is attributed to silica itself, through a complex inorganic polymerisation process, in contrast with precipitation/ dissolution reactions described for carbonate and phosphate minerals. ${ }^{249}$ Some authors argue that $\mathrm{pH}$, the presence of cations and salts and the concentration of silica precursors play an important role in biosilicification of diatoms. ${ }^{250}$ Other authors reinforce the importance of silicic acid, ${ }^{251}$ key molecules called silaffins $^{252}$ and polyamines ${ }^{253}$ in silica formation in diatoms. $^{254}$

The siliceous exoskeletons remain intact when cells die, rendering inorganic structures with morphological features, which are of potential interest for industrial applications. ${ }^{250}$ These silicified structures have two basic types of macromorphologies, derived from the two types of diatoms: one with bilateral symmetry and other with radial symmetry (Fig. 20).

From these, there are an enormous variety of micromorphologies, such as porous (with all types of pore arrangements and morphologies), tubes and ribbons, which exhibit high surface area being quite interesting for the development of silica-based materials. These micromorphology is reproduced with high precision within a given species since the process is genetically encoded. ${ }^{253}$ However, in the oceans, after the cellular death, the inorganic features sink to the ocean floor, reappearing to the surface after millions of years of aging as 'diatomaceous earth', which is much less interesting for application purposes, since aging reactions 


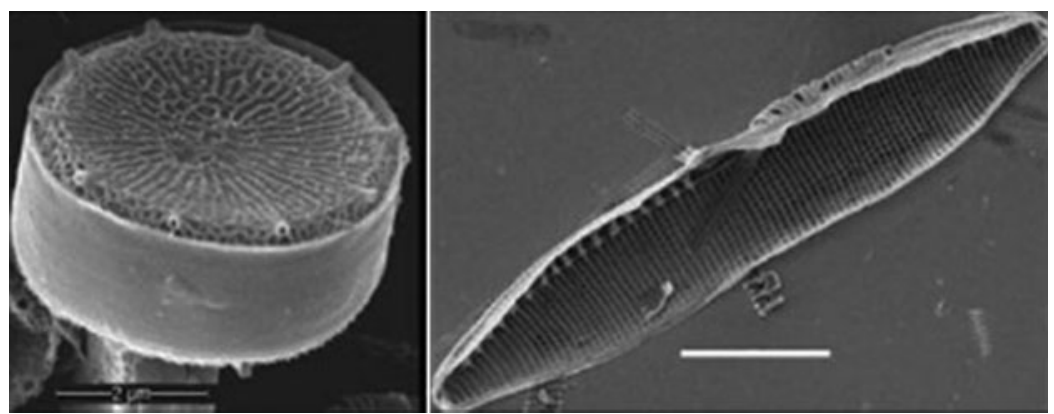

20 Electron micrographs representing the two types of diatoms: at left, Thalassiorisa pseudonana, scale bar $=2 \mu \mathrm{m}$; at right, Nitzschia alba, scale bar $=5 \mu \mathrm{m}$ (reproduced from Sandia National Laboratories report SAND2007-6359)

contribute to the destruction of the attractive morphologies and moreover to the incorporation of contaminating minerals. Thus, when considering new applications of biosilica, one should consider fresh diatomaceous silica, harvested from the field or prepared from culture. Moreover, fresh diatomaceous silica presents low contamination with metals, such as $\mathrm{Al}$ or $\mathrm{Fe}$, indicating that diatoms synthesise a nearly pure silica matrix and thus, for its further use, purification is not required. ${ }^{250}$

Besides the inherent interest of the morphology of such silica features, it is also interesting to know and understand the process of formation of such exoskeletons, since there may be a mimetic possibility of controlling the formation and assembly of silica nanoparticles in biological conditions, which can be quite interesting for the design of nanodevices, such as membranes and systems for controlled release or bioencapsulation. ${ }^{249,255}$ In particular, the work that is being developed by Kroeger, Sandhage and co-workers is a good example of it, where the mechanism of biosilica formation has been studied, in particular the role of silaffins ${ }^{256-258}$ and that knowledge was further used for the bioinspired synthesis of silica and titania materials, including the co-assembly of other entities, such as enzymes, which can be used on the design of new biosensors. ${ }^{259-261}$ In fact, as in the abovementioned case of sponge biosilica enzyme mediators, silicateins, this biomimetic approach to the synthesis of silica and titania materials can be pursued based on extracted proteins and peptides, but also by using synthetic peptide analogous. ${ }^{254}$

Biosilica is also being considered for biomedical approaches, namely, for bone replacement and regeneration strategies. For instance, it has been observed that human osteogenic sarcoma cells (SaOS-2) exhibited an increased mineralisation activity when cultivated on biosilica surfaces in the presence of $\beta$-glycerophosphate. Moreover, concurrent coating of the substrate with biosilica and type 1 collagen not only increased the cellular Ca phosphate deposition but also stimulated cell proliferation. ${ }^{234}$

In addition to biosilica obtained from biosilicifying organisms, there are also other silicon derivatives with interest for biomedical interest. Among them, one would like to highlight the elegant work of Lopez-Alvarez et al. ${ }^{262}$ which describes the preparation of biomorphic silicon carbide ceramics from marine precursors. In this work, molten $\mathrm{Si}$ is infiltrated in carbon templates, with interesting microstructure, porosity and pore interconnectivity, obtained by controlled pyrolysis of algae or marine plants. The resultant product is a light, tough and high-strength material with predictable microstructure. Figure 21 shows an example of such material, derived from the aquatic plant Juncus maritimus, where can be seen the morphology of the plant after pyrolisis, before (Fig. 21a) and after (Fig. 21b) silicon infiltration.

In fact, biological structures often exhibited amazing morphologies that justify all the efforts for biomimetic approaches to allow its synthetic reproduction. In particular, biomineralising organisms have such a hierarchical structure, making nature a manufacturer with which mankind could never compete. In this perspective, biomimetic approaches to replicate those hierarchical structures are constantly being explored by different researchers, such as the one just mentioned by Lopez-Alvarez et $a l^{262}$ or the work of Sandhage et $a .^{263-265}$ on the use of diatom frustules as templates for the production of other ceramic structures with matching morphological features, such as $\mathrm{MgO}$ or $\mathrm{BaTiO}_{3}$. In the work of Sandhage et al., instead of an

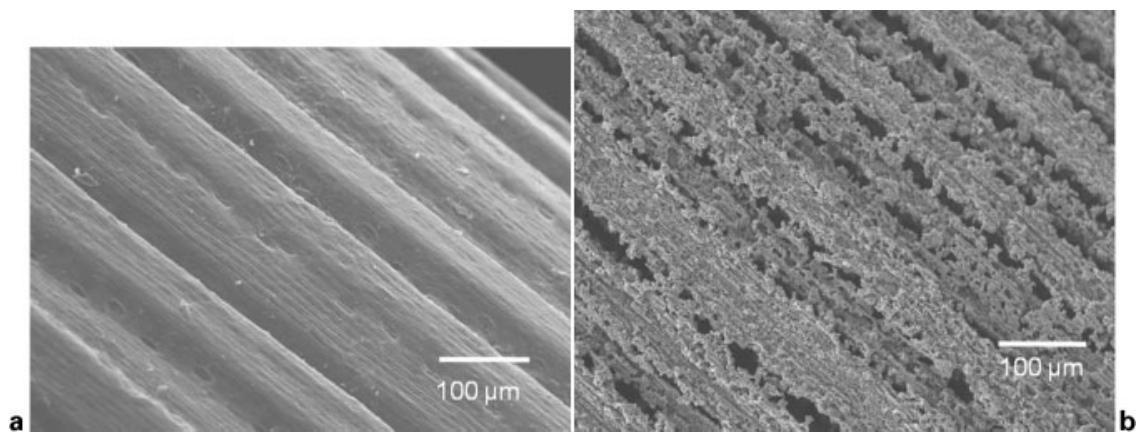

21 SEM images evidencing the morphology of the aquatic plant Juncus maritimus after pyrolisis, before (a) and after (b) silicon infiltration (reprinted with kind permission of Professor Pio González, University of Vigo) 

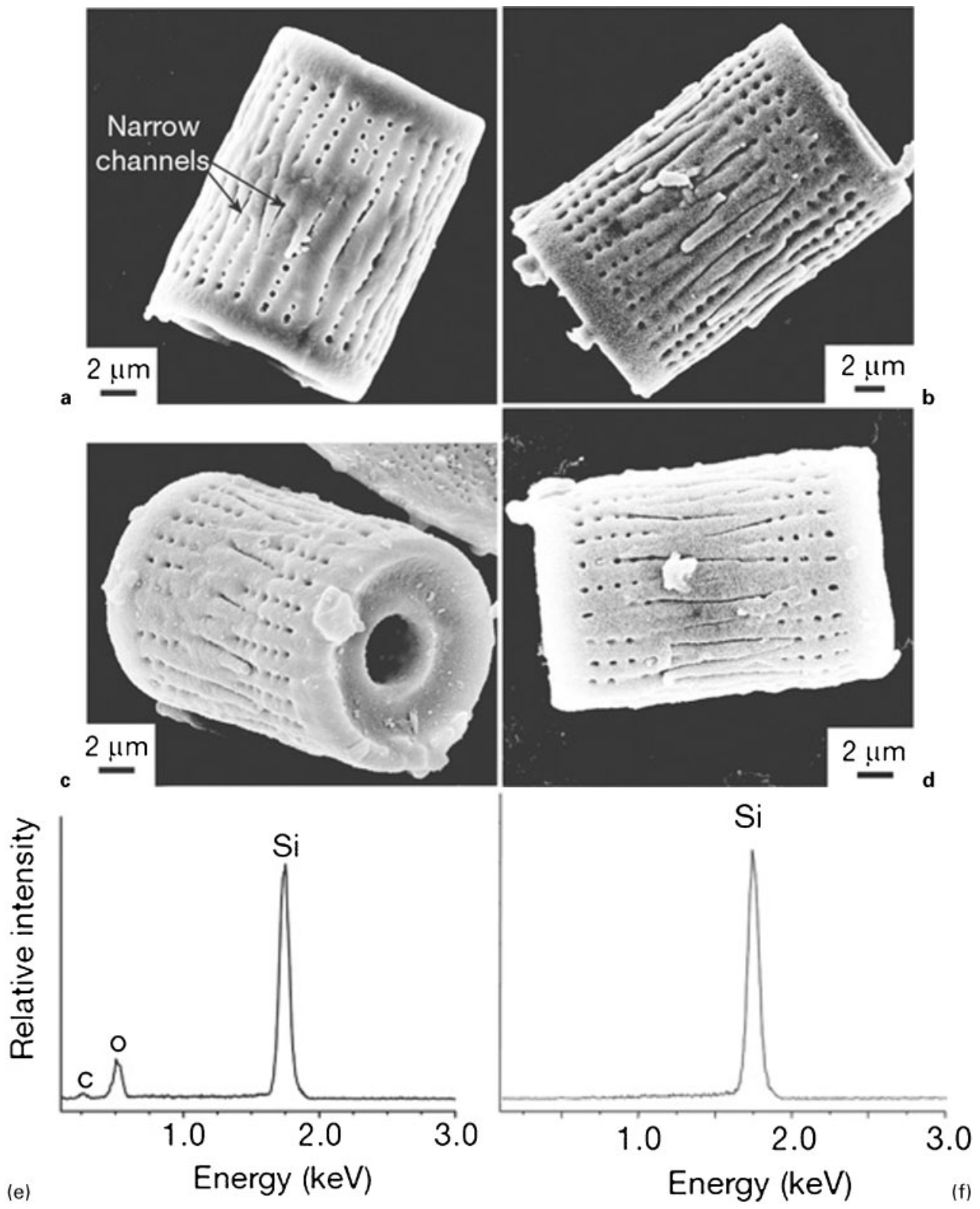

22 SEM images of a Aulacoseira diatom frustules, $b \mathrm{MgO} / \mathrm{Si}$ replica obtained after reaction of frustule with $\mathrm{Mg}$ at $650^{\circ} \mathrm{C}$, $c$ silicon-based replica produced after treatment with $\mathrm{HCl}$ solution and $d$ silicon replica obtained after additional treatment with HF solution. $e$ and $f$ are the results of the energy dispersive X-ray analysis of silicon-based replicas shown in $c$ and $d$ respectively (reprinted from Ref. 263 with permission from Nature Publishing Group)

infiltration process, there is a chemical transformation, for instance according to equation (2)

$$
2 \mathrm{Mg}(\mathrm{g})+\mathrm{SiO}_{2}(\mathrm{~s}) \rightarrow 2 \mathrm{MgO}(\mathrm{s})+\{\mathrm{Si}\}
$$

where $\{\mathrm{Si}\}$ represents a silicon-based product resulting from the chemical reduction, such as $\mathrm{Mg}-\mathrm{Si}$ liquid or $\mathrm{Mg}_{2} \mathrm{Si}^{264,265}$ This reaction occurs when submitting diatom frustules, as for instance the ones from Aulacoseira genre, to heating until $900^{\circ} \mathrm{C}$, in the presence of magnesium. At this temperature, there is evaporation of magnesium that can thus react in a redox process with $\mathrm{SiO}_{2}$, without affecting the morphology of the structure, as illustrated in Fig. 22..$^{263,264}$ This structures can be submitted to further treatments to render other ceramic solids, such as treatments with $\mathrm{HCl}$ solution and ethanol-based hydrofluoric acid solution to render silicon structures ${ }^{263}$ (Fig. 22c-f). Another possibility is an additional deposition of a barium titanate
$\left(\mathrm{BaTiO}_{3}\right)$ layer onto the magnesia solids, using a sol-gel process, ${ }^{265}$ resulting in bioclastic-based ceramics with multicomponent and nanocrystalline features. Moreover, the inclusion of genetic modification steps in order to render self-replicating structures with defined shapes is envisaged, taking advantage of the recent genome mapping and genetic engineering technologies, which may allow the development of genetically engineered micro/nanodevices. ${ }^{265}$

\section{Common applications}

Recent screening techniques have revealed a vast chemical diversity of the oceans, much higher than the one that can be achieved by synthesis and standard chemical approaches, which opens new and exciting research scenarios. In fact, the real value of marinederived materials and compounds can only be roughly imagined as much of sea life, particularly in deep waters, 
is still to be discovered. Thus, the sustainable exploitation of ocean diversity for industrial and medical purposes is of enormous interest and promises a huge impact not only in research, but particularly in the progress of society, which is reflected on the emergence of marine biotechnology, also known as blue biotechnology, as a fast-growing sector. ${ }^{266,267}$

For the stated above, though the focus of this review is to highlight marine biopolymers and ceramics with interest for biomedical application, it would be unforgivable not to comment on the applications of those marine materials in other sectors, particularly by illustration of applications already in use. Thus, this section will briefly portray the most common applications of the materials reviewed above, with indication of bibliographic references where the readers can find deeper discussions.

Agar possesses a long and ancient history, with its gellike properties being alleged to have been first observed by a Chinese Emperor in the mid-sixteenth century. Afterwards, a flourishing agar manufacturing industry was established. The development path of agar closely follows the appearance and growth of microbiology, as it was first reported to be used as a bacteriological culture medium by Koch. ${ }^{27}$ Over a century, it is still the medium of choice for general microbiological research. ${ }^{93}$ Besides its use in the preparation of microbiological media, agar is usually applied also in cell/tissue culture, in affinity chromatography, as a component of dental impression materials, as a raw material for the production of agarose or as a gelling agent in food industry, cosmetics and pharmaceutical products, besides applications in medicine. ${ }^{23,26,27,93}$ Although agar does not possess direct medicinal use, its application in biomedical research is well known. The industrial and commercial relevance of agar lies on its excellent thickening and gelling properties.

The history of alginate starts in 1881, when it was discovered by Stanford, followed by a patent where Stanford claims the application of alginate as a pharmaceutical agent. In 1929, Kelco Co. starts to commercialise this polysaccharide, extracted from kelp, also known as the giant brown seaweed, Macrocystis pyrifera. In 1959, alginate had evolved to a worldwide production. ${ }^{43}$ Nowadays, alginate is widely used as a gelling agent for different applications, namely, in the food industry, pharmaceutical, biomedical and personal care. $^{42,268,269}$ The success of commercial development of alginate lies in its ability to retain water, and in its gelling, viscosifying and stabilising properties, in particular the fact that it increases the viscosity of aqueous solutions and forms gels without temperature dependence, in contrast with other polysaccharides like agar and carrageenan. ${ }^{45}$ Other biotechnological applications can take advantage of the specific biological effects of alginate, like hypocholesterolemic and hypolipidemic effects. ${ }^{270}$ It is then expected that future expansion of alginate market will be through more knowledgedemanding areas, such as pharmacy, biotechnology and biomedicine.

Carrageenan is another family of polysaccharides that find application in very different sectors of activity, including slurry stabilisation and suspension, interaction with polyols, and entrapment/immobilisation of enzymes or microbial cells in fermentation processes at industrial level, ${ }^{271}$ dentifrice preparations, anti-icers, cosmetics, pharmacological excipient, ${ }^{272}$ capsules, ${ }^{273}$ hydrogels ${ }^{274}$ and films, ${ }^{275}$ and texturising agent in food applications. ${ }^{276,277}$ In fact, when used in food products in the European Union, carrageenans are designated by the reference E407, according to the classification of food additives, being used in particular as stabilisers, thickeners and emulsifiers. ${ }^{278}$ This huge potential of application of carrageenan in such a broad range of fields can be weighted by the several thousands of patents registered using carrageenan in food and non-food applications.

Chitin, chitosan and its derivatives are widespread in economical sectors, being used in areas such as agriculture, water treatment, food preservation, cosmetic industry, pharmaceutical and veterinary medicine. ${ }^{279-285}$ Properties such as antimicrobial activity, film-forming ability, high adsorption, excellent chelation behaviour, biocompatibility and non-toxicity have been pointed out as main responsible by performance of chitosan on the cited applications. ${ }^{19,286,287}$ For example, antimicrobial chitosan films have been used as a packaging material for a preservation of a variety of foods and antioxidant in sausages. ${ }^{279,288,289}$ In agriculture, both chitin and chitosan have been utilised to enhance the plant innate defense. $^{282}$ On the other hand, many works ${ }^{285,290-292}$ suggested chitosan as an effective biosorbent for the removal of aquatic pollutants, such as phenol, pesticides, anions, metal ions (zinc, copper, lead and cadmium) and dyes. Besides, chitosan and its derivatives have been recognised as ingredient for cosmetic formulations ${ }^{281,293}$ and have also been studied as promising materials for biological functionalisation of microelectromechanical systems ${ }^{294}$ due to its physicalchemical properties and the easy integration of chitosan films in microdevices. In some of those applications, chitosan needs to be physically or chemically modified and the current research on the improvement of its properties is expected to increase the presence of chitosanbased products on the various segments of the world market.

Although the attention on the GAG, particularly from marine origin, is increasing during the last years, their application or large-scale use is scarce. Nevertheless, a few applications can be identified to illustrate the huge potential possess of this class of biopolymers. Marine CS is being studied to explore its potential as a biomedical gel forming polymer, anticoagulant activity and as a supplement in arthritis-related diseases. ${ }^{154,295-301}$ Marine DS is also an object of research to explore its anticoagulant activity aiming a potential replacement agent for heparin. ${ }^{295-297,302-307}$ In fact, the search for new natural sulfated polysaccharides with relevant anticoagulant and antithrombotic action is an attractive alternative for the traditional heparin use in medicine, and there are several reports of other sulphated compounds from marine origin, such as heparin and fucans, also with this aim. ${ }^{152,154,296,308,309}$

Hyaluronic acid is ubiquitously present in the human body, namely, in intercellular matrix of most connective tissues, as thus have found applications mainly in the biomedical field. In particular, it is used as surgical aid in ophthalmology and exhibits significant therapeutic potential in joint disease and wound-healing. ${ }^{310,311}$ Its ophthalmological use is based on the semiflexible 
properties of the high molecular weight chains and the interactions between them, which renders solutions with unique viscoelastic properties. ${ }^{312}$ In fact, the most common application of hyaluronic acid is as a viscoelastic adjunct in patients undergoing cataract surgery. ${ }^{312}$ Regarding the therapeutic potential in joint disease, its role for supplementation of impaired synovial fluid in arthritic patients by means of intra-articular injections is highlighted. ${ }^{313}$ Hyaluronic acid has also other clinical medicine uses, as a diagnostic marker for diseases such as cancer, rheumatoid arthritis and liver pathologies, ${ }^{313}$ but also promises application in the surface modification of titanium orthopedic implants aiming to reduce bacterial infection and enhance cell adhesion. ${ }^{314}$ Moreover, its use in cosmetic regeneration and reconstruction of soft tissue has also been envisaged and described. ${ }^{312,313}$ Hyaluronic acid also finds pharmaceutical application, with drug delivery systems being proposed or already demonstrated. ${ }^{312,315}$

Being the main protein in mammals, collagen is an important ingredient for health-related applications, being used in cosmetics, dental composites, skin regeneration templates, biodegradable matrices and shields in ophthalmology, cardiovascular surgery, plastic surgery, orthopedics, urology and neurology. ${ }^{316}$ However, collagen and gelatin (denaturated collagen) are also used in very different sectors, as in food industry, for instance, in sausage casings made of dispersed insoluble collagen extruded as a tube and formed or cut into links as it is filled. Marine collagen in particular is currently being studied to be used in all the traditional areas where mammal collagen finds application, to overcome the abovementioned disease-related issues, as well as in advanced methodologies for artificial organs, tissue engineering and drug delivery applications. ${ }^{317-320}$

Besides biopolymers, marine ceramics are also very interesting for several applications. Calcium phosphates, despite being used mainly as bioceramics in drug delivery systems, ${ }^{321}$ tissue engineering scaffolding, bone graft substitutes and facial fillers, ${ }^{322,323}$ have also been found outside biomedical area but in related fields, namely as supplements for pharmaceutical and cosmetics industries, oral care products and jelling agent. ${ }^{324,325}$ Besides, it can also be used as an ingredient is many industrial cements and chemicals.

Another marine ceramic with quite interesting properties is biosilica, mainly due to the biomineralisation process. For instance, sponges (phylum Porifera) have a biosilicification process mediated by enzymes resulting in silica structures ranging in size from micrometres to metres, which can be conjugated with polymers such as collagen to form micro- and nanocomposites. These structures present an interesting physical stability and an impressive light transmission capability similar to optic fibres. These properties have been further explored in recent years in order to study the development of new applications for biomedicine, in particular for biosilicamediated regeneration of tooth and bone defects, and for micro-optics, in particular through the in vitro synthesis of light waveguides. ${ }^{234,235,326}$ A quite interesting morphology is also observed in diatoms, where the silica skeleton exhibits symmetric patterns of micro- and nanopores in which light transmission is found to be, in some cases, strongly wavelength dependent, ${ }^{327}$ suggesting their exploitation in biomimetic optical applications,

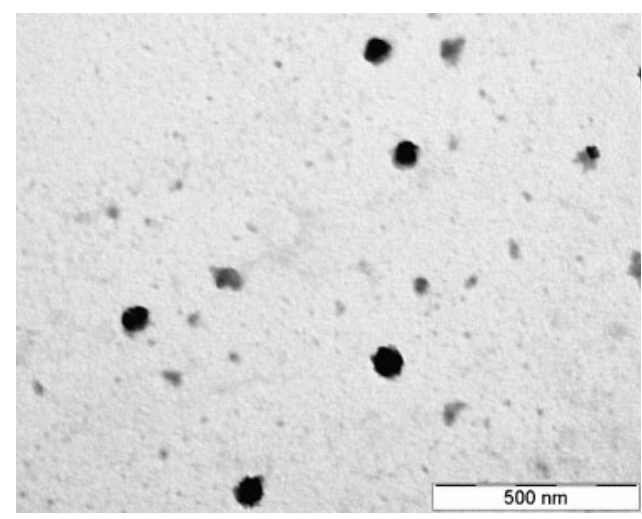

23 TEM image of carboxymethylchitosan/poly(amidoamine) dendrimer nanoparticles

such as light guiding and optical transducing. ${ }^{328}$ Besides the mentioned applications, others are being explored with silica-based materials, such as the protein-silica nanocomposites for biosensing applications reported by Ramanathan et al. ${ }^{329}$ or silica particles for the development of oral drug delivery vehicles reviewed by Rigby et al. ${ }^{330}$ which may enhance the potential for application of biosilica in other fields.

\section{Drug delivery applications}

Marine-derived materials, especially polysaccharides, have been widely used in the development of drug delivery devices, especially with the shape of spheres of different sizes. ${ }^{331,332}$

Chitosan and alginate have been probably the most used marine-derived polymers in the preparation of drug delivery particles. ${ }^{269,333-340}$ Chitosan itself may be chemically modified to control the interaction with drug molecules. For example, the chemical attachment of cyclodextrins or amphiphilic molecules to chitosanbased macromolecules may enhance the affinity of the polysaccharide with hydrophobic drugs. ${ }^{341,342}$

Nanoparticles are especially adequate to act as injectable delivery systems of a variety of therapeutic molecules. Polysaccharides-based nanoparticles have been produced by different methods, including covalent cross-linking, ionic cross-linking, polyelectrolyte complex and the self-assembly of hydrophobically modified polysaccharides. $^{343}$ For example, poly(amidoamine) low-generation dendrimers are surface chemical modified by carboxymethylchitosan, rendering dendritic nanoparticles (Fig. 23). These nanoparticles are shown to be internalised by cells and thus be used in intracellular drug delivery strategies. ${ }^{344}$ Using a rational of electrostatic interactions, chitosan/carrageenan nanoparticles are produced in mild conditions and showed to permit the encapsulation and posterior release of proteins. ${ }^{345}$ Using a equivalent methodology, microparticles of carrageenan and gelatin, as well as of ulvan and chitosan, has also been prepared, as illustrated in Fig. 24. Interactions between polyelectrolytes may be also used to coat particles or drug crystals or to produce capsules using the layer-by-layer methodology, as illustrated by the scheme in Fig. 25. Chitosan or alginates have been used to produce such multilayered nanostructured coatings. ${ }^{346-349}$ Such films are usually stable in physiological conditions and may act as a 


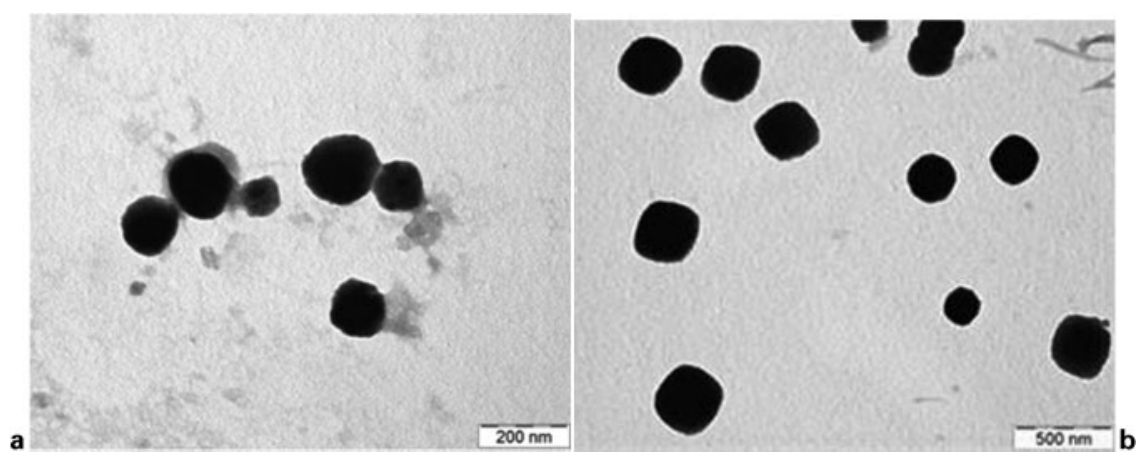

24 SEM images of microparticles of $a$ carrageenan and gelatin and $b$ ulvan and chitosan, prepared by ionic interaction between polymers

physical barrier for the release of the encapsulated molecules. The permeability can be controlled by changing the nature of the polyelectrolytes used and the number of multilayers.

Marine origin polysaccharides have acidic or basic functional groups. Thus, the ionisation level of the pendant group changes strongly around the $\mathrm{p} K_{\mathrm{a}}$, causing a modification of the water solubility of the polymer chains or the swelling in the case of cross-linked systems. Hydrogels with such characteristics are $\mathrm{pH}$ responsive and have been proposed for the smart delivery of bioactive agents. ${ }^{350-352}$ They are based on the fact that swelling or degradation will be highly sensitive to changes in the $\mathrm{pH}$ in the body or inside cells. Systems that can respond simultaneously and independently to more than one external stimulus, such as $\mathrm{pH}$ and temperatures, have also been developed. ${ }^{352,353}$ In most of the cases, they are produced by combining $\mathrm{pH}$-responsive macromolecules and temperaturesensitive polymers, especially poly( $N$-isopropyacrylamide), PNIPAAm, either by grafting or by blending. A possibility to produce dual-responsive systems is by combining the two macromolecules by means of interpenetrating or semi-interpenetrating networks. An example included the combination of alginate and PNIPAAm where the $\mathrm{pH}$ responsive polysaccharide was cross-linked with calcium ions; ${ }^{354}$ the swelling of the obtained beads were highly dependent on both temperature and $\mathrm{pH}$, and strong deviations were also found in the delivery profile of indomethacin. In order to try to slow down the release profile, such particles were coated with chitosan, followed by alginate. ${ }^{355}$ Such kinds of particles were also partially mineralised with calcium phosphate in order to potentially improved their biocompatibility with bone tissue: ${ }^{356}$ the calcified systems were shown to maintain their $\mathrm{pH}$ and temperature responsiveness, and could be useful in the delivery of relevant therapeutic agents or in the construction of scaffolds for orthopedic applications.

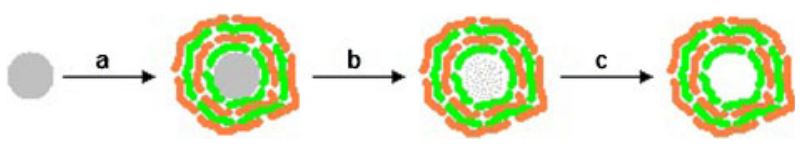

25 Cartoon of the methodology to prepare polyelectrolyte capsules: a coating of a colloid with polyelectrolyte multilayers; $b$ nucleolus decomposition; $c$ nucleolus residues leave the system through the multilayered membrane, rendering a capsule

\section{Tissue engineering applications}

In the general tissue engineering approach, matrices are developed to support cells, promoting their differentiation and proliferation towards the formation of new and functional tissue. ${ }^{357}$ Such strategy allows producing hybrid constructs that can be implantable in patients to induce the regeneration of tissues or replace failing or malfunctioning organs. Different materials have been proposed to be used in the processing of scaffolds, namely, biodegradable polymers derived from marine resources. Natural-based polymers offer the advantage similar to biological macromolecules, where the biological environment is prepared to recognise and to deal with metabolically. Owing to their similarity with the extracellular matrix, natural polymers may also avoid the stimulation of chronic inflammation or immunological reactions and toxicity, often detected with synthetic polymers. The sea may be an important source of materials to be used in such applications, in which a variety of polysaccharides with different chemical natures, proteins and minerals can be found.

An important aspect is the processing of such kind of materials into porous matrices, a task that usually needs other technologies than those usually employed in the processing of conventional synthetic polymers that often implies the melting of the material or the use of organic solvents. ${ }^{358}$ Mild methods have been widely used to process marine-derived polymers that may be also attractive by the fact that cells or unstable proteins can be incorporating during the fabrication of the device.

Freeze-drying has been widely used to process natural polymers, including marine-derived polysaccharides. A classic example is the production of scaffolds from chitosan: ${ }^{73}$ acidic aqueous solutions are frozen and lyophilised and the final scaffold is neutralised and stabilised in an alkaline solution and water, rendering structures like the one depicted in Fig. 26a. Figures $26 b$ and $c$ show the morphology of the produced scaffold with higher detail, using SEM and microcomputed tomography. The structure of the final scaffold will essentially depend on the initial chitosan concentration and on the shape and size of the ice crystals generated during the freezing step. Cross-linking or the incorporation of other biomacromolecules can be also combined with such method. ${ }^{359}$ For orthopedic application, such scaffolds can be incorporated into more stiff prefabricated scaffolds ${ }^{360}$ or can also be combined with inorganic bioactive particles, ${ }^{361,362}$ including marinederived ceramics. ${ }^{363}$ Such osteoconductive scaffolds 


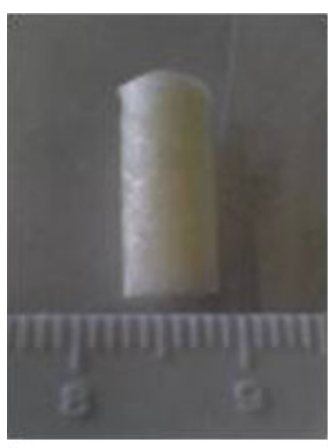

a b

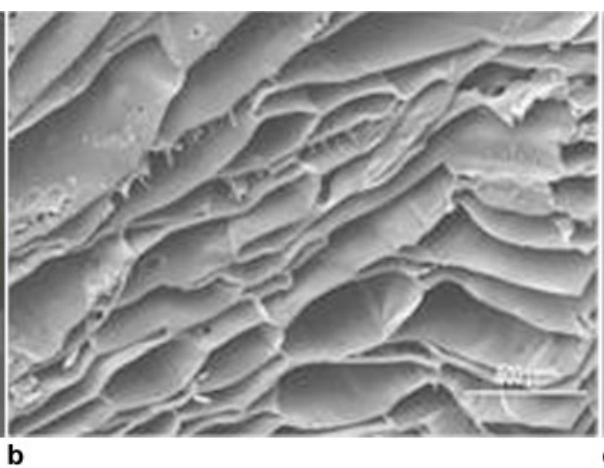

(a) and respective SEM image (b) and microcomputed tomo- containing chitosan-derivatives may be also produced by precipitation-related methodologies. ${ }^{364}$ Another method to fabricate macrofibres from chitosan-containing solutions is by wet-spinning where the polymer from a solution filament is continuously precipitated into a coagulation bath. ${ }^{77,365}$ Chitosan solutions can be also precipitated into spheres that may be used in tissue engineering, either by agglomerating them into scaffolds ${ }^{76,366}$ producing structures like the ones shown in Fig. 27, or use them directly with cells as an injectable system. ${ }^{367}$ Matrices for regenerative medicine may be also produced using electrospinning, which enables to produce non-woven supports made of nanofibres, for example, using polysaccharides. ${ }^{368}$ Such technology has been used to produce nanofibres of marine-derived materials such as chitosan, ${ }^{369,370}$ alginate ${ }^{371}$ or even materials containing marine-derived collagen. $^{372}$

Complexation of polysaccharides with oppositely charges, such as chitosan and alginate, may be also used to produce scaffolds. ${ }^{373}$ For example, by using spray-spinning, a chitosan solution was sprayed into a flowing sodium alginate solution and sheared into streamlines - the elongated streamlines subsequently transformed into alginate/chitosan polyelectrolyte complexes fibres. $^{374}$

The ability of alginate to cross-link with calcium ions may be also used to produce scaffolds. ${ }^{375}$ The calcium source may be even from hydroxyapatite allowing to process nanocomposite porous structures. ${ }^{376}$ However, alginates have been much more used in tissue engineering as non-porous structures, as cells may be easily encapsulated during the hydrogel formation. ${ }^{377,378}$ Alginate molecules have been modified by incorporating RGD sequences along the macromolecular structure, in order to enhance the specific interaction with cells - such systems may be used as injectable systems in which cells may act as cross-linking entities. ${ }^{379,380}$ Moreover, ionic cross-linking can be also used with other polymers, such as carrageenans, preparing organised structures aimed for cell culture, by rapid prototyping, through extrusion of carrageenan solution from a syringe into a coagulation bath. Figure 28 illustrates the structures that can be produced with such technique.

Injectable systems are very attractive as they can deliver and fix cells and molecules in specific sites in the body using minimally invasive methods. ${ }^{381,382}$ The materials may harden in situ from different ways, including through ionic, hydrogen or covalent bonds. Thermoreversible gels are very popular as such system may exist in a liquid state at room temperature but turn into a self-sustained gel at body temperature. ${ }^{383}$ An interesting example is the chitosan/ $\beta$-glycerolphosphate systems: in 2000, Chenite and co-workers developed such kind of formulations to produce an injectable thermosensitive, $\mathrm{pH}$-dependent solution, which is liquid at physiological $\mathrm{pH}$ and room temperature, and becomes a gel if heated at body temperature. ${ }^{384}$ Such materials may be combined with bioactive glass-ceramic particles to produce biodegradable injectable osteoconductive biomaterials. ${ }^{385}$ Higher contents of calcium phosphates may be incorporated in chitosan to produce composites bioresorbable cements able to be replaced by new bone. ${ }^{386}$

Other marine-derived materials have been developed to produce injectable systems for tissue engineering, such as carrageenan - this polysaccharide, combined with fibrin/hyaluronic acid, may have potential in cartilage regeneration. ${ }^{387}$ Alginate-based injectable hydrogels have also been proposed for such applications ${ }^{388}$ or for cardiac remodeling. ${ }^{389}$ The main drawback of such

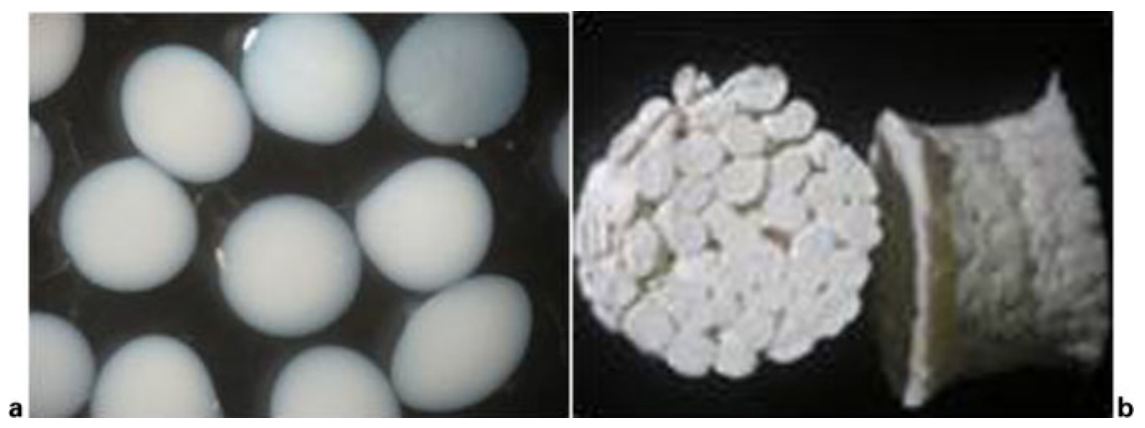

27 Photos of (a) chitosan particles prepared by precipitation of droplets of chitosan solution into an alkaline coagulation bath, which can be agglomerated forming a porous structure $(b)$ 


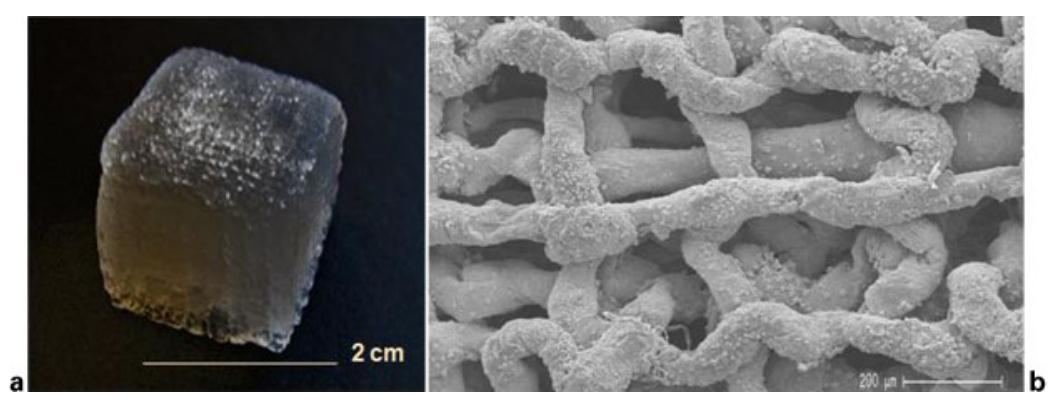

Photo of carrageenan scaffold produced by rapid prototyping (a) and respective SEM image (b)

biomaterials will be always limited by the mechanical properties - further developments are required to enhance the cross-linking extent and stability and the incorporation of other strategies to enhance the stiffness and strength of the hydrogels in physiological conditions.

Besides polysaccharides, other marine-derived biopolymers are also being used on tissue engineering strategies, as collagen. Being the main protein in the body, collagen is a biomaterial for excellence and a relevant choice when one wants to develop a tissue engineering scaffold. In this perspective, marine-derived collagen scaffolds were developed by freeze-drying using jellyfish collagen, further cross-linked, which did not induce a significant cytotoxic effect and had higher cell viability than other biomaterials, including bovine collagen. Moreover, in vivo tests demonstrated that jellyfish collagen induced a comparable immune response to that induced by bovine collagen. ${ }^{187}$ Jellyfish collagen has also been combined with poly(lacticco-glycolic acid) and processed by freeze-drying and electrospinning to obtain tubular scaffolds, in which smooth muscle cells and endothelial cells were shown to proliferate. ${ }^{372}$ Taken together, these results support the great potential of marine origin collagen for tissue engineering applications.

\section{Concluding remarks and future outlook}

Sea has proven to be a huge source of materials, even though the available knowledge of marine materials and mechanism are still in its beginning. Nevertheless, with the technological development, such as the appearance of new remotely operated (underwater) vehicles that allow collection of materials in deep waters, an enormous new door is being open. In fact, marine biomaterials are of particular interest as they might have novel characteristics as well as unique biochemical properties. Moreover, the diversity of these materials and its potential, in particular of polysaccharides, can be increased by physical or chemical modifications, like complexation with other polymeric materials, chemicals or salts or modifications introduced in the polysaccharidic chain. The possibility of developing a wide variety of chemically modified derivatives makes these polysaccharides versatile materials that can be applied in different fields of technological interest, including the biomedical one. This is a continuing challenge to polymer and biomaterial scientists, but it is already possible to anticipate that these strategic approaches will widen up perspectives and potential applications in the future. On the other hand, this will render low environmental impact products that have a lower carbon footprint at the end of product cycle. The enhancement of the performance of marine-derived polysaccharides will increase their competitiveness against synthetic biodegradable polymers and polymers from petroleum sources. In an era of increasing oil prices, global warming and other environmental problems (e.g. waste), the change from fossil feedstock to renewable resources can considerably contribute to a sustainable development in the future.

It is envisaged that biomedical field will be an area in which marine-derived materials will have a role of major relevance, in particular with their use on tissue repair and regeneration. This multidisciplinary approach that aims to go from engineered scaffolds to clinical applications that allow regeneration of damaged or injured tissues or organs is not that fair to accomplish its goals and marine-derived materials are being increasingly studied. However, strong efforts are still needed to obtain medical grade biopolymers from marine raw materials, in a reproducible way, to allow its use on the development of three-dimensional scaffolds in which different cells can be seeded and then proliferate, rendering a new tissue that can be implanted in the patient. In addition, the use of marine origin materials in tissue engineering approaches, in particular their success in in vivo testing, is still needed to boost their potential in this area. Nevertheless, this is a route that is being followed together with other materials by tissue engineers to turn biomaterial-based regenerative medicine into a real clinical solution.

\section{Acknowledgements}

The authors wish to acknowledge the financial support of FEDER through INTERREG III A Project PROTEUS and POCTEP Project IBEROMARE. Portuguese Foundation for Science and Technology is also gratefully acknowledged for post-doc grants of T. H. Silva, J. M. Oliveira and S. S. Silva and for PhD grant of A. Alves.

\section{References}

1. G. M. Luz and J. F. Mano: 'Mineralized structures in nature: examples and inspirations for the design of new composite materials and biomaterials', Compos. Sci. Technol., 2010, 70, (13), 1777-1788.

2. I. Paterson and E. A. Anderson: 'The renaissance of natural products as drug candidates', Science, 2005, 310, (5747), 451453.

3. D. J. Newman and G. M. Cragg: 'Marine natural products and related compounds in clinical and advanced preclinical trials', J. Nat. Prod., 2004, 67, (8), 1216-1238.

4. V. M. Dembitsky, T. A. Gloriozova and V. V. Poroikov: 'Novel antitumor agents: marine sponge alkaloids, their synthetic analogs and derivatives', Mini-Rev. Med. Chem., 2005, 5, (3), 319-336. 
5. S. Urban, S. J. H. Hickford, J. W. Blunt and M. H. G. Munro: 'Bioactive marine alkaloids', Curr. Org. Chem., 2000, 4, (7), 765807

6. J. L. Frenz, A. C. Kohl, and R. G. Kerr: 'Marine natural products as therapeutic agents: Part 2', Expert Opin. Ther. Patents, 2004 14, (1), 17-33.

7. J. W. Blunt, B. R. Copp, W. P. Hu, M. H. G. Munro, P. T. Northcote and M. R. Prinsep: 'Marine natural products', Nat. Prod. Rep., 2007, 24, (1), 31-86.

8. J. W. Blunt, B. R. Copp, W. P. Hu, M. H. G. Munro, P. T. Northcote and M. R. Prinsep: 'Marine natural products', Nat. Prod. Rep., 2008, 25, (1), 35-94.

9. J. W. Blunt, B. R. Copp, W. P. Hu, M. H. G. Munro, P. T Northcote and M. R. Prinsep: 'Marine natural products', Nat. Prod. Rep., 2009, 26, (2), 170-244.

10. J. W. Blunt, B. R. Copp, M. H. G. Munro, P. T. Northcote and M. R. Prinsep: 'Marine natural products', Nat. Prod. Rep., 2003 , 20, (1), 1-48.

11. J. W. Blunt, B. R. Copp, M. H. G. Munro, P. T. Northcote and M. R. Prinsep: 'Marine natural products', Nat. Prod. Rep., 2004, 21, (1), 1-49.

12. J. W. Blunt, B. R. Copp, M. H. G. Munro, P. T. Northcote and M. R. Prinsep: 'Marine natural products', Nat. Prod. Rep., 2005, 22, (1), 15-61.

13. J. W. Blunt, B. R. Copp, M. H. G. Munro, P. T. Northcote and M. R. Prinsep: 'Marine natural products', Nat. Prod. Rep., 2006, 23, (1), 26-78

14. J. W. Blunt, B. R. Copp, M. H. G. Munro, P. T. Northcote and M. R. Prinsep: 'Marine natural products', Nat. Prod. Rep., 2010, 27, (2), 165-237.

15. J. W. Blunt, B. R. Copp, M. H. G. Munro, P. T. Northcote and M. R. Prinsep: 'Marine natural products', Nat. Prod. Rep., 2010 , 27, (2), 165-237.

16. J. W. Blunt, B. R. Copp, M. H. G. Munro, P. T. Northcote and M. R. Prinsep: 'Marine natural products', Nat. Prod. Rep., 2011, 28, (2), 196-268.

17. V. P. Gullo, J. McAlpine, K. S. Lam, D. Baker and F. Petersen: 'Drug discovery from natural products', J. Ind. Microbiol. Biotechnol., 2006, 33, (7), 523-531.

18. G. G. d'Ayala, M. Malinconico and P. Laurienzo: 'Marine derived polysaccharides for biomedical applications: chemical modification approaches', Molecules, 2008, 13, (9), 2069-2106.

19. M. Rinaudo: 'Chitin and chitosan: properties and applications', Prog. Polym. Sci., 2006, 31, (7), 603-632.

20. A. D. McNaught, A. Wilkinson and A. Jenkins: 'Compendium of chemical terminology (the 'Gold Book')', 2nd edn, B00661; 1997, Oxford, Blackwell Scientific Publications.

21. T. E. Hardingham and A. J. Fosang: 'Proteoglycans - many forms and many functions', FASEB J., 1992, 6, (3), 861-870.

22. T. C. Laurent and J. R. E. Fraser: 'Hyaluronan', FASEB J., 1992, 6, (7), 2397-2404

23. H. Y. Li, X. J. Yu, Y. Jin, W. Zhang and Y. L. Liu: 'Development of an eco-friendly agar extraction technique from the red seaweed Gracilaria lemaneiformis', Bioresour. Technol., 2008, 99, (8), 33013305 .

24. M. Duckworth and W. Yaphe: 'The structure of agar: Part I. Fractionation of a complex mixture of polysaccharides', Carbohydr. Res., 1971, 16, (1), 189-197.

25. E. Murano, R. Toffanin, F. Zanetti, S. H. Knutsen, S. Paoletti and R. Rizzo: 'Chemical and macromolecular characterisation of agar polymers from Gracilaria dura (C. Agardh) J. Agardh (Gracilariaceae, Rhodophyta)', Carbohydr. Polym., 1992, 18, (3), 171-178.

26. C. Rochas and M. Lahaye: 'Average molecular weight and molecular weight distribution of agarose and agarose-type polysaccharides', Carbohydr. Polym., 1989, 10, (4), 289-298.

27. K. B. Guiseley: 'Chemical and physical properties of algal polysaccharides used for cell immobilization', Enzyme Microb. Technol., 1989, 11, (11), 706-716.

28. F. Pereira-Pacheco, D. Robledo, L. Rodriguez-Carvajal and Y. Freile-Pelegrin: 'Optimization of native agar extraction from Hydropuntia cornea from Yucatan, Mexico', Bioresour. Technol. 2007, 98, (6), 1278-1284.

29. V. Kumar and R. Fotedar: 'Agar extraction process for Gracilaria cliftonii (Withell, Millar, \& Kraft, 1994)', Carbohydr. Polym., 2009, 78, (4), 813-819.

30. M. M. El-Sayed: 'Purification and characterization of agar from digenea simplex', Carbohydr. Res., 1983, 118, 119-126.
31. M. Rinaudo: 'Main properties and current applications of some polysaccharides as biomaterials', Polym. Int., 2008, 57, (3), 397430.

32. E. Percival: 'Polysaccharides of green, red and brown seaweeds their basic structure, biosynthesis and function', Br. Phycol. J., 1979, 14, (2), 103-117.

33. P. Nyvall, E. Corre, C. Boisset, T. Barbeyron, S. Rousvoal, D. Scornet, B. Kloareg and C. Boyen: 'Characterization of mannuronan C-5-epimerase genes from the brown alga Laminaria digitata', Plant Physiol., 2003, 133, (2), 726-735.

34. C. K. Siew, P. A. Williams and N. W. G. Young: 'New insights into the mechanism of gelation of alginate and pectin: charge annihilation and reversal mechanism', Biomacromolecules, 2005, 6, (2), 963-969.

35. H. Ertesvag and S. Valla: 'Biosynthesis and applications of alginates', Polym. Degrad. Stab., 1998, 59, (1-3), 85-91.

36. B. H. A. Rehm and S. Valla: 'Bacterial alginates: biosynthesis and applications', Appl. Microbiol. Biotechnol., 1997, 48, (3), 281-288.

37. H. Mizuno, T. Saito, N. Iso, N. Onda, K. Noda and K. Takada: 'Solution properties of sodium alginate from brown seaweeds living along the coast of Japan. 4. Mannuronic to guluronic acid ratios of alginic acids prepared from various brown seaweeds', Bull. Jpn Soc. Sci. Fish., 1983, 49, (10), 1591-1593.

38. L. E. Rioux, S. L. Turgeon and M. Beaulieu: 'Rheological characterisation of polysaccharides extracted from brown seaweeds', J. Sci. Food Agric., 2007, 87, (9), 1630-1638.

39. S. Jothisaraswathi, B. Babu and R. Rengasamy: 'Seasonal studies on alginate and its composition II: Turbinaria conoides (J.Ag.) Kutz. (Fucales, Phaeophyceae)', J. Appl. Phycol., 2006, 18, (2), 161-166.

40. B. J. Kelly and M. T. Brown: 'Variations in the alginate content and composition of Durvillaea antarctica and D-willana from southern New Zealand', J. Appl. Phycol., 2000, 12, (3-5), 317-324.

41. J. W. A. McKee, L. Kavalieris, D. J. Brasch, M. T. Brown and L. D. Melton: 'Alginate content and composition of Macrocystis pyrifera from New Zealand', J. Appl. Phycol., 1992, 4, (4), 357369.

42. J. L. Drury, R. G Dennis and D. J. Mooney: 'The tensile properties of alginate hydrogels', Biomaterials, 2004, 25, (16), 3187-3199.

43. G. d'Ayala, M. Malinconico and P. Laurienzo: 'Marine derived polysaccharides for biomedical applications: chemical modification approaches', Molecules, 2008, 13, (9), 2069-2106.

44. L. B. Li, Y. P. Fang, R. Vreeker and I. Appelqvist: 'Reexamining the egg-box model in calcium-alginate gels with X-ray diffraction', Biomacromolecules, 2007, 8, (2), 464-468.

45. C. G. Gomez, M. V. P. Lambrecht, J. E. Lozano, M. Rinaudo and M. A. Villar: 'Influence of the extraction-purification conditions on final properties of alginates obtained from brown algae (Macrocystis pyrifera)', Int. J. Biol. Macromol., 2009, 44, (4), 365-371.

46. W. Sabra, A. P. Zeng and W. D. Deckwer: 'Bacterial alginate: physiology, product quality and process aspects', Appl. Microbiol. Biotechnol., 2001, 56, (3-4), 315-325.

47. T. Windhues and W. Borchard: 'Effect of acetylation on physicochemical properties of bacterial and algal alginates in physiological sodium chloride solutions investigated with light scattering techniques', Carbohydr. Polym., 2003, 52, (1), 47-52.

48. G. Hernandez-Carmona, D. J. McHugh, D. L. Arvizu-Higuera and Y. E. Rodriguez-Montesinos: 'Pilot plant scale extraction of alginate from Macrocystis pyrifera. 1. Effect of pre-extraction treatments on yield and quality of alginate', J. Appl. Phycol., 1998, 10, (6), 507-513.

49. N. Fleury and M. Lahaye: 'Studies on by-products from the industrial extraction of alginate.1. Chemical and physicalchemical characteristics of dietary-fibers from flotation cellulose', J. Appl. Phycol., 1993, 5, (1), 63-69.

50. G. Hernandez-Carmona, D. J. McHugh and F. Lopez-Gutierrez: 'Pilot plant scale extraction of alginates from Macrocystis pyrifera. 2. Studies on extraction conditions and methods of separating the alkaline-insoluble residue', J. Appl. Phycol., 1999, 11, (6), 493-502.

51. P. Vauchel, K. Le Roux, R. Kaas, A. Arhaliass, R. Baron and J. Legrand: 'Kinetics modeling of alginate alkaline extraction from Laminaria digitata (vol 100, pg 1291, 2009)', Bioresour. Technol., 2009, 100, (20), 4918-4918.

52. D. J. McHugh, G. Hernandez-Carmona, D. Luz Arvizu-Higuera and Y. E. Rodriguez-Montesinos: 'Pilot plant scale extraction of alginates from Macrocystis pyrifera - 3. Precipitation, bleaching 
and conversion of calcium alginate to alginic acid', J. Appl. Phycol., 2001, 13, (6), 471-479.

53. J. Fleurence: 'Seaweed proteins: biochemical, nutritional aspects and potential uses', Trends Food Sci. Technol., 1999, 10, (1), 25 28.

54. R. Falshaw, H. J. Bixler and K. Johndro: 'Structure and performance of commercial kappa-2 carrageenan extracts: I Structure analysis', Food Hydrocoll., 2001, 15, (4-6), 441-452.

55. R. Falshaw, H. J. Bixler and K. Johndro: 'Structure and performance of commercial kappa-2 carrageenan extracts. Part III. Structure analysis and performance in two dairy applications of extracts from the New Zealand red seaweed, Gigartina atropurpurea', Food Hydrocoll., 2003, 17, (2), 129-139.

56. F. van de Velde, H. A. Peppelman, H. S. Rollema and R. H. Tromp: 'On the structure of kappa/iota-hybrid carrageenans', Carbohydr. Res., 2001, 331, (3), 271-283.

57. Y. Yuguchi, H. Urakawa and K. Kajiwara: 'Structural characteristics of carrageenan gels: various types of counter ions', Food Hydrocoll., 2003, 17, (4), 481-485.

58. L. Hilliou, F. D. S. Larotonda, P. Abreu, A. M. Ramos, A. M. Sereno and M. P. Goncalves: 'Effect of extraction parameters on the chemical structure and gel properties of kappa/iota-hybrid carrageenans obtained from Mastocarpus stellatus', Biomol. Eng., 2006, 23, (4), 201-208.

59. M. Ciancia, M. D. Noseda, M. C. Matulewicz and A. S. Cerezo: 'Alkali-modification of carrageenans: mechanism and kinetics in the kappa/iota-, mu/nu- and lambda-series', Carbohydr. Polym., 1993, 20, (2), 95-98.

60. D. Goff: 'Carrageenan functionality', Dairy Ind. Int., 2004, 69, (2), 31-33.

61. M. R. Mangione, D. Giacomazza, D. Bulone, V. Martorana, G Cavallaro and P. L. San Biagio: ' $\mathrm{K}^{+}$and $\mathrm{Na}^{+}$effects on the gelation properties of kappa-Carrageenan', Biophys. Chem., 2005, 113, (2), 129-135.

62. V. L. Campo, D. F. Kawano, D. B. da Silva and I. Carvalho: 'Carrageenans: biological properties, chemical modifications and structural analysis - a review', Carbohydr. Polym., 2009, 77, (2), 167-180.

63. F. R. F. Silva, C. M. P. G. Dore, C. T. Marques, M. S. Nascimento, N. M. B. Benevides, H. A. O. Rocha, S. F. Chavante and E. L. Leite: 'Anticoagulant activity, paw edema and pleurisy induced carrageenan: action of major types of commercial carrageenans', Carbohydr. Polym., 2010, 79, (1), 26-33.

64. C. Peniche, W. Argüelles-Monal and F. Goycoolea: 'Chitin and chitosan: major sources, properties and applications', in 'Monomers, polymers and composites from renewable resources', (ed. M. Belgacem et al.), 517-542; 2008, Amsterdam, Elsevier.

65. M. N. V. R. Kumar: 'A review of chitin and chitosan applications', React. Funct. Polym., 2000, 46, (1), 1-27.

66. K. Kurita: 'Chitin and chitosan: functional biopolymers from marine crustaceans', Mar. Biotechnol., 2006, 8, (3), 203-226.

67. N. L. B. M. Yusof, L. Y. Lee and E. Khor: 'Flexible chitin films: structural studies', Carbohydr. Res., 2004, 339, (16), 2701-2711.

68. E. Yilmaz and M. Bengisu: 'Preparation and characterization of physical gels and beads from chitin solutions', Carbohydr. Polym., 2003, 54, (4), 479-488.

69. Y. Wu, T. Sasaki, S. Irie and K. Sakurai: 'A novel biomass-ionic liquid platform for the utilization of native chitin', Polymer, 2008, 49, 2321-2327.

70. V. Dodane and V. D. Vilivalam: 'Pharmaceutical applications of chitosan', Pharm. Sci. Technol. Today, 1998, 1, (6), 246-253.

71. C. K. S. Pillai, W. Paul and C. P. Sharma: 'Chitin and chitosan polymers: chemistry, solubility and fiber formation', Prog. Polym. Sci., 2009, 34, (7), 641-678.

72. J. K. Francis Suh and H. W. T. Matthew: 'Application of chitosan-based polysaccharide biomaterials in cartilage tissue engineering: a review', Biomaterials, 2000, 21, (24), 2589.

73. S. V. Madihally and H. W. T. Matthew: 'Porous chitosan scaffolds for tissue engineering', Biomaterials, 1999, 20, (12), 1133-1142.

74. R. M. Silva, G. A. Silva, O. P. Coutinho, J. F. Mano and R. L. Reis: 'Preparation and characterisation in simulated body conditions of glutaraldehyde crosslinked chitosan membranes', J. Mater. Sci: Mater. Med., 2004, 15, (10), 1105-1112.

75. S. S. Silva, M. I. Santos, O. P. Coutinho, J. F. Mano and R. L. Reis: 'Physical properties and biocompatibility of chitosan/soy blended membranes', J. Mater. Sci.: Mater. Med., 2005, 16, (6), 575-579.

76. P. B. Malafaya, A. J. Pedro, A. Peterbauer, C. Gabriel, H. Redl and R. L. Reis: 'Chitosan particles agglomerated scaffolds for cartilage and osteochondral tissue engineering approaches with adipose tissue derived stem cells', J. Mater. Sci.: Mater. Med., 2005, 16, (12), 1077-1085.

77. K. Tuzlakoglu, C. M. Alves, J. F. Mano and R. L. Reis: 'Production and characterization of chitosan fibers and 3-D fiber mesh scaffolds for tissue engineering applications', Macromol. Biosci., 2004, 4, (8), 811-819.

78. J. K. F. Suh and H. W. T. Matthew: 'Application of chitosanbased polysaccharide biomaterials in cartilage tissue engineering: a review', Biomaterials, 2000, 21, (24), 2589-2598.

79. A. Denuziere, D. Ferrier, O. Damour and A. Domard: 'Chitosanchondroitin sulfate and chitosan-hyaluronate polyelectrolyte complexes: biological properties', Biomaterials, 1998, 19, 12751285

80. V. Thomas, M. M. Yallapu, B. Sreedhar and S. K. Bajpai: 'Fabrication, characterization of chitosan/nanosilver film and its potential antibacterial application', J. Biomater. Sci. Polym. Ed., 2009, 20, (14), 2129-2144.

81. Y. C. Chung and C. Y. Chen: 'Antibacterial characteristics and activity of acid-soluble chitosan', Bioresour. Technol., 2008, 99, (8), 2806-2814

82. R. C. Goy, D. de Britto and O. B. G. Assis: 'A review of the antimicrobial activity of chitosan', Polimeros, 2009, 19, (3), 241247.

83. H. S. Whang, W. Kirsch, Y. H. Zhu, C. Z. Yang and S. M. Hudson: 'Hemostatic agents derived from chitin and chitosan', J. Macromol. Sci. Part C: Polym. Rev., 2005, 45C, (4), 309-323.

84. P. Miretzky and A. F. Cirelli: ' $\mathrm{Hg}$ (II) removal from water by chitosan and chitosan derivatives: a review', J. Hazard. Mater., 2009, 167, (1-3), 10-23.

85. V. K. Mourya and N. N. Inamdar: 'Chitosan-modifications and applications: opportunities galore', React. Funct. Polym., 2008, 68, (6), 1013-1051.

86. F. Shahidi and J. Synowiecki: 'Isolation and characterization of nutrients and value-added products from snow crab (Chinoecetes opilio) and shrimp (Pandalus borealis) processing discards', J. Agric. Food Chem., 1991, 39, (8), 1527-1532.

87. A. Tolaimate, J. Desbrieres, M. Rhazi and A. Alagui: 'Contribution to the preparation of chitins and chitosans with controlled physico-chemical properties', Polymer, 2003, 44, (26), 7939-7952.

88. M. Hayes, B. Carney, J. Slater and W. Bruck: 'Mining marine shellfish wastes for bioactive molecules: chitin and chitosan - Part A: extraction methods', J. Biotechnol., 2008, 3, 871-877.

89. M. Rhazi, J. Desbrieres, A. Tolaimate, A. Alagui and P. Vottero: 'Investigation of different natural sources of chitin: influence of the source and deacetylation process on the physicochemical characteristics of chitosan', Polym. Int., 2000, 49, (4), 337-344.

90. A. Chandumpai, N. Singhpibulporn, D. Faroongsarng and P. Sornprasit: 'Preparation and physico-chemical characterization of chitin and chitosan from the pens of the squid species, Loligo lessoniana and Loligo formosana', Carbohydr. Polym., 2004, 58, (4), 467-474.

91. P. Broussignac: 'Chitosan: a natural polymer not well known by the industry', Chim. Ind. Genie Chim., 1968, 99, 1241-1247.

92. K. Kurita, K. Tomita, T. Tada, S. Ishii, S. I. Nishimura and K. Shimoda: 'Squid chitin as a potential alternative chitin source deacetylation behavior and characteristic properties', J. Polym. Sci. Part A: Polym. Chem., 1993, 31A, (2), 485-491.

93. D. W. Renn: 'Agar and agarose: indispensable partners in biotechnology', Ind. Eng. Chem. Prod. Res. Dev., 1984, 23, (1), $17-21$.

94. B. Li, F. Lu, X. J. Wei and R. X. Zhao: 'Fucoidan: structure and bioactivity', Molecules, 2008, 13, (8), 1671-1695.

95. M. Lahaye and A. Robic: 'Structure and functional properties of ulvan, a polysaccharide from green seaweeds', Biomacromolecules, 2007, 8, (6), 1765-1774.

96. P. S. Belton, S. F. Tanner, N. Cartier and H. Chanzy: 'Highresolution solid-state $\mathrm{C}-13$ nuclear magnetic-resonance spectroscopy of tunicin, an animal cellulose', Macromolecules, 1989, 22, (4), 1615-1617

97. Z. C. Pang, K. Otaka, T. Maoka, K. Hidaka, S. Ishijima, M. Oda and M. Ohnishi: 'Structure of $\beta$-glucan oligomer from laminarin and its effect on human monocytes to inhibit the proliferation of U937 cells', Biosci. Biotechnol. Biochem., 2005, 69, (3), 553-558.

98. K. Laos and S. G. Ring: 'Note: characterisation of furcellaran samples from Estonian Furcellaria lumbricalis (Rhodophyta), J. Appl. Phycol., 2005, 17, (5), 461-464 
99. M. S. Zierer and P. A. S. Mourao: 'A wide diversity of sulfated polysaccharides are synthesized by different species of marine sponges', Carbohydr. Res., 2000, 328, (2), 209-216.

100. M. G. Tingbø, S. O. Kolset, R. Ofstad, G. Enersen and K. O. Hannesson: 'Sulfated glycosaminoglycans in the extracellular matrix of muscle tissue in Atlantic cod (Gadus morhua) and Spotted wolffish (Anarhichas minor)', Comp. Biochem. Physiol. Part B: Biochem. Mol. Biol., 2005, 140B, (3), 349-357.

101. M. G. Ting $\bar{b}$, S. O. Kolset, R. Ofstad, G. Enersen and K. O. Hannesson: 'Identification and distribution of heparan sulfate proteoglycans in the white muscle of Atlantic cod (Gadus morhua) and spotted wolffish (Anarhichas minor)', Comp. Biochem. Physiol. Part B: Biochem. Mol. Biol., 2006, 143B, (4), 441-452.

102. A. R. Im, J. S. Sim, Y. Park, B. S. Hahn, T. Toida and Y. S. Kim: 'Isolation and characterization of chondroitin sulfates from the by-products of marine organisms', Food Sci. Biotechnol., 2009, 18, (4), 872-877.

103. G. F. Medeiros, A. Mendes, R. A. B. Castro, E. C. Baú, H. B. Nader and C. P. Dietrich: 'Distribution of sulfated glycosaminoglycans in the animal kingdom: widespread occurrence of heparin-like compounds in invertebrates', Biochim. Biophys. Acta, 2000, 1475, (3), 287-294.

104. F. Zhang, Z. Zhang and R. J. Linhardt: 'Glycosaminoglycans', in 'Handbook of glycomics', (ed. D. C. Richard et al.), 59-80; 2010, San Diego, CA, Academic Press.

105. Y. Yamaguchi, D. M. Mann and E. Ruoslahti: 'Negative regulation of transforming growth factor- $\beta$ by the proteoglycan decorin', Nature, 1990, 346, (6281), 281-284

106. J. D. Esko and S. B. Selleck: 'Order out of chaos: assembly of ligand binding sites in heparan sulfatel', Annu. Rev. Biochem., 2002, 71, (1), 435-471.

107. L. Kjellen and U. Lindahl: 'Proteoglycans: structures and interactions', Апnи. Rev. Biochem., 1991, 60, (1), 443-475.

108. Y. Renaudineau, R. Rèvèlen, M. Dueymes, Y. Levy and P. Youinou: 'Autoantibodies to heparan sulfate proteoglycans', Autoimmun. Rev., 2002, 1, (5), 305-312.

109. K. E. Dow and W. Wang: 'Cell biology of astrocyte proteoglycans', Cell. Mol. Life Sci., 1998, 54, (6), 567-581.

110. W. D. Comper and T. C. Laurent: 'Physiological function of connective tissue polysaccharides', Physiol. Rev., 1978, 58, (1), 255-315.

111. C. B. N. Mendes de Aguiar, R. C. Garcez, M. Alvarez-Silva and A. G. Trentin: 'Undersulfation of proteoglycans and proteins alter C6 glioma cells proliferation, adhesion and extracellular matrix organization', Int. J. Dev. Neurosci., 2002, 20, (7), 563-571.

112. V. Chascall, A. Calabro, R. J. Midura and M. Yanagishita: 'Isolation and characterization of proteoglycans', in 'Methods in enzymology', (ed. J. L. William et al.), 390-417; 1994, San Diego, CA, Academic Press.

113. V. C. Hascall and J. H. Kimura: 'Proteoglycans: Isolation and Characterization', in 'Methods in enzymology', (ed. W. C. Leon et al.), 769-800; 1982, San Diego, CA, Academic Press.

114. M. Yanagishita, R. J. Midura and V. C. Hascall: 'Proteoglycans: isolation and purification from tissue cultures', in 'Methods in enzymology', (ed. G. Victor), 279-289; 1987, New York, Academic Press.

115. J. A. McBain and G. C. Mueller: 'Isolation of proteoglycans using phenol extraction and isopycnic centrifugation in cesium trifluoroacetate', Anal. Biochem., 1990, 188, (1), 203-213.

116. T. Nishiumi, T. Fukuda and T. Nishimura: 'Isolation and characterization of a small proteoglycan associated with porcine intramuscular connective tissue', J. Agric. Food Chem., 1997, 45, (8), 2978-2983.

117. P. G. Scott, T. Nakano and C. M. Dodd: 'Isolation and characterization of small proteoglycans from different zones of the porcine knee meniscus', Biochim. Biophys. Acta, 1997, 1336, (2), 254-262.

118. M. Yanagishita, K. Podyma-Inoue and M. Yokoyama: 'Extraction and separation of proteoglycans', Glycoconj. J., 2009, 26, (8), 953-959.

119. B. Lignot, V. Lahogue and P. Bourseau: 'Enzymatic extraction of chondroitin sulfate from skate cartilage and concentrationdesalting by ultrafiltration', J. Biotechnol., 2003, 103, (3), 281-284.

120. C. M. Cássaro and C. P. Dietrich: 'Distribution of sulfated mucopolysaccharides in invertebrates', J. Biol. Chem., 1977, 252 (7), 2254-2261.

121. F. N. Lamari, A. D. Theocharis, A. P. Asimakopoulou, C. J. Malavaki and N. K. Karamanos: 'Metabolism and biochemical/ physiological roles of chondroitin sulfates: analysis of endogenous and supplemental chondroitin sulfates in blood circulation', Biomed. Chromatogr., 2006, 20, (6-7), 539-550.

122. X. Luo, G. Fosmire and R. Leach, Jr: 'Chicken keel cartilage as a source of chondroitin sulfate', Poult. Sci., 2002, 81, (7), 10861089.

123. Y. M. Michelacci and C. P. Dietrich: 'Structure of chondroitin sulphate from whale cartilage: distribution of 6- and 4-sulphated oligosaccharides in the polymer chains', Int. J. Biol. Macromol., 1986, 8, (2), 108-113.

124. N. Seno and K. Meyer: 'Comparative biochemistry of skin the mucopolysaccharides of shark skin', Biochim. Biophys. Acta, 1963, 78, (2), 258-264.

125. C. D. Nandini, N. Itoh and K. Sugahara: 'Novel 70-kDa chondroitin sulfate/dermatan sulfate hybrid chains with a unique heterogenous sulfation pattern from shark skin, which exhibit neuritogenic activity and binding activities for growth factors and neurotrophic factors', J. Biol. Chem., 2005, 280, (6), 4058-4069.

126. S. R. Srinivasan, B. Radhakrishnamurthy, E. R. Dalferes, Jr and G. S. Berenson: 'Glycosaminoglycans from squid skin', Comp. Biochem. Physiol., 1969, 28, (1), 169-172, IN165, 173-176.

127. A. Kinoshita-Toyoda, S. Yamada, S. M. Haslam, K.-H. Khoo, M. Sugiura, H. R. Morris, A. Dell and K. Sugahara: 'Structural determination of five novel tetrasaccharides containing 3-Osulfated D-glucuronic acid and two rare oligosaccharides containing a $\beta$-D-glucose branch isolated from squid cartilage chondroitin sulfate E" Biochemistry, 2004, 43, (34), 11063-11074.

128. M. Majima, K. Takagaki, S.-I. Sudo, S. Yoshihara, Y. Kudo and S. Yamagishi: 'Effect of proteoglycan on experimental colitis', Int. Cong. Ser., 2001, 1223, 221-224.

129. H. Kitagawa, Y. Tanaka, S. Yamada, N. Seno, S. M. Haslam, H. R. Morris, A. Dell and K. Sugahara: 'A novel pentasaccharide sequence $\operatorname{GlcA}(3$-sulfate)( $\beta 1-3) \operatorname{GalNAc}(4$-sulfate)( $\beta 1-4)($ Fuc $\alpha 1$ $3) \operatorname{GlcA}(\beta 1-3) \mathrm{GalNAc}(4$-sulfate) in the oligosaccharides isolated from king crab cartilage chondroitin sulfate $\mathrm{K}$ and its differential susceptibility to chondroitinases and hyaluronidase" Biochemistry, 1997, 36, (13), 3998-4008.

130. R. P. Vieira and P. A. Mourão: 'Occurrence of a unique fucosebranched chondroitin sulfate in the body wall of a sea cucumber', J. Biol. Chem., 1988, 263, (34), 18176-18183.

131. A. G. Cole and B. K. Hall: 'The nature and significance of invertebrate cartilages revisited: distribution and histology of cartilage and cartilage-like tissues within the Metazoa', Zoology, 2004, 107, (4), 261-273.

132. L. F. Silva: 'Isolation and purification of chondroitin sulfate', in 'Advances in pharmacology', (ed. V. Nicola), 21-31; 2006, San Diego, CA, Academic Press.

133. A. Kinoshita, S. Yamada, S. M. Haslam, H. R. Morris, A. Dell and K. Sugahara: 'Isolation and structural determination of novel sulfated hexasaccharides from squid cartilage chondroitin sulfate E that exhibits neuroregulatory activities" Biochemistry, 2001, 40, (42), 12654-12665

134. R. Falshaw, U. Hubl, D. Ofman, G. C. Slim, M. Amjad Tariq, D. K. Watt and S. C. Yorke: 'Comparison of the glycosaminoglycans isolated from the skin and head cartilage of Gould's arrow squid (Nototodarus gouldi)', Carbohydr. Polym., 2000, 41, (4), 357-364.

135. K. Sugahara, Y. Tanaka, S. Yamada, N. Seno, H. Kitagawa, S. M. Haslam, H. R. Morris and A. Dell: 'Novel sulfated oligosaccharides containing 3-O-sulfated glucuronic acid from king crab cartilage chondroitin sulfate K', J. Biol. Chem., 1996, 271, (43), 26745-26754.

136. K. Sugahara, T. Mikami, T. Uyama, S. Mizuguchi, K. Nomura and H. Kitagawa: 'Recent advances in the structural biology of chondroitin sulfate and dermatan sulfate', Curr. Opin. Struct. Biol., 2003, 13, (5), 612-620.

137. L. Rodèn, J. R. Baker, J. Anthony Cifonelli and M. B. Mathews: 'Isolation and characterization of connective tissue polysaccharides', in 'Methods in enzymology', (ed. G. Victor), 73-140; 1972, New York, Academic Press.

138. R. W. Farndale, D. J. Buttle and A. J. Barrett: 'Improved quantitation and discrimination of sulphated glycosaminoglycans by use of dimethylmethylene blue', Biochim. Biophys. Acta, 1986, 883, (2), 173-177.

139. H. H. Sunwoo, T. Nakano, R. J. Hudson and J. S. Sim: 'Isolation, characterization and localization of glycosaminoglycans in growing antlers of wapiti (Cervus elaphus)', Comp. Biochem. Physiol. Part B: Biochem. Mol. Biol., 1998, 120B, (2), 273-283.

140. S. Cavari and S. Vannucchi: 'Detection of heparin-like glycosaminoglycans in normal human plasma by polyacrylamide-gel electrophoresis', Clin. Chim. Acta, 1996, 252, (2), 159-170. 
141. L. A. G. Rocha, R. C. L. Martins, C. C. Werneck, E. J. FeresFilho and L. F. Silva: 'Human gingival glycosaminoglycans in cyclosporin-induced overgrowth', J. Periodontal Res., 2000, 35, (3), 158-164.

142. N. Volpi: 'Disaccharide analysis and molecular mass determination to microgram level of single sulfated glycosaminoglycan species in mixtures following agarose-gel electrophoresis', Anal. Biochem., 1999, 273, (2), 229-239.

143. M. Ben Mansour, M. Dhahri, I. Bertholon, V. Ollivier, I. Bataille, N. Ajzenberg, M. Hassine, M. Jandrot-Perrus, F. Chaubet and R. M. Maaroufi: 'Characterization of a novel dermatan sulfate with high antithrombin activity from ray skin (Raja radula), Thromb. Res., 2009, 123, (6), 887-894.

144. M. Ben Mansour, H. Majdoub, I. Bataille, M. S. Roudesli, M. Hassine, N. Ajzenberg, F. Chaubet and R. M. Maaroufi: 'Polysaccharides from the skin of the ray Raja radula. Partial characterization and anticoagulant activity', Thromb. Res., 2009, 123, (4), 671-678.

145. N. Volpi and F. Maccari: 'Structural characterization and antithrombin activity of dermatan sulfate purified from marine clam Scapharca inaequivalvis', Glycobiology, 2008, 19, 356-367.

146. A. A. Pelli, R. A. Azevedo, L. P. Cinelli, P. A. S. Mourão and L. de Brito-Gitirana: 'Dermatan sulfate is the major metachromatic glycosaminoglycan in the integument of the anuran Bufo ictericus', Comp. Biochem. Physiol. Part B: Biochem. Mol. Biol., 2007, 146B, (2), 160-165.

147. J. M. Trowbridge and R. L. Gallo: 'Dermatan sulfate: new functions from an old glycosaminoglycan', Glycobiology, 2002, 12, (9), 117R-125R.

148. A. E. Chemouni, E. Lopez and E. Chemouni: 'Aqueous extraction of nacre to give product having cell proliferation stimulating properties', Patent, 2001.

149. J. T. Gallagher and A. Walker: 'Molecular distinctions between heparan sulphate and heparin. Analysis of sulphation patterns indicates that heparan sulphate and heparin are separate families of $N$-sulphated polysaccharides', Biochem. J., 1985, 230, (3), 665674.

150. S. E. Stringer and J. T. Gallagher: 'Heparan sulphate', Int. J. Biochem. Cell Biol., 1997, 29, (5), 709-714.

151. T. Toida, H. Yoshida, H. Toyoda, I. Koshiishi, T. Imanari, R. E. Hileman, J. R. Fromm and R. J. Linhardt: 'Structural differences and the presence of unsubstituted amino groups in heparan sulphates from different tissues and species', Biochem. J., 1997, 322, (2), 499-506.

152. M. Cesaretti, E. Luppi, F. Maccari and N. Volpi: 'Isolation and characterization of a heparin with high anticoagulant activity from the clam Tapes phylippinarum: evidence for the presence of a high content of antithrombin III binding site', Glycobiology, 2004, 14, (12), 1275-1284.

153. R. Saravanan and A. Shanmugam: 'Isolation and characterization of low molecular weight glycosaminoglycans from marine mollusc Amussium pleuronectus (Linne) using chromatography', Appl. Biochem. Biotechnol., 2010, 160, (3), 791-799.

154. P. A. S. Mourão and M. S. Pereira: 'Searching for alternatives to heparin: sulfated fucans from marine invertebrates', Trends Cardiovasc. Med., 1999, 9, (8), 225-232.

155. T. C. G. de Azevedo, M. E. B. Bezerra, M. D. D. Santos, L. A Souza, C. T. Marques, N. M. B. Benevides and E. L. Leite: 'Heparinoids algal and their anticoagulant, hemorrhagic activities and platelet aggregation', Biomed. Pharmacother., 2009, 63, (7), $477-483$.

156. R. V. Iozzo: 'Matrix proteoglycans: from molecular design to cellular function', Annu. Rev. Biochem., 1998, 67, (1), 609-652.

157. G. R. Dodge and R. Heimer: 'Proteoglycans analyzed by composite gel electrophoresis and immunoblotting', Methods Mol. Biol., 2001, 171, 149-158.

158. U. Lindahl and J.-P. Li: 'Chapter 3 - Interactions between heparan sulfate and proteins-design and functional implications', Int. Rev. Cell Mol. Biol., 2009, 276, 105-159.

159. J. R. Ralphs and M. Benjamin: 'Chondroitin and keratan sulphate in the epidermal club cells of teleosts', J. Fish Biol., 1992, 40, (3), $473-475$.

160. M. Ito and T. Yamagata: 'The linkage of teleost skin keratan sulfate to protein', Biochim. Biophys. Acta, 1984, 801, (3), 381387.

161. T. N. Huckerby: 'The keratan sulphates: structural investigations using NMR spectroscopy', Prog. Nucl. Magn. Reson. Spectrosc., 2002, 40, (1), 35-110.
162. A. H. Plaas, A. L. Ison and J. Ackland: 'Synthesis of small proteoglycans substituted with keratan sulfate by rabbit articular chondrocytes', J. Biol. Chem., 1989, 264, (24), 14447-14454.

163. B. A. Bray, R. Lieberman and K. Meyer: 'Structure of human skeletal keratosulfate', J. Biol. Chem., 1967, 242, (14), 3373-3380.

164. H. W. Jarrett and J. Kyte: 'Human erythrocyte calmodulin. Further chemical characterization and the site of its interaction with the membrane', J. Biol. Chem., 1979, 254, (17), 8237-8244.

165. T. Krusius, J. Finne, R. K. Margolis and R. U. Margolis: 'Identification of an O-glycosidic mannose-linked sialylated tetrasaccharide and keratan sulfate oligosaccharides in the chondroitin sulfate proteoglycan of brain', J. Biol. Chem., 1986, 261, (18), 8237-8242.

166. E. Pfeiler: 'Isolation and partial characterization of a novel keratan sulfate proteoglycan from metamorphosing bonefish (Albula) larvae', Fish Physiol. Biochem., 1988, 4, (4), 175-187.

167. Y. H. Liao, S. A. Jones, B. Forbes, G. P. Martin and M. B. Brown: 'Hyaluronan: pharmaceutical characterization and drug delivery', Drug Deliv., 2005, 12, (6), 327-342.

168. T. C. Laurent, U. B. G. Laurent and J. R. E. Fraser: 'Functions of hyaluronan', Ann. Rheum. Dis., 1995, 54, (5), 429-432.

169. M. I. Tammi, A. J. Day and E. A. Turley: 'Hyaluronan and homeostasis: a balancing act', J. Biol. Chem., 2002, 277, (7), 45814584.

170. H. P. Xu, T. Ito, A. Tawada, H. Maeda, H. Yamanokuchi, K. Isahara, K. Yoshida, Y. Uchiyama and A. Asari: 'Effect of hyaluronan oligosaccharides on the expression of heat shock protein 72', J. Biol. Chem., 2002, 277, (19), 17308-17314.

171. P. Prehm: 'Hyaluronan', in 'Biopolymers', Vol. 5, 'Polysaccharides I. Polysaccharides from prokaryotes', (ed. J. Erick Vandamme et al.), 379-404; 2002, Weinheim, Wiley-VCH.

172. J. Schiller, B. Fuchs, J. Arnhold and K. Arnold: 'Contribution of reactive oxygen species to cartilage degradation in rheumatic diseases: molecular pathways, diagnosis and potential therapeutic strategies', Curr. Med. Chem., 2003, 10, (20), 2123-2145.

173. K. Nishinari and R. Takahashi: 'Interaction in polysaccharide solutions and gels', Curr. Opin. Colloid Interface Sci., 2003, 8, (4 5), 396-400.

174. L. Soltes, R. Mendichi, G. Kogan, J. Schiller, M. Stankovska and J. Arnhold: 'Degradative action of reactive oxygen species on hyaluronan', Biomacromolecules, 2006, 7, (3), 659-668.

175. L. Juhlin: 'Hyaluronan in skin', J. Intern. Med., 1997, 242, (1), 6166.

176. E. A. Balazs: 'Ultra pure, high molecular wt. hyaluronic acid - is non-antigenic and used as synthetic aq. humour and synovial fluid, as nerve tissue and wound protector and drug carrier', Patent US4141973, 1979.

177. M. C. Gomez-Guillen, J. Turnay, M. D. Fernandez-Diaz, N. Ulmo, M. A. Lizarbe and P. Montero: 'Structural and physical properties of gelatin extracted from different marine species: a comparative study', Food Hydrocoll., 2002, 16, (1), 25-34.

178. I. Kolodziejska, Z. E. Sikorski and C. Niecikowska: 'Parameters affecting the isolation of collagen from squid (Illex argentinus) skins', Food Chem., 1999, 66, (2), 153-157.

179. E. Mendis, N. Rajapakse, H.-G. Byun and S.-K. Kim: 'Investigation of jumbo squid (Dosidicus gigas) skin gelatin peptides for their in vitro antioxidant effects', Life Sci., 2005, 77, (17), 2166-2178.

180. D. Swatschek, W. Schatton, J. Kellermann, W. E. G. Muller and J. Kreuter: 'Marine sponge collagen: isolation, characterization and effects on the skin parameters surface-pH, moisture and sebum', Eur. J. Pharm. Biopharm., 2002, 53, (1), 107-113.

181. T. Nagai and N. Suzuki: 'Isolation of collagen from fish waste material - skin, bone and fins', Food Chem., 2000, 68, (3), 277281.

182. J. Morales, P. Montero and A. Moral: 'Isolation and partial characterization of two types of muscle collagen in some cephalopods', J. Agric. Food Chem., 2000, 48, (6), 2142-2148.

183. I. S. Arvanitoyannis and A. Kassaveti: 'Fish industry waste: treatments, environmental impacts, current and potential uses', Int. J. Food Sci. Technol., 2008, 43, (4), 726-745.

184. D. Leary, M. Vierros, G. Hamon, S. Arico and C. Monagle: 'Marine genetic resources: a review of scientific and commercial interest', Mar. Policy, 2009, 33, (2), 183-194.

185. S. Heinemann, H. Ehrlich, T. Douglas, C. Heinemann, H. Worch, W. Schatton and T. Hanke: 'Ultrastructura studies on the collagen of the marine sponge Chondrosia reniformis nardo', Biomacromolecules, 2007, 8, (11), 3452-3457. 
186. T. Nagai, T. Ogawa, T. Nakamura, T. Ito, H. Nakagawa, K Fujiki, M. Nakao and T. Yano: 'Collagen of edible jellyfish exumbrella', J. Sci. Food Agric., 1999, 79, (6), 855-858.

187. E. Song, S. Y. Kim, T. Chun, H. J. Byun and Y. M. Lee: 'Collagen scaffolds derived from a marine source and their biocompatibility', Biomaterials, 2006, 27, (15), 2951-2961.

188. S. Miura and S. Kimura: 'Jellyfish mesoglea collagen characterization of molecules as alpha-1-alpha-2-alpha-3 heterotrimers', J. Biol. Chem., 1985, 260, (28), 5352-5356.

189. H. Ehrlich, P. Simon, W. Carrillo-Cabrera, V. V. Bazhenov, J. P Botting, M. Ilan, A. V. Ereskovsky, G. Muricy, H. Worch, A. Mensch, R. Born, A. Springer, K. Kummer, D. V. Vyalikh, S. L. Molodtsov, D. Kurek, M. Kammer, S. Paasch and E. Brunner: 'Insights into chemistry of biological materials: newly discovered silica-aragonite-chitin biocomposites in demosponges', Chem. Mater., 2010, 22, (4), 1462-1471.

190. P. Montero and M. C. Gomez-Guillen: 'Extracting conditions for megrim (Lepidorhombus boscii) skin collagen affect functional properties of the resulting gelatin', J. Food Sci., 2000, 65, (3), 434 438.

191. J. A. M. Ramshaw, J. F. Bateman and W. G. Cole: 'Precipitation of collagens by polyethylene glycols', Anal. Biochem., 1984, 141, (2), 361-365.

192. F. Ruggiero and M. Koch: 'Making recombinant extracellular matrix proteins', Methods, 2008, 45, (1), 75-85.

193. J. M. Cregg, J. L. Cereghino, J. Y. Shi and D. R. Higgins: 'Recombinant protein expression in Pichia pastoris', Mol. Biotechnol., 2000, 16, (1), 23-52.

194. G. P. L. Cereghino, J. L. Cereghino, C. Ilgen and J. M. Cregg: 'Production of recombinant proteins in fermenter cultures of the yeast Pichia pastoris', Curr. Opin. Biotechnol., 2002, 13, (4), 329 332 .

195. S. Macauley-Patrick, M. L. Fazenda, B. McNeil and L. M Harvey: 'Heterologous protein production using the Pichia pastoris expression system', Yeast, 2005, 22, (4), 249-270.

196. O. Cos, R. Ramon, J. L. Montesinos and F. Valero: 'Operational strategies, monitoring and control of heterologous protein production in the methylotrophic yeast Pichia pastoris under different promoters: a review', Microb. Cell. Fact., 2006, 5, 20.

197. M. Jahic, A. Veide, T. Charoenrat, T. Teeri and S. O. Enfors: 'Process technology for production and recovery of heterologous proteins with Pichia pastoris', Biotechnol. Prog., 2006, 22, (6), 1465-1473.

198. A. Vuorela, J. Myllyharju, R. Nissi, T. Pihlajaniemi and K. I. Kivirikko: 'Assembly of human prolyl 4-hydroxylase and type III collagen in the yeast Pichia pastoris: formation of a stable enzyme tetramer requires coexpression with collagen and assembly of a stable collagen requires coexpression with prolyl 4-hydroxylase', EMBO J., 1997, 16, (22), 6702-6712.

199. J. Myllyharju, M. Nokelainen, A. Vuorela and K. I. Kivirikko: 'Expression of recombinant human type I-III collagens in the yeast Pichia pastoris', Biochem. Soc. Trans., 2000, 28, 353-357.

200. M. Nokelainen, H. M. Tu, A. Vuorela, H. Notbohm, K. I. Kivirikko and J. Myllyharju: 'High-level production of human type I collagen in the yeast Pichia pastoris', Yeast, 2001, 18, (9), 797-806.

201. G. D. Stanley: 'The evolution of modern corals and their early history', Earth Sci. Rev., 2003, 60, (3-4), 195-225.

202. I. Sethmann and G. Wörheide: 'Structure and composition of calcareous sponge spicules: a review and comparison to structurally related biominerals', Micron, 2008, 39, (3), 209-228.

203. F. H. Wilt, C. E. Killian and B. T. Livingston: 'Development of calcareous skeletal elements in invertebrates', Differentiation, 2003, 71, (4-5), 237-250.

204. E. C. Elsinger and L. Leal: 'Coralline hydroxyapatite bone graft substitutes', J. Foot Ankle Surg., 1996, 35, (5), 396-399.

205. N. A. Kamenos, M. Cusack, T. Huthwelker, P. Lagarde and R. E. Scheibling: 'Mg-lattice associations in red coralline algae', Geochim. Cosmochim. Acta, 2009, 73, (7), 1901-1907.

206. A. F. Lemos, J. H. G. Rocha, S. S. F. Quaresma, S. Kannan, F. N. Oktar, S. Agathopoulos and J. M. F. Ferreira: 'Hydroxyapatite nano-powders produced hydrothermally from nacreous material', J. Eur. Ceram. Soc., 2006, 26, (16), 3639-3646.

207. F. Heinemann, L. Treccani and M. Fritz: 'Abalone nacre insoluble matrix induces growth of flat and oriented aragonite crystals', Biochem. Biophys. Res. Commun., 2006, 344, (1), 45-49.

208. G. Yaping and Z. Yu: 'Transformation of nacre coatings into apatite coatings in phosphate buffer solution at low temperature', J. Biomed. Mater. Res. Part A, 2008, 86A, (2), 510-521.
209. D. E. Jacob, A. L. Soldati, R. Wirth, J. Huth, U. Wehrmeister and W. Hofmeister: 'Nanostructure, composition and mechanisms of bivalve shell growth', Geochim. Cosmochim. Acta, 2008, 72, (22), 5401-5415.

210. M. Boutinguiza, F. Lusquiños, R. Comesaña, A. Riveiro, F. Quintero and J. Pou: 'Production of microscale particles from fish bone by gas flow assisted laser ablation', Appl. Surf. Sci., 2007, 254, (4), 1264-1267.

211. J. Laine, M. Labady, A. Albornoz and S. Yunes: 'Porosities and pore sizes in coralline calcium carbonate', Mater. Charact., 2008, 59, (10), 1522-1525.

212. J.-H. Kuhne, R. Bart, B. Frisch, C. Hamme, V. Jansson and M. Zimmer: 'Bone formation in coralline hydroxyapatite: effects of pore size studied in rabbits', Acta Orthop. Scand., 1994, 65, (3), 246-252.

213. B. Ben-Nissan: 'Natural bioceramics: from coral to bone and beyond', Curr. Opin. Solid State Mater. Sci., 2003, 7, (4-5), 283288.

214. F. Braye, J. L. Irigaray, E. Jallot, H. Oudadesse, G. Weber, N. Deschamps, C. Deschamps, P. Frayssinet, P. Tourenne, H. Tixier, S. Terver, J. Lefaivre and A. Amirabaldi: 'Resorption kinetics of osseous substitute: natural coral and synthetic hydroxyapatite', Biomaterials, 1996, 17, (13), 1345-1350.

215. B. Ben-Nissan, A. Milev and R. Vago: 'Morphology of sol-gel derived nano-coated coralline hydroxyapatite', Biomaterials, 2004, 25, (20), 4971-4975.

216. C. Balázsi, F. Wéber, Z. Kövér, E. Horváth and C. Németh: 'Preparation of calcium-phosphate bioceramics from natural resources', J. Eur. Ceram. Soc., 2007, 27, (2-3), 1601-1606.

217. B. K. Bay, R. B. Martin, N. A. Sharkey and M. W. Chapman: 'Repair of large cortical defects with block coralline hydroxyapatite', Bone, 1993, 14, (3), 225-230.

218. D. Turhani, E. Watzinger, M. Weienböck, B. Cvikl, D. Thurnher, G. Wittwer, K. Yerit and R. Ewers: 'Analysis of cell-seeded 3dimensional bone constructs manufactured in vitro with hydroxyapatite granules obtained from red algae', J. Oral Maxillof. Surg., 2005, 63, (5), 673-681.

219. R. A. Finn, W. H. Bell and J. A. Brammer: 'Interpositional "Grafting" with autogenous bone and coralline hydroxyapatite', J. Maxillof. Surg., 1980, 8, 217-227.

220. J. M. Oliveira, J. M. R. Grech, I. B. Leonor, J. F. Mano and R. L. Reis: 'Calcium-phosphate derived from mineralized algae for bone tissue engineering applications', Mater. Lett., 2007, 61, (16), 3495-3499.

221. M. Sivakumar, T. S. S. Kumar, K. L. Shantha and K. P. Rao: 'Development of hydroxyapatite derived from Indian coral', Biomaterials, 1996, 17, (17), 1709-1714.

222. D. M. Roy and S. K. Linnehan: 'Hydroxyapatite formed from coral skeletal carbonate by hydrothermal exchange', Nature, 1974, 247, 220-222.

223. P. J. Walsh, F. J. Buchanan, M. Dring, C. Maggs, S. Bell and G. M. Walker: 'Low-pressure synthesis and characterisation of hydroxyapatite derived from mineralise red algae', Chem. Eng. J., 2008, 137, (1), 173-179.

224. M. Boutinguiza, E. Lusquinos, R. Comesana, A. Riveiro, F. Quintero and J. Pou: 'Production of microscale particles from fish bone by gas flow assisted laser ablation', Appl. Surf. Sci., 2007, 254, (4), 1264-1267.

225. M. Boutinguiza, F. Lusquinos, A. Riveiro, R. Comesana and J. Pou: 'Hydroxylapatite nanoparticles obtained by fiber laserinduced fracture', Appl. Surf. Sci., 2009, 255, (10), 5382-5385.

226. M. Boutinguiza, R. Comesana, F. Lusquinos, A. Riveiro and J. Pou: 'Production of nanoparticles from natural hydroxylapatite by laser ablation', Nanoscale Res. Lett., 2011, 6, 255-259.

227. M. Boutinguiza, J. Pou, F. Lusquinos, R. Comesana and A. Riveiro: 'Laser-assisted production of tricalcium phosphate nanoparticles from biological and synthetic hydroxyapatite in aqueous medium', Appl. Surf. Sci., 2011, 257, (12), 51955199.

228. B. Ji: 'A study of the interface strength between protein and mineral in biological materials', J. Biomech., 2008, 41, (2), 259266.

229. H. C. Schroder, X. H. Wang, W. Tremel, H. Ushijima and W. E. G. Muller: 'Biofabrication of biosilica-glass by living organisms', Nat. Prod. Rep., 2008, 25, (3), 455-474.

230. J. Aizenberg, J. C. Weaver, M. S. Thanawala, V. C. Sundar, D. E. Morse and P. Fratzl: 'Skeleton of Euplectella sp.: structural hierarchy from the nanoscale to the macroscale', Science, 2005, 309, (5732), 275-278 
231. V. Venugopal: 'Marine products for healthcare: functional and bioactive nutraceutical compounds from the ocean', 382-387; 2009, New York, CRC Press.

232. K. Shimizu, J. Cha, G. D. Stucky and D. E. Morse: 'Silicatein alpha: cathepsin L-like protein in sponge biosilica', Proc. Natl Acad. Sci. USA, 1998, 95, (11), 6234-6238.

233. W. E. G. Muller, X. H. Wang, Z. Burghard, J. Bill, A. Krasko, A Boreiko, U. Schlossmacher, H. C. Schroder and M. Wiens: 'Biosintering processes in hexactinellid sponges: fusion of bio-silica in giant basal spicules from Monorhaphis chuni', J. Struct. Biol., 2009, 168, (3), 548-561.

234. W. E. G. Muller, X. H. Wang, F. Z. Cui, K. P. Jochum, W. Tremel, J. Bill, H. C. Schroder, F. Natalio, U. Schlossmacher and M. Wiens: 'Sponge spicules as blueprints for the biofabrication of inorganic-organic composites and biomaterials', Appl. Microbiol. Biotechnol., 2009, 83, (3), 397-413.

235. X. H. Wang, M. Wiens, H. C. Schroder, S. X. Hu, E. Mugnaioli, U. Kolb, W. Tremel, D. Pisignano and W. E. G. Muller: 'Morphology of sponge spicules: silicatein a structural protein for bio-silica formation', Adv. Eng. Mater., 2010, 12, (9), B422-B437.

236. J. C. Weaver, L. I. Pietrasanta, N. Hedin, B. F. Chmelka, P. K. Hansma and D. E. Morse: 'Nanostructural features of demosponge biosilica', J. Struct. Biol., 2003, 144, (3), 271-281.

237. R. L. Brutchey and D. E. Morse: 'Silicatein and the translation of its molecular mechanism of biosilicification into low temperature nanomaterial synthesis', Chem. Rev., 2008, 108, (11), 4915-4934.

238. M. Sarikaya, H. Fong, N. Sunderland, B. D. Flinn, G. Mayer, A. Mescher and E. Gaino: 'Biomimetic model of a sponge-spicular optical fiber - mechanical properties and structure', J. Mater. Res., 2001, 16, (5), 1420-1428.

239. G. Mayer, R. Trejo, E. Lara-Curzio, M. Rodriguez, K. Tran, H. Song and W. H. Ma: 'Lessons for new classes of inorganic/organic composites from the spicules and skeleton of the sea sponge Euplectella aspergillum', Mech. Prop. Bioinspir. Biol. Mater., 2005 , 844, 79-86.

240. A. Woesz, J. C. Weaver, M. Kazanci, Y. Dauphin, J. Aizenberg, D. E. Morse and P. Fratzl: 'Micromechanical properties of biological silica in skeletons of deep-sea sponges', J. Mater. Res., 2006, 21, (8), 2068-2078.

241. J. Aizenberg, V. C. Sundar, A. D. Yablon, J. C. Weaver and G Chen: 'Biological glass fibers: correlation between optical and structural properties', Proc. Natl Acad. Sci. USA, 2004, 101, (10), 3358-3363.

242. L. Kubisz and H. Ehrlich: 'Temperature dependence of electric conductivity of bamboo coral skeleton and glass sponge spicules, the marine origin biomaterials', J. Non-Cryst. Solids, 2007, 353, (47-51), 4497-4500.

243. J. N. Cha, K. Shimizu, Y. Zhou, S. C. Christiansen, B. F. Chmelka, G. D. Stucky and D. E. Morse: 'Silicatein filaments and subunits from a marine sponge direct the polymerization of silica and silicones in vitro', Proc. Natl Acad. Sci. USA, 1999, 96, (2), 361-365.

244. D. Kisailus, Q. Truong, Y. Amemiya, J. C. Weaver and D. E. Morse: 'Self-assembled bifunctional surface mimics an enzymatic and templating protein for the synthesis of a metal oxide semiconductor', Proc. Natl Acad. Sci. USA, 2006, 103, (15), 5652-5657.

245. P. Curnow, D. Kisailus and D. E. Morse: 'Biocatalytic synthesis of poly(L-lactide) by native and recombinant forms of the silicatein enzymes', Angew. Chem. Int. Ed., 2006, 45, (4), 613-616.

246. J. N. Cha, G. D. Stucky, D. E. Morse and T. J. Deming: 'Biomimetic synthesis of ordered silica structures mediated by block copolypeptides', Nature, 2000, 403, (6767), 289-292.

247. C. Zurzolo and C. Bowler: 'Exploring bioinorganic pattern formation in diatoms. A story of polarized trafficking', Plant Physiol., 2001, 127, (4), 1339-1345.

248. V. Venugopal: 'Marine products for healthcare: functional and bioactive nutraceutical compounds from the ocean', 39-45; 2009, New York, CRC Press.

249. P. J. Lopez, C. Gautier, J. Livage and T. Coradin: 'Mimicking biogenic silica nanostructures formation', Curr. Nanosci., 2005, 1, (1), 73-83.

250. E. G. Vrieling, T. P. M. Beelen, R. A. van Santen and W. W. C. Gieskes: 'Diatom silicon biomineralization as an inspirational source of new approaches to silica production', J. Biotechnol., 1999, 70, (1-3), 39-51.

251. M. A. Brzezinski, T. A. Villareal and F. Lipschultz: 'Silica production and the contribution of diatoms to new and primary production in the central North Pacific', Mar. Ecol. Prog. Ser., 1998, 167, 89-104.
252. R. Wetherbee: 'The diatom glasshouse', Science, 2002, 298, (5593), 547-547.

253. D. B. R. B. A. Simmons, T. W. Lane, P. Lane, F. Zendejas, H. Tran, S. Aubry, E. Spoerke and C. A. Bauer: 'Understanding Amine catalyzed silica polymerization: diatoms as bioarchitects', Sandia National Laboratories, Albuquerque, NM, USA, 2007.

254. M. B. Dickerson, K. H. Sandhage and R. R. Naik: 'Protein- and peptide-directed syntheses of inorganic materials', Chem. Rev., 2008, 108, (11), 4935-4978.

255. E. G. Vrieling, Q. Y. Sun, T. P. M. Beelen, S. Hazelaar, W. W. C. Gieskes, R. A. van Santen and N. A. J. M. Sommerdijk: 'Controlled silica synthesis inspired by diatom silicon biomineralization', J. Nanosci. Nanotechnol., 2005, 5, (1), 68-78.

256. M. Sumper and N. Kroger: 'Silica formation in diatoms: the function of long-chain polyamines and silaffins', J. Mater. Chem., 2004, 14, (14), 2059-2065.

257. N. Kroger, S. Lorenz, E. Brunner and M. Sumper: 'Self-assembly of highly phosphorylated silaffins and their function in biosilica morphogenesis', Science, 2002, 298, (5593), 584-586.

258. N. Kroger, R. Deutzmann and M. Sumper: 'Polycationic peptides from diatom biosilica that direct silica nanosphere formation', Science, 1999, 286, (5442), 1129-1132.

259. Y. Fang, Q. Wu, M. B. Dickerson, Y. Cai, S. Shian, J. D. Berrigan, N. Poulsen, N. Kroeger and K. H. Sandhage: 'Proteinmediated layer-by-layer syntheses of freestanding microscale titania structures with biologically assembled 3-D morphologies', Chem. Mater., 2009, 21, (24), 5704-5710.

260. N. R. Haase, S. Shian, K. H. Sandhage and N. Kroeger: 'Biocatalytic nanoscale coatings through biomimetic layer-bylayer mineralization', Adv. Funct. Mater., 2011, 21, (22), 42434251 .

261. N. Kroeger and K. H. Sandhage: 'From diatom biomolecules to bioinspired syntheses of silica- and titania-based materials', $M R S$ Bull., 2010, 35, (2), 122-126.

262. M. Lopez-Alvarez, L. Rial, J. P. Borrajo, P. Gonzalez, J. Serra, E. Solla, B. Leon, J. M. Sanchez, J. M. Fernandez, A. R. de Arellano-Lopez and F. M. Varela-Feria: 'Marine precursorsbased biomorphic SiC ceramics', Adv. Mater. Forum IV, 2008, $\mathbf{5 8 7 - 5 8 8}, 67-71$

263. Z. H. Bao, M. R. Weatherspoon, S. Shian, Y. Cai, P. D. Graham, S. M. Allan, G. Ahmad, M. B. Dickerson, B. C. Church, Z. T. Kang, H. W. Abernathy, C. J. Summers, M. L. Liu and K. H. Sandhage: 'Chemical reduction of three-dimensional silica microassemblies into microporous silicon replicas', Nature, 2007, 446, (7132), 172-175.

264. K. H. Sandhage, M. B. Dickerson, P. M. Huseman, M. A. Caranna, J. D. Clifton, T. A. Bull, T. J. Heibel, W. R. Overton and M. E. A. Schoenwaelder: 'Novel, bioclastic route to selfassembled, 3D, chemically tailored meso/nanostructures: shapepreserving reactive conversion of biosilica (diatom) microshells', Adv. Mater., 2002, 14, (6), 429-433.

265. M. R. Weatherspoon, S. M. Allan, E. Hunt, Y. Cai and K. H. Sandhage: 'Sol-gel synthesis on self-replicating single-cell scaffolds: applying complex chemistries to nature's 3-D nanostructured templates', Chem. Commun., 2005, (5), 651-653.

266. L. Giuliano, M. Barbier and F. Briand: 'Editorial - preview', Microb. Biotechnol., 2010, 3, (5), 489-490.

267. W. E. G. Muller and H. C. Schroder: 'The power of marine genomics', Proc. 6th European Conf. on 'Marine natural products', Porto, Portugal, July 2009, CIMAR. PL08.

268. I. A. Brownlee, A. Allen, J. P. Pearson, P. W. Dettmar, M. E. Havler, M. R. Atherton and E. Onsoyen: 'Alginate as a source of dietary fiber', Crit. Rev. Food Sci. Nutr., 2005, 45, (6), 497-510.

269. H. H. Tonnesen and J. Karlsen: 'Alginate in drug delivery systems', Drug Dev. Ind. Pharm., 2002, 28, (6), 621-630.

270. A. J. Smit: 'Medicinal and pharmaceutical uses of seaweed natural products: a review', J. Appl. Phycol., 2004, 16, (4), 245-262.

271. R. J. Tye: 'Industrial and non-food uses for carrageenan', Carbohydr. Polym., 1989, 10, (4), 259-280.

272. M. Bornhöft, M. Thommes and P. Kleinebudde: 'Preliminary assessment of carrageenan as excipient for extrusion/spheronisation', Eur. J Pharm. Biopharm., 2005, 59, (1), 127-131.

273. R. T. Patil and T. J. Speaker: 'Carrageenan as an anionic polymer for aqueous microencapsulation', Drug Deliv., 1998, 5, (3), 179182.

274. S. Francis, M. Kumar and L. Varshney: 'Radiation synthesis of superabsorbent poly(acrylic acid)-carrageenan hydrogels', Radiat. Phys. Chem., 2004, 69, (6), 481-486. 
275. D. Su Cha, J. H. Choi, M. S. Chinnan and H. J. Park: 'Antimicrobial films based on $\mathrm{Na}$-alginate and $\kappa$-carrageenan', Lebensm. Wiss. Technol., 2002, 35, (8), 715-719.

276. R. I. Baeza, D. J. Carp, O. E. Perez and A. M. R. Pilosof: ' $\kappa$ carrageenan-protein interactions: effect of proteins on polysaccharide gelling and textural properties', Lebensm. Wiss. Technol., 2002, 35, (8), 741-747.

277. A. J. Aliste, F. F. Vieira and N. L. del Mastro: 'Radiation effects on agar, alginates and carrageenan to be used as food additives', Radiat. Phys. Chem., 2000, 57, (3-6), 305-308.

278. R. S. Rasmussen and M. T. Morrissey: 'Marine biotechnology for production of food ingredients', in 'Advances in food and nutrition research', (ed. L. T. Steve), 237-292; 2007, San Diego, CA, Academic Press.

279. D. Campaniello, A. Bevilacqua, M. Sinigaglia, and M. R. Corbo: 'Chitosan: antimicrobial activity and potential applications for preserving minimally processed strawberries', Food Microbiol., 2008, 25, (8), 992-1000.

280. F. Devlieghere, A. Vermeulen and J. Debevere: 'Chitosan: antimicrobial activity, interactions with food components and applicability as a coating on fruit and vegetables', Food Microbiol., 2004, 21, (6), 703-714.

281. T. Drovetskaya, W. H. Yu, E. Diantonio and S. Jordan: 'Hair styling and conditioning personal care films', Patent US2010/ 0247459A1, 2010.

282. A. El Hadrami, L. R. Adam, I. El Hadrami and F. Daayf: 'Chitosan in plant protection', Mar. Drugs, 2010, 8, (4), 968-987.

283. P. Baldrick: 'The safety of chitosan as a pharmaceutical excipient', Regul. Toxicol. Pharmacol., 2010, 56, (3), 290-299.

284. S. Senel and S. J. McClure: 'Potential applications of chitosan in veterinary medicine', Adv. Drug Deliv. Rev., 2004, 56, (10), 1467 1480 .

285. A. Bhatnagar and M. Sillanpää: 'Applications of chitin- and chitosan-derivatives for the detoxification of water and wastewater - a short review', Adv. Colloid Interface Sci., 2009, 152, (1-2), 26-38.

286. S. S. Silva, J. F. Mano and R. L. Reis: 'Potential applications of natural origin polymer-based systems in soft tissue regeneration', Crit. Rev. Biotechnol., 2010, 30, (3), 200-221.

287. H. Honarkar and M. Barikani: 'Applications of biopolymers I: chitosan', Mon. Chem., 2009, 140, (12), 1403-1420.

288. M. Aider: 'Chitosan application for active bio-based films production and potential in the food industry: review', $L W T$ Food Sci. Technol., 2010, 43, (6), 837-842.

289. A. Ali, M. T. M. Muhammad, K. Sijam and Y. Siddiqui: 'Effect of chitosan coatings on the physicochemical characteristics of Eksotika II papaya (Carica papaya L.) fruit during cold storage', Food Chem., 124, (2), 620-626.

290. U. K. Aravind, B. George, M. S. Baburaj, S. Thomas, A. P. Thomas and C. T. Aravindakumar: 'Treatment of industrial effluents using polyelectrolyte membranes', Desalination, 2010, 252, (1-3), 27-32.

291. A. Srinivasan and T. Viraraghavan: 'Decolorization of dye wastewaters by biosorbents: a review', J. Environ. Manage., 2010, 91, (10), 1915-1929.

292. R. Fabris, C. W. K. Chow and M. Drikas: 'Evaluation of chitosan as a natural coagulant for drinking water treatment', Water Sci. Technol., 2010, 61, (8), 2119-2128.

293. M. Rosen (ed.): 'Delivery system handbook for personal care and cosmetic products: technology, applications and formulations'; 2005, Norwich, NY, William Andrew, Inc.

294. S. T. Koev, P. H. Dykstra, X. Luo, G. W. Rubloff, W. E. Bentley, G. F. Payne and R. Ghodssi: 'Chitosan: an integrative biomaterial for lab-on-a-chip devices', Lab Chip, 2010, 10, (22), 3026-3042.

295. M. S. Pereira, B. Mulloy and P. A. S. Mourão: 'Structure and anticoagulant activity of sulfated fucans', J. Biol. Chem., 1999, 274, (12), 7656-7667.

296. M. S. G. Pavão, P. A. S. Mourão, B. Mulloy and D. M. Tollefsen: 'A unique dermatan sulfate-like glycosaminoglycan from ascidian', J. Biol. Chem., 1995, 270, (52), 31027-31036.

297. N. Volpi and F. Maccari: 'Structural characterization and antithrombin activity of dermatan sulfate purified from marine clam Scapharca inaequivalvis', Glycobiology, 2009, 19, (4), 356367

298. R. G. Pacheco, C. P. Vicente, P. Zancan and P. A. S. Mourão: 'Different antithrombotic mechanisms among glycosaminoglycans revealed with a new fucosylated chondroitin sulfate from an echinoderm', Blood Coagul. Fibrinol., 2000, 11.

299. C. D. Nandini and K. Sugahara: 'Role of the sulfation pattern of chondroitin sulfate in its biological activities and in the binding of growth factors', (ed. V. Nicola), 253-279; 2006, San Diego, CA, Academic Press.

300. K. Sugahara and S. Yamada: 'Structure and function of oversulfated chondroitin sulfate variants. unique sulfation patterns and neuroregulatory activities', Trends Glycosci. Glycotechnol., 2000, 12, (67), 321-349.

301. P. A. S. Mourao: 'Use of sulfated fucans as anticoagulant and antithrombotic agents: future perspectives', Curr. Pharm. Des., 2004, 10, (9), 967-981.

302. G. C. Calabrese, M. F. Alberto, R. Tubio, M. M. Marani, M. E. Fernándezde Recondo, M. Lazzari and E. F. Recondo: 'A small fraction of dermatan sulfate with significantly increased anticoagulant activity was selected by interaction with the first complement protein', Thromb. Res., 2004, 113, (3-4), 243-250.

303. S. Colliec, A. M. Fischer, J. Tapon-Bretaudiere, C. Boisson, P. Durand and J. Jozefonvicz: 'Anticoagulant properties of a fucoidan fraction', Thromb. Res., 1991, 64, (2), 143-154.

304. C. P. Vicente, L. He, M. S. G. Pavao and D. M. Tollefsen: 'Antithrombotic activity of dermatan sulfate in heparin cofactor II-deficient mice', Blood, 2004, 104, (13), 3965-3970.

305. W. R. L. Farias, A.-P. Valente, M. S. Pereira and P. A. S. Mourão: 'Structure and anticoagulant activity of sulfated galactans', J. Biol. Chem., 2000, 275, (38), 29299-29307.

306. V. Grauffel, B. Kloareg, S. Mabeau, P. Durand and J. Jozefonvicz: 'New natural polysaccharides with potent antithrombic activity: fucans from brown algae', Biomaterials, 1989, 10, (6), 363-368.

307. M. L. S. Souza, J. M. M. Dellias, F. R. Melo and L.-C. F. Silva: 'Structural composition and anticoagulant activity of dermatan sulfate from the skin of the electric eel, Electrophorus electricus (L.)', Comp. Biochem. Physiol. Part B: Biochem. Mol. Biol., 2007, 147B, (3), 387-394

308. A. S. Brito, D. S. Arimatéia, L. R. Souza, M. A. Lima, V. O. Santos, V. R. P. Medeiros, P. A. Ferreira, R. A. Silva, C. V. Ferreira, G. Z. Justo, E. L. Leite, G. P. V. Andrade, F. W. Oliveira, H. B. Nader and S. F. Chavante: 'Anti-inflammatory properties of a heparin-like glycosaminoglycan with reduced anticoagulant activity isolated from a marine shrimp', Bioorg. Med. Chem., 2008, 16, (21), 9588-9595.

309. D. S. McLellan and K. M. Jurd: 'Anticoagulants from marine algae', Blood Coagul. Fibrinol., 1992, 3, (1).

310. K. L. Goa and P. Benfield: 'Hyaluronic-acid - a review of its pharmacology and use as a surgical aid in ophthalmology, and its therapeutic potential in joint disease and wound-healing', Drugs, 1994, 47, (3), 536-566.

311. S. B. Lee, Y. M. Lee, K. W. Song and M. H. Park: 'Preparation and properties of polyelectrolyte complex sponges composed of hyaluronic acid and chitosan and their biological behaviors', J. Appl. Polym. Sci., 2003, 90, (4), 925-932.

312. L. Lapcik, L. Lapcik, S. de Smedt, J. Demeester and P. Chabrecek: 'Hyaluronan: preparation, structure, properties, and applications', Chem. Rev., 1998, 98, (8), 2663-2684.

313. G. Kogan, L. Soltes, R. Stern and P. Gemeiner: 'Hyaluronic acid: a natural biopolymer with a broad range of biomedical and industrial applications', Biotechnol. Lett., 2007, 29, (1), 17-25.

314. P. H. Chua, K. G. Neoh, E. T. Kang and W. Wang: 'Surface functionalization of titanium with hyaluronic acid/chitosan polyelectrolyte multilayers and RGD for promoting osteoblast functions and inhibiting bacterial adhesion', Biomaterials, 2008, 29, (10), 1412-1421.

315. A. Szarpak, I. Pignot-Paintrand, C. Nicolas, C. Picart and R. Auzely-Velty: 'Multilayer assembly of hyaluronic acid/poly(allylamine): control of the buildup for the production of hollow capsules', Langmuir, 2008, 24, (17), 9767-9774.

316. C. Meena, S. Mengi and S. Deshpande: 'Biomedical and industrial applications of collagen', J. Chem. Sci., 1999, 111, (2), 319-329.

317. E. Song, S. Yeon Kim, T. Chun, H.-J. Byun and Y. M. Lee: 'Collagen scaffolds derived from a marine source and their biocompatibility', Biomaterials, 2006, 27, (15), 2951-2961.

318. Y. Nomura, K. Oohashi, M. Watanabe and S. Kasugai: 'Increase in bone mineral density through oral administration of shark gelatin to ovariectomized rats', Nutrition, 21, (11-12), 1120-1126.

319. D. Swatschek, W. Schatton, W. E. G. Müller and J. Kreuter: 'Microparticles derived from marine sponge collagen (SCMPs): preparation, characterization and suitability for dermal delivery of all-trans retinol', Eur. J. Pharm. Biopharm., 2002, 54, (2), 125133.

320. S. In Jeong, S. Y. Kim, S. K. Cho, M. S. Chong, K. S. Kim, H. Kim, S. B. Lee and Y. M. Lee: 'Tissue-engineered vascular grafts 
composed of marine collagen and PLGA fibers using pulsatile perfusion bioreactors', Biomaterials, 2007, 28, (6), 1115-1122.

321. F. Ye, H. F. Guo, H. J. Zhang and X. L. He: 'Polymeric micelletemplated synthesis of hydroxyapatite hollow nanoparticles for a drug delivery system', Acta Biomater., 2010, 6, (6), 2212-2218.

322. E. C. Shors: 'Coralline bone graft substitutes', Orthop. Clin. $N$ Am., 1999, 30, (4), 599-614.

323. P. F. Jacovella: 'Calcium hydroxylapatite facial filler (Radiesse ${ }^{\mathrm{TM}}$ ): indications, technique, and results', Clin. Plast. Surg., 2006, 33, (4), 511.

324. J. Scheel and M. Hermann: 'Integrated risk assessment of a hydroxyapatite-protein-composite for use in oral care products: a weight-of-evidence case study', Regul. Toxicol. Pharmacol., 2011, 59, (2), 310-323.

325. M. I. Carretero and M. Pozo: 'Clay and non-clay minerals in the pharmaceutical and cosmetic industries. Part II. Active ingredients', Appl. Clay Sci., 2010, 47, (3-4), 171-181.

326. M. Wiens, X. H. Wang, F. Natalio, H. C. Schroder, U. Schlossmacher, S. F. Wang, M. Korzhev, W. Geurtsen and W. E. G. Muller: 'Bioinspired fabrication of bio-silica-based bone-substitution materials', Adv. Eng. Mater., 2010, 12, (9), B438-B450.

327. J. Noyes, M. Sumper and P. Vukusic: 'Light manipulation in a marine diatom', J. Mater. Res., 2008, 23, (12), 3229-3235.

328. L. De Stefano, P. Maddalena, L. Moretti, I. Rea, I. Rendina, E. de Tommasi, V. Mocella and M. de Stefano: 'Nano-biosilica from marine diatoms: a brand new material for photonic applications', Superlattices Microstruct., 2009, 46, (1-2), 84-89.

329. M. Ramanathan, H. R. Luckarift, A. Sarsenova, J. R. Wild, E. K. Ramanculov, E. V. Olsen and A. L. Simonian: 'Lysozymemediated formation of protein-silica nano-composites for biosensing applications', Colloids Surf. B: Biointerfaces, 2009, 73, (1), 58-64.

330. S. P. Rigby, M. Fairhead and C. F. van der Walle: 'Engineering silica particles as oral drug delivery vehicles', Curr. Pharm. Des., 2008, 14, (18), 1821-1831.

331. A. D. Baldwin and K. L. Kiick: 'Polysaccharide-modified synthetic polymeric biomaterials', Biopolymers, 2010, 94, (1), $128-140$.

332. K. A. Janes, P. Calvo and M. J. Alonso: 'Polysaccharide colloidal particles as delivery systems for macromolecules', Adv. Drug Deliv. Rev., 2001, 47, (1), 83-97.

333. H. S. Kas: 'Chitosan: properties, preparations and application to microparticulate systems', J. Microencapsul., 1997, 14, (6), 689711.

334. M. Prabaharan and J. F. Mano: 'Chitosan-based particles as controlled drug delivery systems', Drug Deliv., 2005, 12, (1), 4157.

335. S. J. De and D. Robinson: 'Polymer relationships during preparation of chitosan-alginate and poly-L-lysine-alginate nanospheres', J. Controlled Release, 2003, 89, (1), 101-112.

336. M. L. Gonzalez-Rodriguez, M. A. Holgado, C. SanchezLafuente, A. M. Rabasco and A. Fini: 'Alginate/chitosan particulate systems for sodium diclofenac release', Int. J. Pharm., 2002, 232, (1-2), 225-234.

337. A. Grenha, B. Seijo and C. Remunan-Lopez: 'Microencapsulated chitosan nanoparticles for lung protein delivery', Eur. J. Pharm. Sci., 2005, 25, (4-5), 427-437.

338. C. V. Liew, L. W. Chan, A. L. Ching and P. W. S. Heng: 'Evaluation of sodium alginate as drug release modifier in matrix tablets', Int. J. Pharm., 2006, 309, (1-2), 25-37.

339. J. K. Oh, R. Drumright, D. J. Siegwart and K. Matyjaszewski: 'The development of microgels/nanogels for drug delivery applications', Prog. Polym. Sci., 2008, 33, (4), 448-477.

340. A. Vila, A. Sanchez, M. Tobio, P. Calvo and M. J. Alonso: 'Design of biodegradable particles for protein delivery', $J$. Controlled Release, 2002, 78, (1-3), 15-24.

341. M. Prabaharan and J. F. Mano: 'Hydroxypropyl chitosan bearing beta-cyclodextrin cavities: synthesis and slow release of its inclusion complex with a model hydrophobic drug', Macromol. Biosci., 2005, 5, (10), 965-973.

342. M. Prabaharan, R. L. Reis and J. F. Mano: 'Carboxymethyl chitosan-graft-phosphatidylethanolamine: amphiphilic matrices for controlled drug delivery', React. Funct. Polym., 2007, 67, (1), 43-52.

343. Z. H. Liu, Y. P. Jiao, Y. F. Wang, C. R. Zhou and Z. Y. Zhang: 'Polysaccharides-based nanoparticles as drug delivery systems', Adv. Drug Deliv. Rev., 2008, 60, (15), 1650-1662.

344. J. M. Oliveira, N. Kotobuki, A. P. Marques, R. P. Pirraco, J. Benesch, M. Hirose, S. A. Costa, J. F. Mano, H. Ohgushi and
R. L. Reis: 'Surface engineered carboxymethylchitosan/poly(amidoamine) dendrimer nanoparticles for intracellular targeting', Adv. Funct. Mater., 2008, 18, (12), 1840-1853.

345. A. Grenha, M. E. Gomes, M. Rodrigues, V. E. Santo, J. F. Mano, N. M. Neves and R. L. Reis: 'Development of new chitosan/ carrageenan nanoparticles for drug delivery applications', $J$. Biomed. Mater. Res. Part A, 2010, 92A, (4), 1265-1272.

346. X. P. Qiu, S. Leporatti, E. Donath and H. Mohwald: 'Studies on the drug release properties of polysaccharide multilayers encapsulated ibuprofen microparticles', Langmuir, 2001, 17, (17), 53755380 .

347. Q. H. Zhao, Z. W. Mao, C. Y. Gao and J. C. Shen: 'Assembly of multilayer microcapsules on $\mathrm{CaCO}_{3}$ particles from biocompatible polysaccharides', J. Biomater. Sci. Polym. Ed., 2006, 17, (9), 9971014.

348. B. G. de Geest, N. N. Sanders, G. B. Sukhorukov, J. Demeester and S. C. de Smedt: 'Release mechanisms for polyelectrolyte capsules', Chem. Soc. Rev., 2007, 36, (4), 636-649.

349. J. M. R. Grech, J. F. Mano and R. L. Reis: 'Chitosan beads as templates for layer-by-layer assembly and their application in the sustained release of bioactive agents', J. Bioact. Compat. Polym., 2008, 23, (4), 367-380.

350. P. Gupta, K. Vermani and S. Garg: 'Hydrogels: from controlled release to pH-responsive drug delivery', Drug Discov. Today, 2002, 7, (10), 569-579.

351. S. Dai, P. Ravi and K. C. Tam: 'pH-responsive polymers: synthesis, properties and applications', Soft Matter, 2008, 4, (3), 435-449.

352. J. F. Mano: 'Stimuli-responsive polymeric systems for biomedical applications', Adv. Eng. Mater., 2008, 10, (6), 515-527.

353. M. Prabaharan and J. F. Mano: 'Stimuli-responsive hydrogels based on polysaccharides incorporated with thermo-responsive polymers as novel biomaterials', Macromol. Biosci., 2006, 6, (12), 991-1008.

354. J. Shi, N. M. Alves and J. F. Mano: 'Drug release of $\mathrm{pH} /$ temperature-responsive calcium alginate/poly(N-isopropylacrylamide) semi-IPN beads', Macromol. Biosci., 2006, 6, (5), 358-363.

355. J. Shi, N. M. Alves and J. F. Mano: 'Chitosan coated alginate beads containing poly(N-isopropylacrylamide) for dual-stimuliresponsive drug release', J. Biomed. Mater. Res. Part B: Appl. Biomater., 2008, 84B, (2), 595-603.

356. J. Shi, L. H. Liu, X. M. Sun, S. K. Cao and J. F. Mano: 'Biomineralized polysaccharide beads for dual-stimuli-responsive drug delivery', Macromol. Biosci., 2008, 8, (3), 260-267.

357. R. Langer and J. P. Vacanti: 'Tissue engineering', Science, 1993, 260, (5110), 920-926.

358. D. W. Hutmacher: 'Scaffolds in tissue engineering bone and cartilage', Biomaterials, 2000, 21, (24), 2529-2543.

359. S. S. Silva, A. Motta, M. T. Rodrigues, A. F. M. Pinheiro, M. E. Gomes, J. F. Mano, R. L. Reis and C. Migliaresi: 'Novel genipincross-linked chitosan/silk fibroin sponges for cartilage engineering strategies', Biomacromolecules, 2008, 9, (10), 2764-2774.

360. M. Prabaharan, M. A. Rodriguez-Perez, J. A. de Saja and J. F. Mano: 'Preparation and characterization of poly(L-lactic acid)chitosan hybrid scaffolds with drug release capability', J. Biomed. Mater. Res. Part B: Appl. Biomater., 2007, 81B, (2), 427-434.

361. Y. Zhang and M. Q. Zhang: 'Synthesis and characterization of macroporous chitosan/calcium phosphate composite scaffolds for tissue engineering', J. Biomed. Mater. Res., 2001, 55, (3), 304-312.

362. J. M. Oliveira, M. T. Rodrigues, S. S. Silva, P. B. Malafaya, M. E. Gomes, C. A. Viegas, I. R. Dias, J. T. Azevedo, J. F. Mano and R. L. Reis: 'Novel hydroxyapatite/chitosan bilayered scaffold for osteochondral tissue-engineering applications: scaffold design and its performance when seeded with goat bone marrow stromal cells', Biomaterials, 2006, 27, (36), 6123-6137.

363. R. M. Silva, P. B. Malafaya, J. F. Mano and R. L. Reis: 'Bioactive composite chitosan membranes to be used in bone regeneration applications', Bioceramics, 2003, 240, (2), 423-426.

364. J. M. Oliveira, S. A. Costa, I. B. Leonor, P. B. Malafaya, J. F. Mano and R. L. Reis: 'Novel hydroxyapatite/carboxymethylchitosan composite scaffolds prepared through an innovative "autocatalytic" electroless coprecipitation route', J. Biomed. Mater. Res. Part A, 2009, 88A, (2), 470-480.

365. V. N. Malheiro, S. G. Caridade, N. M. Alves and J. F. Mano: 'New poly(epsilon-caprolactone)/chitosan blend fibers for tissue engineering applications', Acta Biomater., 2010, 6, (2), 418-428.

366. E. S. Miranda, T. H. Silva, R. L. Reis and J. F. Mano: 'Nanostructured natural-based polyelectrolyte multilayers to agglomerate chitosan particles into scaffolds for tissue engineering', Tissue Eng., 2011, 17, (21-22), 2663-2674. 
367. D. M. G. Cruz, J. L. E. Ivirico, M. M. Gomes, J. L. G. Ribelles, M. S. Sanchez, R. L. Reis and J. F. Mano: 'Chitosan microparticles as injectable scaffolds for tissue engineering', $J$. Tissue Eng. Regen. Med., 2008, 2, (6), 378-380.

368. K. Y. Lee, L. Jeong, Y. O. Kang, S. J. Lee and W. H. Park: 'Electrospinning of polysaccharides for regenerative medicine', Adv. Drug Deliv. Rev., 2009, 61, (12), 1020-1032.

369. N. Bhattarai, D. Edmondson, O. Veiseh, F. A. Matsen and M. Q. Zhang: 'Electrospun chitosan-based nanofibers and their cellular compatibility', Biomaterials, 2005, 26, (31), 6176-6184.

370. Y. Zhang, J. R. Venugopal, A. El-Turki, S. Ramakrishna, B. Su and C. T. Lim: 'Electrospun biomimetic nanocomposite nanofibers of hydroxyapatite/chitosan for bone tissue engineering', Biomaterials, 2008, 29, (32), 4314 4322.

371. N. Bhattarai, Z. S. Li, D. Edmondson and M. Q. Zhang: 'Alginate-based nanofibrous scaffolds: structural, mechanical, and biological properties', Adv. Mater., 2006, 18, (11), 1463-1467.

372. S. I. Jeong, S. Y. Kim, S. K. Cho, M. S. Chong, K. S. Kim, H. Kim, S. B. Lee and Y. M. Lee: 'Tissue-engineered vascular grafts composed of marine collagen and PLGA fibers using pulsatile perfusion bioreactors', Biomaterials, 2007, 28, (6), 1115-1122.

373. Z. S. Li, H. R. Ramay, K. D. Hauch, D. M. Xiao and M. Q. Zhang: 'Chitosan-alginate hybrid scaffolds for bone tissue engineering', Biomaterials, 2005, 26, (18), 3919-3928.

374. J. Z. Wang, X. B. Huang, J. Xiao, N. Li, W. T. Yu, W. Wang, W. Y. Xie, X. J. Ma and Y. L. Teng: 'Spray-spinning: a novel method for making alginate/chitosan fibrous scaffold', $J$ Mater Sci: Mater. Med., 2010, 21, (2), 497-506.

375. C. K. Kuo and P. X. Ma: 'Ionically crosslinked alginate hydrogels as scaffolds for tissue engineering: Part 1. Structure, gelation rate and mechanical properties', Biomaterials, 2001, 22, (6), 511-521.

376. G. Turco, E. Marsich, F. Bellomo, S. Semeraro, I. Donati, F. Brun, M. Grandolfo, A. Accardo and S. Paoletti: 'Alginate/hydroxyapatite biocomposite for bone ingrowth: a trabecular structure with high and isotropic connectivity', Biomacromolecules, 2009, 10, (6), 1575-1583.

377. K. Y. Lee and D. J. Mooney: 'Hydrogels for tissue engineering', Chem. Rev., 2001, 101, (7), 1869-1879.

378. J. A. Rowley, G. Madlambayan and D. J. Mooney: 'Alginate hydrogels as synthetic extracellular matrix materials', Biomaterials, 1999, 20, (1), 45-53.

379. K. Y. Lee, H. J. Kong, R. G. Larson and D. J. Mooney: 'Hydrogel formation via cell crosslinking', Adv. Mater., 2003, 15, (21), 1828-1832.
380. H. Park, S. W. Kang, B. S. Kim, D. J. Mooney and K. Y. Lee: 'Shear-reversibly crosslinked alginate hydrogels for tissue engineering', Macromol. Biosci., 2009, 9, (9), 895-901.

381. J. S. Temenoff and A. G. Mikos: 'Injectable biodegradable materials for orthopedic tissue engineering', Biomaterials, 2000, 21, (23), 2405-2412.

382. J. D. Kretlow, L. Klouda and A. G. Mikos: 'Injectable matrices and scaffolds for drug delivery in tissue engineering', Adv. Drug Deliv. Rev., 2007, 59, (4-5), 263-273.

383. B. Jeong, S. W. Kim and Y. H. Bae: 'Thermosensitive sol-gel reversible hydrogels', Adv. Drug Deliv. Rev., 2002, 54, (1), 37-51.

384. A. Chenite, C. Chaput, D. Wang, C. Combes, M. D. Buschmann, C. D. Hoemann, J. C. Leroux, B. L. Atkinson, F. Binette and A. Selmani: 'Novel injectable neutral solutions of chitosan form biodegradable gels in situ', Biomaterials, 2000, 21, (21), 21552161.

385. D. S. Couto, Z. K. Hong and J. F. Mano: 'Development of bioactive and biodegradable chitosan-based injectable systems containing bioactive glass nanoparticles', Acta Biomater., 2009, 5 , (1), 115-123.

386. J. L. Moreau and H. H. K. Xu: 'Mesenchymal stem cell proliferation and differentiation on an injectable calcium phosphate - chitosan composite scaffold', Biomaterials, 2009, 30, (14), 2675-2682.

387. R. C. Pereira, M. Scaranari, P. Castagnola, M. Grandizio, H. S. Azevedo, R. L. Reis, R. Cancedda and C. Gentili: 'Novel injectable gel (system) as a vehicle for human articular chondrocytes in cartilage tissue regeneration', J. Tissue Eng. Regen. Med., 2009, 3, (2), 97-106.

388. M. M. Stevens, H. F. Qanadilo, R. Langer and V. P. Shastri: 'A rapid-curing alginate gel system: utility in periosteum-derived cartilage tissue engineering', Biomaterials, 2004, 25, (5), 887-894.

389. N. Landa, L. Miller, M. S. Feinberg, R. Holbova, M. Shachar, I. Freeman, S. Cohen and J. Leor: 'Effect of injectable alginate implant on cardiac remodeling and function after recent and old infarcts in rat', Circulation, 2008, 117, (11), 1388-1396.

390. M. Izydorczyk: 'Understanding the chemistry of food carbohydrates', in 'Food carbohydrates - chemistry, physical properties and applications', (ed. S. W. Cui) 1-65; 2005, Boca Raton, FL, CRC Press.

391. Q. Wang and S. W. Cui: 'Understanding the physical properties of food polysaccharides', in 'Food carbohydrates - chemistry, physical properties and applications', (ed. S. W. Cui) 161-217; 2005, Boca Raton, FL, CRC Press. 